MARCO ANTÔNIO BRASIEL SAMPAIO

\title{
O MÉTODO DOS ELEMENTOS DISCRETOS COM SUPERELIPSÓIDES USANDO A PARAMETRIZAÇÃO DAS ROTAÇÕES DE RODRIGUES
}




\title{
O MÉTODO DOS ELEMENTOS DISCRETOS COM SUPERELIPSÓIDES USANDO A PARAMETRIZAÇÃO DAS ROTAÇÕES DE RODRIGUES
}

\author{
Tese apresentada à Escola Politécnica da \\ Universidade de São Paulo para obtenção do \\ título de Doutor em Ciências. \\ Área de Concentração: \\ Engenharia de Estruturas \\ Orientador: \\ Prof. Dr. Paulo de Mattos Pimenta
}


Nome: SAMPAIO, Marco Antônio Brasiel

Título: O método dos elementos discretos com superelipsóides usando a parametrização das rotações de Rodrigues

Dissertação apresentada à Escola Politécnica da Universidade de São Paulo para obtenção do título de Doutor em Ciências. Área de concentração: engenharia de estruturas.

Aprovado em:

Banca Examinadora

Prof. Dr. Instituição

Julgamento: Assinatura

Prof. Dr. Instituição

Julgamento: Assinatura

Prof. Dr. Instituição

Julgamento: Assinatura

Prof. Dr. Instituição Julgamento: Assinatura

Prof. Dr. Instituição

Julgamento: Assinatura 


\title{
O método dos elementos discretos com superelipsóides usando a pa- rametrização das rotações de Rodrigues
}

\author{
Esta versão da tese contem as correções e al- \\ terações sugeridas pela Comissão Julgadora \\ durante a defesa da versão original do traba- \\ lho, realizada em 09/12//2016.
}

Banca Examinadora:

- Prof. Dr. Paulo de Mattos Pimenta (orientador) - POLI-USP

- Prof. Dr. Alfredo Gay Neto - POLI-USP

- Prof. Dr. Eduardo de Morais Barreto Campello - POLI-USP

- Prof. Dr. André Maués Brabo Pereira - UFF-RJ

- Prf. Dr. José Luis Drummond Alves - COPPE-UFRJ 
Este exemplar foi revisado e corrigido em relação à versão original, sob responsabilidade única do autor e com a anuência de seu orientador.

São Paulo, de de

Assinatura do autor:

Assinatura do orientador:

Catalogação-na-publicação

Sampaio, Marco Antonio Brasiel

O método dos elementos discretos com superelipsóides usando a parametrização das rotações de Rodrigues / M. A. B. Sampaio -- versão corr. -São Paulo, 2017.

$94 \mathrm{p}$.

Tese (Doutorado) - Escola Politécnica da Universidade de São Paulo. Departamento de Engenharia de Estruturas e Geotécnica.

1.Método dos elementos discretos 2.Superelipsóides 3.Geomecânica 4.Mecânica do contato 5.Rotações vetoriais I.Universidade de São Paulo. Escola Politécnica. Departamento de Engenharia de Estruturas e Geotécnica II.t. 
"À minha família". 


\section{AGRADECIMENTOS}

Meus sinceros agradecimentos ao Prof. Paulo Pimenta, pela competente orientação, dedicação e incessante incentivo à pesquisa.

À minha esposa Hellen, pelo imenso apoio durante todo doutorado, por me ajudar em todos os momentos difíceis desta etapa, e pelas grandes alegrias compartilhadas.

Agradeço ao Prof. Peter Wriggers, por ter me aceitado na Leibniz Universität Hannover, para passar cinco meses sob sua coorientação, no IKM (Institut für Kontinuumsmechanik).

Aos meus pais, Fernando e Eládia, e irmãos, Marco Túlio e Fernando, pelos exemplos de vida e carinho incondicional que me fortalecem todos os dias.

Ao Prof. Noronha, um grande mestre e amigo, pelos conselhos sinceros e pelos incentivos para que eu me torne um Professor.

À Edna Frazillio, Paulo Ferroni e Luciana Loures pela confiança que depositaram em mim para eu pudesse fazer o doutorado.

Agradeço aos professores Rafael Muscat e Thelma Lascala pela compreensão e esforço para que eu mantivesse as minhas turmas na FAAP durante minha ida para Hannover.

A todos os colegas do JAC, pela ótima companhia no dia-a-dia desta jornada e conhecimentos compartilhados. Também agradeço à Betinha, que teve que nos aguentar como hóspedes por um período razoável de tempo, quando retornamos para o Brasil.

Aos professores Alfredo e Eduardo, pela disponibilidade em compartilhar seus conhecimentos.

À Coordenação de Aperfeiçoamento de Pessoal de Nível Superior (CAPES). 


\section{RESUMO}

Este trabalho apresenta uma formulação do Método dos Elementos Discretos (MED) utilizando uma abordagem vetorial para o tratamento das rotações. As rotações são calculadas com a parametrização de Rodrigues. As principais contribuições do trabalho são: o cálculo dos deslocamentos tangentes utilizando o vetor das rotações incrementais da parametrização de Rodrigues; e, a integração do movimento de rotação utilizando o método leapfrog com as expressões da parametrização das rotações de Rodrigues. A formulação é apresentada para partículas esféricas e superelipsóides.

O cálculo do deslocamento tangente, que é utilizado para o cálculo das forças de atrito, é feito a partir da velocidade angular da partícula. Em geral, o deslocamento tangente é calculado a partir da velocidade linear instantânea do ponto de contato. Aqui, o deslocamento do ponto de contato é dado pelo movimento da partícula, tanto de translação quanto de rotação. Apesar da abordagem por meio de rotações, é mostrado este cálculo pode ser feito sem o uso de tensores de segunda ordem.

O movimento da partícula é descrito por uma abordagem incremental. É apresentada uma formulação do método de integração leapfrog com a utilização da expressão das rotações sucessivas da parametrização de Rodrigues.

A detecção do contato entre superelipsóides é feita por um método do tipo "vetor normal comum", resolvido como um problema de minimização.

Os resultados mostram que a parametrização de Rodrigues pode ser utilizada com método dos elementos discretos tanto para a execução da rotação quanto para o cálculo de grandezas que envolvem este tipo de movimento como o deslocamento tangente.

Palavras-chave: Método dos Elementos Discretos; Rotações vetoriais; Parametrização de Rodrigues; Superelipsóide 


\begin{abstract}
This work presents a formulation for Discrete Element Method (DEM) adopting a vector approach to solve rotations. Herein, rotations are solved using Rodrigues parameterization. The main contributions of this work are: tangential displacements using the incremental rotation vector from Rodrigues parameterization, and integration of the rotation movement using leapfrog method and Rodrigues rotation tensor. The formulations are presented to spheres and superelliptical particles.
\end{abstract}

Tangential displacements, which are used to get friction forces, are calculated through angular velocity. In most of DEM implementations, tangential displacements are calculated through the instantaneous linear velocity of the contact point. Instead, here the displacement of the contact point is given through the rotation of the particle. It is showed that the vector of incremental rotations can be calculated through the angular velocity.

Particle movement is described using an updated Lagrangian approach. Leapfrog method is formulated in such a way to use the Rodrigues expression for successive rotations.

Contact detection between superellipsoids is solved using a technic called "common normal approach", and it is solved as a minimization problem.

The results show that the Rodrigues parameterization can be applied to discrete element method to both execute rotations and to evaluate physical quantities that are related to this kind of movement as tangential displacement.

Keywords: Discrete Element Method; Vector rotations; Rodrigues parameterization; Superelliptical 


\section{LISTA DE ILUSTRAÇÕES}

Figura 1 - Exemplos de elementos discretos. (a) elementos poligonais; (b) elementos de curvatura contínua, superelipsóides; (c) elemento de representação discreta. Fonte: [28]...... 10

Figura 2 - Contato sem atrito. (a) contato com lubrificante. (b) forças na superfície de contato.

Figura 3 - Contato com atrito. (a) forças em situação tipo stick. (b) forças em situação tipo slip.

Figura 4 - Rolamento de uma partícula. 16

Figura 5 - Representação das rotações sucessivas.

Figura 6 - Superelipsóides com diferentes parâmetros de curvatura e dimensões constantes $R 1=R 2=R 3 / 2$. 25

Figura 7 - Superelipsóides com $R 1=R 2=R 3 / 2$ e: (a) $\epsilon \mathrm{i}=0.3$; (b) $\epsilon \mathrm{i}=1$; (c) $\epsilon \mathrm{i}=1.7$...26

Figura 8 - Divisão do domínio em células para detecção de possíveis contatos. 29

Figura 9 - Esferas em contato. 30

Figura 10 - Detecção de contato entre superelipsóides. 33

Figura 11 - Plano que define uma condição de contorno 36

Figura 12 - Integração com leapfrog. 37

Figura 13 - Partículas esféricas $i$ e $j$ em contato. 38

Figura 14 - Vetores $\boldsymbol{t} 1$ e $\boldsymbol{t} 2$ que definem o plano de contato. 39

Figura 15 - Definição do vetor raio. 39

Figura 16 - Descrição da rotação. 41

Figura 17 - Mapeamento das variáveis velocidades linear e angular e posição com o método leapfrog. 47 
Figura 18 - Sequência proposta para integração das rotações.

Figura 19 - Ilustração do exemplo numérico.

Figura 20 - Elemento esférico representando cilindro.

Figura 21 - Superelipsóides parametrizados para formar cilindroides (esq.: $\epsilon 2=0,3$, dir.: $\epsilon 2=0,2)$.

Figura 22 - Velocidades linear e angular para simulação com partículas esféricas (esq.: vel. linear; dir: vel. Angular).

Figura 23 - Variação do incremento de tempo usando Euler e leapfrog (0 - Euler com $\Delta t=10-3 ; 1-$ leapfrog com $\Delta t=10-3 ; 2$ - Euler com $\Delta t=71 \cdot 10-2 ; 3$ - leapfrog $\operatorname{com} \Delta t=71 \cdot 10-2)$. 56

Figura 24 - Configuração inicial da simulação com quatro superelipsóides. 57

Figura 25 - Avançado da simulação com quatro superelipsóides. 57

Figura 26 - Avaliação do afastamento horizontal relativo entre as partículas $\mathcal{P} 1$ e $\mathcal{P} 2$. 58

Figura 27 - Deslizamento na zona de singularidade: configuração inicial. 59

Figura 28 - Deslizamento na zona de singularidade: condição com contatos ativos.

Figura 29 - Deslizamento na zona de singularidade: configuração final. 61

Figura 30 - Condições de contorno da simulação com múltiplas partículas..... 62

Figura 31 - Sequencia da simulação com múltiplos superelipsóides. 63

Figura 32 - Formas de representações das rotações 68 


\section{SUMÁRIO}

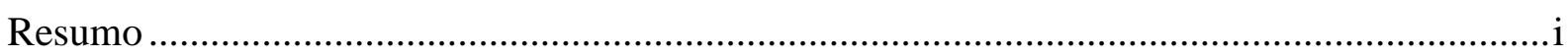

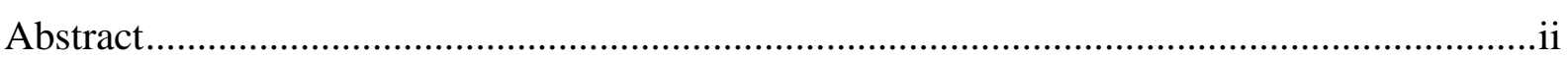

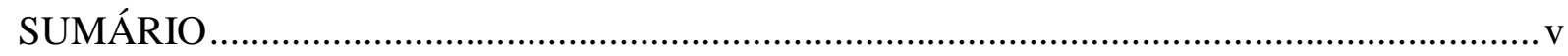

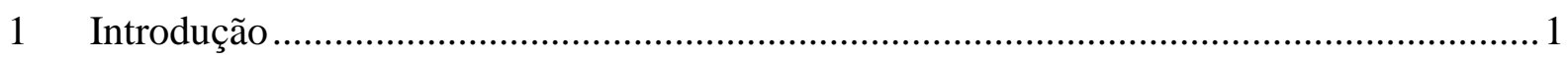

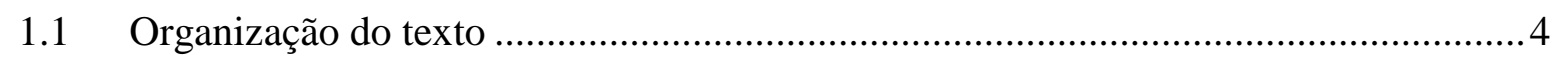

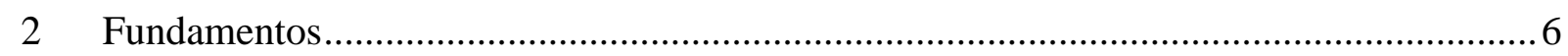

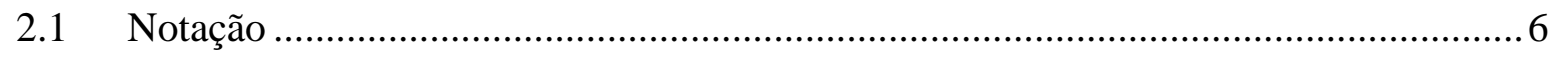

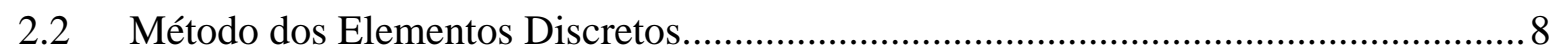

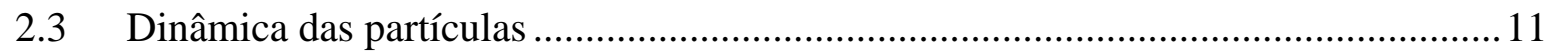

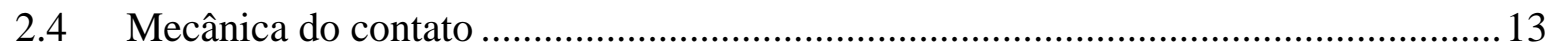

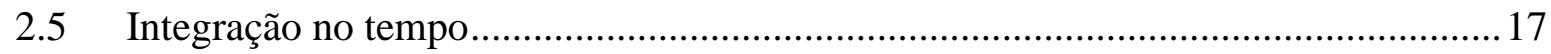

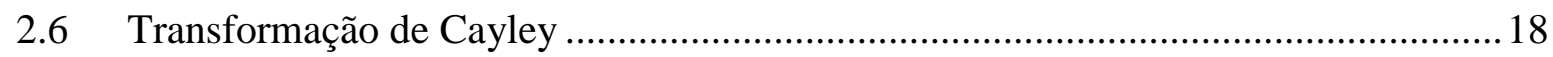

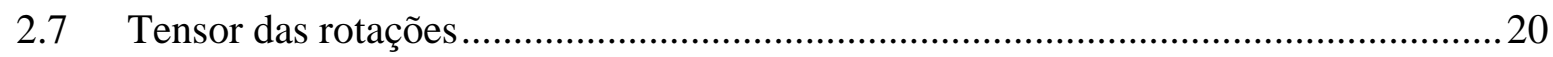

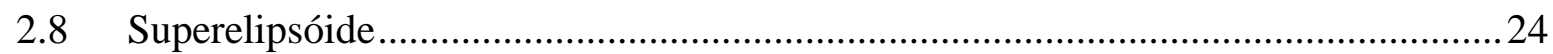

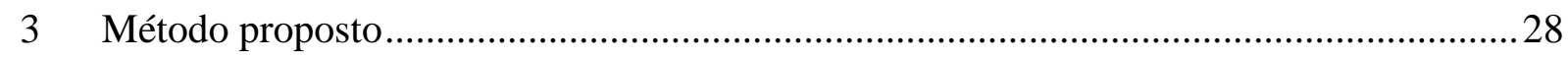

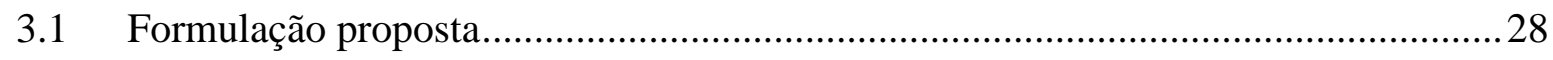

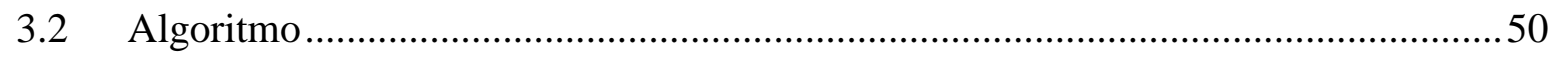

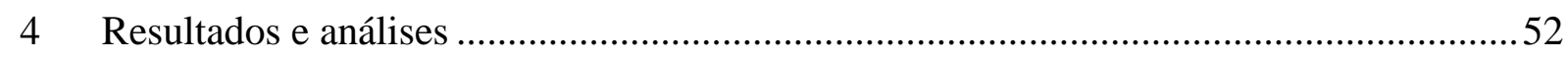

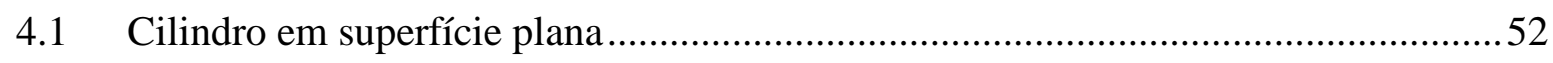

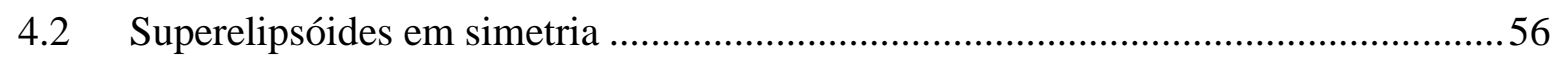

4.3 Verificação dos pontos de singularidade ......................................................... 58

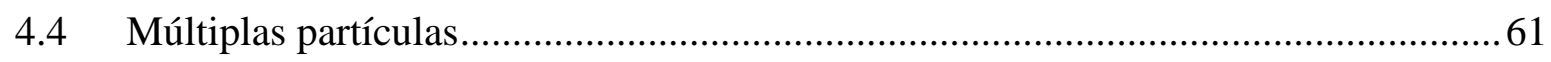

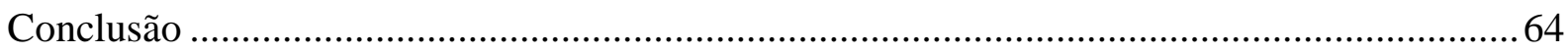




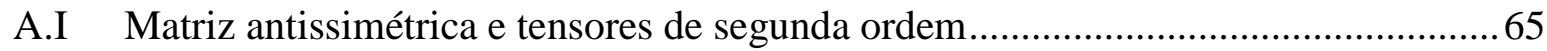

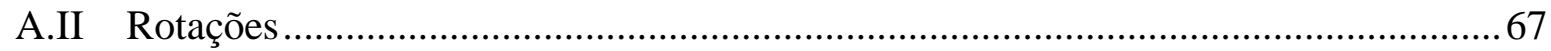

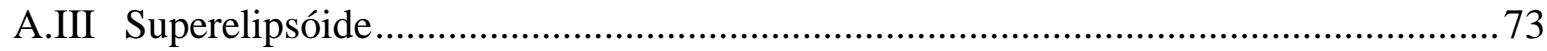

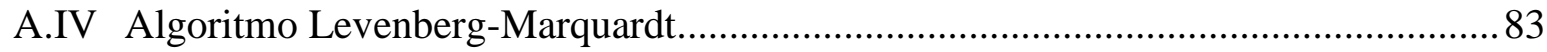

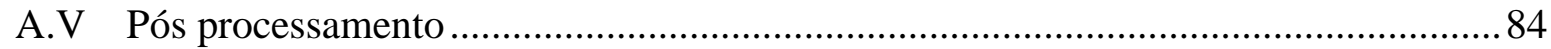

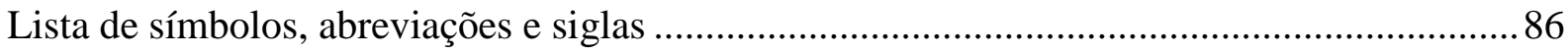

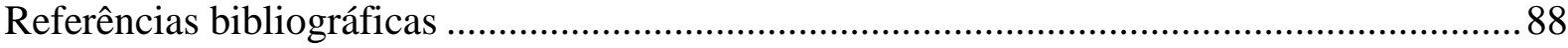




\section{INTRODUÇÃO}

A solução de problemas que envolvem meios físicos pode ser dada pela engenharia através de diferentes modelos, ou métodos, matemáticos, cada um com as suas particularidades e limitações. Para uma determinada situação, um mesmo método pode ser aplicado de formas diferentes para que se consiga resolver o problema com precisão e esforço computacional adequados. Em algumas situações, dois ou mais métodos são acoplados para que se consiga uma melhor aproximação do problema real. Métodos como o Método dos elementos Finitos (MEF), o Método dos Elementos de Contorno (MEC), o Método das Diferenças Finitas (MDF) e o Método dos Elementos Discretos (MED) e suas variações são bastante empregados na engenharia.

Mohammadi, em seu livro sobre a mecânica do descontinuo [1], utiliza um exemplo simples para descrever a diversidade e particularidade dos problemas reais e o seu tratamento matemático (com tradução nossa),

Uma ampulheta de areia foi, durante séculos, uma simples ferramenta para medir o tempo, tão boa quanto um medidor preciso e confiável usado para experimentos científicos. No entanto, até recentemente, mesmo na era dos supercomputadores e métodos numéricos eficientes como o método dos elementos finitos, não é possível modelar com precisão este simples fenômeno. Uma geometria extremamente variável, e objetos (areia) interagindo são os principais obstáculos para uma aproximação eficiente.

Com o MED, problemas semelhantes àquele ilustrado por Mohammadi são resolvidos usando representações matemáticas que aproximam a nível granular o meio físico a ser representado, neste caso, a areia.

O método dos elementos discretos foi apresentado por Cundall em 1971 [2] - e que mais tarde, em 1979, foi mais detalhado pelo mesmo autor [3] - mostra o tratamento de partículas circulares interagindo entre si em um sistema com atrito e amortecimento. A existência do atrito faz com que ocorra a rotação e, consequentemente, novas incógnitas são adicionadas ao problema, tanto para o tratamento do contato quanto para o movimento [4] [5] [6].

O tratamento das rotações na Mecânica Computacional é estudado há algumas décadas. Um dos trabalhos mais importantes sobre este assunto data de 1982 [7], em que o autor explora 
detalhadamente as rotações sobre eixos arbitrários. No mesmo trabalho, o autor expõe a sua preferência pelo uso das rotações vetoriais para simulações computacionais.

A rotação no espaço bidimensional pode ser tratada com simplicidade uma vez que ela pode ser representada por um valor escalar. Por este motivo, possui a propriedade de comutatividade e a soma de rotações consecutivas independe da ordem em que elas acontecem, ou seja, $\theta_{1}+\theta_{2}=\theta_{2}+\theta_{1}$. Entretanto, tal propriedade não pode ser considerada no espaço tridimensional, tornando o seu estudo mais complexo.

O estudo das rotações é de grande importância para a maior parte das aplicações do método dos elementos discretos. Em geral, ela só pode ser desprezada em aplicações que envolvam partículas com dimensões muito pequenas, de modo que as suas rotações não produzam efeitos significativos em seu movimento, como pode ser visto em [8], ou quando o efeito do atrito pode ser eliminado como em situações com zonas de contato muito lubrificadas.

As formulações do MED disponíveis na literatura se apoiam basicamente em duas formas de resolver as rotações. A primeira delas utiliza os mesmos conceitos apresentados por Cundall [6] e se baseiam em rotações não vetoriais. A outra abordagem trata as rotações por meio de quatérnions, como pode ser visto em [9] [10] [11]. Os quatérnions foram propostos por Hamilton em uma série de publicações entre 1844 e 1850 [12]. Uma das principais vantagens dos quatérnions é o fato deste ser livre de singularidade. Entretanto, Altman [13], em um dos livros clássicos sobre rotações, expõe as dificuldades do uso dos quatérnions, principalmente quanto à sua interpretação física.

Métodos explícitos de integração no tempo são predominantes nas aplicações do MED. Eles são derivados de uma expansão de Taylor, e a sua precisão e desempenho dependem de diversos fatores como o passo de tempo e dos modelos de contato. O mais simples destes métodos é o chamado foward Euler, ou Euler explícito, que fornece precisão aceitável para maioria das simulações, mas para isso eles dependem de passos de tempo bem pequenos. Alguns autores mostram que métodos baseados em pontos centrais como o leapfrog e os derivados do método de Verlet fornecem resultados mais precisos [14] [15]. Métodos baseados em Runge-Kutta também fornecem bons resultados, mas, em geral, consomem maior tempo de processamento. O método leapfrog fornece precisão e esforço aceitáveis e são comumente utilizados no MED. 
O tratamento das rotações pode ser classificado em três grupos: não vetoriais, vetoriais de três parâmetros, e quatérnions. No primeiro grupo, estão os esquemas baseados nos ângulos de Euler. Uma das características dos métodos deste grupo é o grande número de expressões trigonométricas, além de ser dependente de algumas regras predefinidas e que são necessárias para tornar o método consistente. Por este motivo, as rotações não vetoriais se tornam pouco atrativas para o MED. Os quatérnions são bastante robustos e consistentes e possuem a vantagem de serem livres de singularidade. Entretanto, do ponto de vista computacional, as parametrizações vetoriais possuem algumas vantagens quando comparadas aos quatérnions como o uso de somente três parâmetros para representar a orientação de uma partícula - que são as coordenadas do vetor rotação, o pequeno número de expressões trigonométricas e ser facilmente compreendida pelo ponto de vista da álgebra. As características da parametrização vetorial dependem do tipo de parametrização escolhida. No presente trabalho é utilizada a parametrização vetorial de Rodrigues, devido às suas vantagens para resolver rotações sucessivas.

A parametrização das rotações de Rodrigues, também chamada de Cayley-Gibbs-Rodrigues ou alguma combinação destes nomes, faz parte do conjunto de parametrizações vetoriais das rotações que se baseiam na fórmula de Rodrigues. Pode ser visto em [16] que esta parametrização possui forte relação com os quatérnions. Uma vasta pesquisa na literatura mostrou que a parametrização de Rodrigues não havia sido utilizada como MED até meados deste trabalho, quando foi apresentada a primeira formulação do método proposto, a qual fez parte da qualificação deste trabalho. Não havendo, portanto, o uso das rotações vetoriais com a parametrização de Rodrigues para o Método dos Elementos Discretos antes deste trabalho.

A parametrização de Rodrigues foi usada com sucesso em algumas formulações com o método dos elementos finitos (ex.: [17] [18]). Algumas propriedades particulares da parametrização de Rodrigues são úteis para problemas da mecânica computacional, em destaque: o uso de três parâmetros e uma única expressão para descrever rotações sucessivas. Neste trabalho, apenas as propriedades relevantes da parametrização de Rodrigues são apresentadas. Recomendamos ver [16] [17] [19] [20] para descrições detalhadas desta parametrização.

Este trabalho tem como objetivo desenvolver uma formulação do método dos elementos discretos a partir de uma descrição vetorial, tal que o tratamento das rotações no espaço tridimensional seja feito por meio da parametrização de Rodrigues. As principais contribuições são o cálculo dos deslocamentos tangentes em um evento de contato usando uma descrição livre de tensores de segunda ordem - mas utilizando o vetor das rotações sucessivas da parame- 
trização de Rodrigues, a execução dos movimentos de rotação utilizando o tensor das rotações de Rodrigues, e uma formulação do método de integração leapfrog com as equações resultantes da parametrização de Rodrigues. Para atingir estes objetivos, o incremento das rotações é resolvido segundo uma formulação semelhante à proposta por Pimenta et al. [17], que relaciona a configuração atual com a configuração seguinte a partir de um tensor $\boldsymbol{Q}_{\Delta}$. Também é utilizada a ideia proposta por Gay Neto [18] para o cálculo dos deslocamentos tangentes entre uma esfera e uma superfície plana. Entretanto, em relação ao segundo caso, algumas melhorias são propostas para a formulação. As duas formulações citadas se aplicam à teoria de barras do método dos elementos finitos. Sendo assim, aqui neste trabalho a matemática de ambos os métodos é revista para que seja, quanto necessário, adequada ao método dos elementos discretos.

\subsection{Organização do texto}

Este texto foi organizado de maneira a sedimentar o conteúdo em áreas específicas, iniciando pelas definições matemáticas fundamentais, seguindo para as formulações propostas, exemplos numéricos e, por fim, uma conclusão. Conforme abaixo.

O capítulo 2 inicia com uma seção dedicada às notações matemáticas utilizadas neste texto. Ainda no capítulo 2, são apresentados os conceitos fundamentais para o desenvolvimento da formulação proposta. Contudo, algumas demonstrações matemáticas foram separadas do tema principal para facilitar a leitura do texto. Estas demonstrações podem ser encontradas nos apêndices deste texto, sendo elas: a demonstração das equações usadas para rotações vetoriais, bem como algumas propriedades relacionadas e as derivações das funções dos superelipsóides.

O método proposto pelo autor está descrito ao longo do capítulo 1. Optou-se em segmentar este capítulo de acordo com a sequência de simulação do MED. Sendo assim, o capítulo mostra o método de detecção de contato, seguido do cálculo dos deslocamentos tangentes e das forças de interação, e finalizando com a integração do movimento da partícula.

Intencionalmente, por se tratar de um tema multidisciplinar, a revisão bibliográfica foi distribuída ao longo dos capítulos. De qualquer modo, uma breve revisão é mostrada na introdução.

Exemplos numéricos e discussões são mostrados no capítulo 4, que é seguido pela conclusão deste trabalho. 
Também se optou por apresentar a lista dos símbolos e abreviações no final do texto, como última parte deste trabalho. 


\section{FUNDAMENTOS}

Neste capítulo estão descritos os fundamentos teóricos utilizados na formulação principal deste trabalho, descrita no capítulo 2.

Nos capítulos seguintes, e em todo texto, os termos "elemento discreto" e "partícula" são aná$\log$ os.

\subsection{Notação}

A notação descrita nesta seção é usada no restante do texto. Nos casos em que esta notação não for aplicável, por alguma conveniência, uma notação específica e a sua validade são descritas localmente. Esta notação está baseada em [21] e [22].

Vetores são representados por letras em negrito, minúsculas e em itálico. Em uma base unitária cartesiana $\boldsymbol{e}_{1}, \boldsymbol{e}_{2}, \boldsymbol{e}_{3}$ um vetor $\boldsymbol{v}$ é descrito pelas coordenadas $v_{1}, v_{2}, v_{3}$, também chamadas de componentes de $\boldsymbol{v}$ naquela base, conforme (1).

$$
\boldsymbol{v}=v_{1} \boldsymbol{e}_{1}+v_{2} \boldsymbol{e}_{2}+v_{3} \boldsymbol{e}_{3}
$$

Este mesmo vetor pode ser escrito na forma mostrada em (2).

$$
\boldsymbol{v}=\sum_{i=1}^{3} v_{i} \boldsymbol{e}_{i}=v_{i} \boldsymbol{e}_{i}
$$

Note a notação indicial na somatória introduzida na equação (2). As coordenadas do vetor $\boldsymbol{v}$ na base $\boldsymbol{e}_{i}$ podem ser escritas como uma matriz coluna $v_{i}=\left[\begin{array}{lll}v_{1} & v_{2} & v_{3}\end{array}\right]^{T}$. O expoente [. $]^{T}$ denota transposto.

Na mecânica das partículas é necessário trabalhar com mais do que uma base vetorial. Todas as bases vetoriais deste texto formam um sistema em $\mathbb{R}^{3}$ e são ortonormais, construídas pelas expressões (3). 


$$
\begin{aligned}
& \boldsymbol{e}_{i} \cdot \boldsymbol{e}_{j}=\delta_{i j} \quad(i, j=1,2,3) \\
& \boldsymbol{e}_{1} \cdot \boldsymbol{e}_{2} \times \boldsymbol{e}_{3}=+1
\end{aligned}
$$

A segunda expressão em (3) indica que as bases são construídas pela regra da mão direita. Sempre que não houver confusão de interpretação a variação dos índices $i$ e $j$, quando se referem às coordenadas de um vetor ou aos índices dos vetores de uma base, está implícita e a expressão entre parênteses " $(i, j=1,2,3)$ " é omitida. Além disso, certa base $\boldsymbol{e}_{i}$ pode ser representada acrescentando-se uma barra baixa e omitindo-se o índice, ou seja, $\boldsymbol{e}_{i}=\underline{\boldsymbol{e}}$. Note que $\underline{\boldsymbol{e}}$ é a representação de três vetores $\underline{\boldsymbol{e}}=\left[\begin{array}{lll}\boldsymbol{e}_{1} & \boldsymbol{e}_{2} & \boldsymbol{e}_{3}\end{array}\right]^{T}$.

Uma matriz é representada por uma letra em maiúsculo, itálico, sem negrito e escrito entre colchetes. Por exemplo, $[A],[B]$. Pode-se, quando conveniente e explicitamente descrito, escrever uma matriz somente pela sua letra maiúscula e itálica (ex.: $A, B$ ). Os componentes de uma matriz são escritos pelas letras minúsculas equivalentes (ex.: $\left.a_{m n}, b_{m n}\right)$.

Um tensor é representado por uma letra em maiúsculo, itálico e negrito. Por exemplo, $\boldsymbol{A}, \boldsymbol{B}$. A representação matricial de um tensor segue as regras definidas para matrizes.

O produto escalar entre dois vetores quaisquer $\boldsymbol{a}$ e $\boldsymbol{b}$, é representado por um operador ponto “.”, por exemplo: $\boldsymbol{a} \cdot \boldsymbol{b}$. Este mesmo operador é usado para representar o produto de dois tensores ${ }^{1}$, tal que $\boldsymbol{C}=\boldsymbol{A} \cdot \boldsymbol{B} \equiv[C]=[A][B] \equiv c_{i j}=a_{i k} b_{k j}$, ou entre um tensor e um vetor (ex.: $\boldsymbol{b}=\boldsymbol{R} \cdot \boldsymbol{a})$. Quando a representação matricial é usada, o operador é omitido, ex.: $\boldsymbol{R} \cdot \boldsymbol{a}=$ $[R] \boldsymbol{a}=[R][a], \boldsymbol{A} \cdot \boldsymbol{B}=[A][B]$. O produto vetorial entre dois vetores é representado pelo símbolo "X".

Índices superiores entre parênteses são usados para distinguir as partículas. Assim, alguma grandeza relacionada a uma partícula é escrita na forma $(\cdot)^{(i)}$, quando esta se refere à partícula $i$, e $(\cdot)^{(j)}$ quando a grandeza se refere à partícula $j$. Grandezas sem este índice se referem a uma partícula qualquer.

\footnotetext{
${ }^{1}$ Utiliza-se esta notação para evitar conflito com o a notação comumente usada para representar o produto diádico, também chamada de produto tensorial entre dois vetores, que é representada por $\boldsymbol{a} \boldsymbol{b}^{T} \equiv \boldsymbol{a} \boldsymbol{b} \equiv \boldsymbol{a} \otimes \boldsymbol{b}$.
} 


\subsection{Método dos Elementos Discretos}

O termo "método dos elementos discretos" é comumente usado para definir os métodos computacionais que se baseiam nas definições propostas por Cundall [23], as quais se referem aos métodos que:

1 - Permitem deslocamentos e rotações de corpos discretos, incluindo separação total, e;

2 - Reconhecem novos contatos automaticamente à medida que os cálculos são executados.

Assim, o MED pode ser visto como um conjunto de técnicas apropriadas para simulação do comportamento dinâmico de um conjunto de múltiplos corpos rígidos ou deformáveis - partículas ou domínios com formas aleatórias - sujeitos a variações sucessivas das condições de contato [6].

As primeiras ideias do método dos elementos discretos foram apresentadas por Cundall em 1971, em uma publicação sobre um modelo computacional para o movimento progressivo e em grande escala de blocos de rocha [2]. Apesar de neste artigo terem sido feitas algumas considerações que mais tarde vieram a compor o método, nenhum nome foi dado ao conjunto de técnicas ali usadas. Em 1977 [24], em uma publicação do mesmo autor, o método com o nome de "Distinct Element Method" ("Método dos Elementos Distintos") é "batizado". Em algumas de suas publicações, como em [24] e [25], Cundall apresenta o funcionamento do programa de computador desenvolvido com a sua formulação do MED. Nestas publicações, grande parte do trabalho é dedicado aos elementos distintos poligonais, blocos, que simulavam maciços rochosos. Entretanto, o método, conforme é conhecido hoje, foi totalmente descrito em sua publicação de 1979 [3] em uma formulação que envolve a interação de elementos discretos circulares (discos) contra eles mesmos e contra superfícies planas. No mesmo trabalho é detalhado o algoritmo de resolução do método e o método de integração no tempo das equações de movimento.

Alguns termos são encontrados na literatura se referindo ao mesmo método introduzido por Cundall. Além disso, há também alguns métodos que utilizam partículas, mas que diferem do método original e possuem nome semelhante. Dentre os termos mais comuns, utilizados em métodos que utilizam partículas para discretização do meio, estão: Método dos Elementos Distintos (Distinct Element Method), Método dos Elementos Discretos (Discrete Element Me- 
thod), Dinâmica Molecular (Molecular Dynamics), Event-Driven Simulation, Soft Particles e Hard Particles [5].

A representação do domínio (região) em um problema resolvido com o MED é feita a partir de partes discretas descontínuas, com propriedades e formas distintas que formam um aglomerado de elementos - diferente, por exemplo, do Método dos Elementos Finitos (MEF) e o Método dos Elementos de Contorno (MEC) que possuem como característica fundamental o tratamento do domínio a partir de soluções contínuas [26] [27].

Podem-se diferenciar os métodos que utilizam elementos discretos em duas categorias: aqueles que tratam as partículas como corpos indeformáveis e aqueles que tratam as partículas como sólidos com deformáveis ${ }^{2}$. No primeiro caso, o tratamento do contato comumente é feito a partir do equilíbrio de momentos linear e/ou angular e considerando-se um coeficiente de restituição para tratar as forças de interação. Neste caso, o método é aplicável para os problemas cuja duração do contato é curta o suficiente para que as partículas se separem logo após o contato. Com esta técnica, o custo computacional se torna muito elevado à medida que grandes quantidades de partículas entram em contato ao mesmo tempo formando um único conjunto. Por outro lado, nos métodos que utilizam partículas deformáveis, o tratamento do contato é feito a partir de relações constitutivas entre duas partículas e, portanto, podem ser aplicados, sem grande aumento no custo computacional, aos casos que envolvem contatos de longa duração e também quando há grande quantidade de contatos simultâneos. Entretanto, em geral, devem-se tomar incrementos de tempo menores do que aqueles utilizados para caso anterior.

O processo comum de resolução de um problema pelo MED inicia pela descrição do movimento individual das partículas em cada incremento de tempo. O deslocamento das partículas é dado pela equação geral do movimento de Newton e pela equação de Euler para as rotações, conforme descrito na seção 2.3, a partir das forças resultantes em cada partícula. Estas forças precisam ser calculadas de acordo com as interações de cada elemento discreto com as demais partículas e condições de contorno do problema.

\footnotetext{
${ }^{2}$ Apesar das forças de contato serem calculadas com base em alguma relação constitutiva, que leva em consideração a penetração entre as partículas, a geometria da partícula se mantem em sua forma inicial em todos os instantes da simulação (sem deformação). O que ocorre, de fato, é uma sobreposição entre partículas, que é comumente chamada de penetração ou deformação.
} 
Sendo assim, a rotina de cálculo do MED é dividida basicamente em três etapas: detecção de contato, cálculo das forças de interação e atualização da posição da partícula para o próximo incremento de tempo.

Quanto à descrição geométrica, os elementos discretos podem divididos em três grupos: 1poliedros; 2- elementos de curvatura contínua (ex.: esferas, superelipsóides); 3- elementos de representação discreta. Conforme a abaixo.

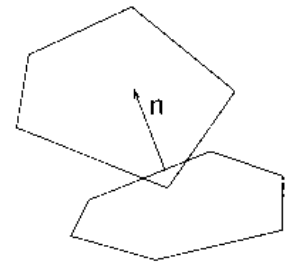

(a)

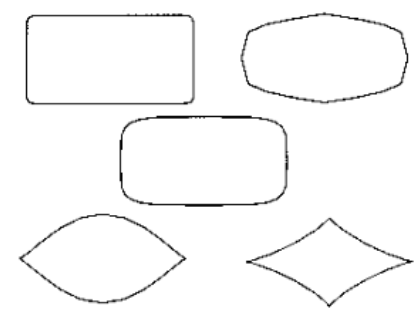

(b)

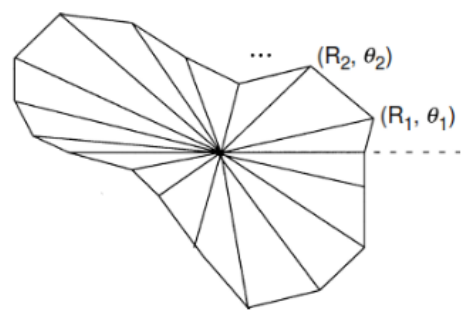

(c)

Figura 1 - Exemplos de elementos discretos. (a) elementos poligonais; (b) elementos de curvatura contínua, superelipsóides; (c) elemento de representação discreta. Fonte: [28].

Uma das grandes dificuldades do MED é a detecção do contato. Esta dificuldade acontece tanto em termos de esforço computacional quanto em termos da solução matemática aplicada. No primeiro caso, o aumento de esforço pode acontecer tanto devido ao grande número de partículas quanto por causa da complexidade geométrica do elemento. Além disso, em uma análise com MED podem ser utilizadas milhares de partículas com diversos tamanhos e formas. A princípio não é possível saber se uma partícula está em contato com outra, senão por meio de testes lógicos. Há, entretanto, diversas técnicas que podem ser usadas para identificar colisões entre partículas.

O contato entre os elementos discretos e as condições de contorno também precisam ser encontrados. Esta busca se torna simples quando as condições de contorno são rígidas e fixas, pois todas as variáveis usadas para sua representação são sempre conhecidas. Um ganho significativo de dificuldade pode surgir quando as condições de contorno possuem movimento e não são rígidas. Neste caso, além dos cálculos para atualização das variáveis das c.c. em cada incremento de tempo, estas paredes precisam ser modeladas usando algum método numérico como o MEF, e o acoplamento matemático entre os dois métodos precisa ser formulado. Neste trabalho, todas as condições de contorno são do tipo rígidas e não possuem graus de liberdade de movimento. 


\subsection{Dinâmica das partículas}

Conforme mencionado, o MED é caracterizado pelo uso de objetos distintos, chamados de elementos discretos, ou partículas. Este conjunto, de fato, forma um sistema com múltiplos corpos cujas propriedades individuais mecânicas, geométricas e cinemáticas são conhecidas. Na mecânica computacional, o termo "dinâmica" é comumente utilizado para descrever estudos que envolvem o movimento de corpos ou partículas, como é o caso do MED. Na física, em sistemas com múltiplos objetos, as expressões "sistemas dinâmicos" e "sistemas dinâmicos multicorpos" são comumente usadas [22] [29]. Os princípios utilizados para descrever este tipo de sistema são mostrados nesta seção.

Um elemento discreto $\mathcal{P}$ é considerado indeformável e a sua posição no espaço é definida pelo seu centro geométrico. A forma geométrica das partículas varia de acordo com a formulação usada, sendo as formas mais comuns: esfera, superelipsóide e poliedros. Existem também as geometrias que são formadas a partir de um aglomerado de esferas, chamados de clusters. Esta última técnica pode ser usada tanto para se conseguir formas geométricas mais complexas quanto para reduzir o esforço computacional em algumas etapas do processo como a detecção do contato, que é mostrada mais adiante. Partículas não esféricas também podem ser usadas em clusters, embora seja menos comum. Neste trabalho são usadas partículas esféricas e superelipsóides, ambas individuais, sem clusters. Independentemente da geometria escolhida, cada elemento discreto possui um sistema de coordenadas local que é usado para descrevê-lo geometricamente. A orientação de uma partícula no espaço é dada pela orientação do seu sistema local em relação a um sistema inercial, também chamado de global. Cada elemento discreto possui seis graus de liberdade, sendo três translações e três rotações, ambos em relação aos eixos ortogonais.

O sistema inercial de referência é o sistema cartesiano cuja base é formada pelos vetores unitários $\boldsymbol{e}_{i}(i=1,2,3)$ com origem em $\boldsymbol{O}$, que definem os eixos globais. Um ponto nesta base é dado por um vetor $\boldsymbol{x}$ definido por

$$
\boldsymbol{x}=x_{1} \boldsymbol{e}_{1}+x_{2} \boldsymbol{e}_{2}+x_{3} \boldsymbol{e}_{3}
$$


Sendo a posição de uma partícula dada pelo seu centro, o vetor $\boldsymbol{x}$ define a localização da partícula no espaço. Um ponto $P$ que pertence à partícula tem a sua posição dada por $\boldsymbol{p}=\boldsymbol{x}+$ $\overrightarrow{X P}$, onde $X$ representa o ponto localizado em $\boldsymbol{x}$.

Para cada partícula é definido um sistema de coordenadas local representado pelos vetores $\hat{\boldsymbol{e}}_{i}$. Uma quantidade, quando representada no sistema de referência da partícula, é representada pelo índice superior $(\cdot)^{r}$. A velocidade angular de uma partícula é escrita pelo vetor $\boldsymbol{\omega}$.

O momento angular de uma partícula é dado por

$$
\boldsymbol{\mu}=\boldsymbol{J} \cdot \boldsymbol{\omega},
$$

onde $\boldsymbol{J}$ é o tensor de inércia da partícula. A variação no tempo do momento angular, comumente chamada de torque, ou momento ${ }^{3}$, é dada por

$$
\dot{\mu}=\boldsymbol{J} \cdot \dot{\boldsymbol{\omega}}+\boldsymbol{\omega} \times(\boldsymbol{J} \cdot \boldsymbol{\omega})
$$

A equação do movimento de uma partícula é dada por

$$
\boldsymbol{f}=m \frac{d \boldsymbol{v}}{d t}=m \ddot{\boldsymbol{x}}
$$

Na equação (7), $\boldsymbol{f}$ é o vetor força resultante no corpo; a massa é dada por $m$; e $\boldsymbol{v}=\dot{\boldsymbol{x}}$ é o vetor velocidade. As equações (6) e (7) são chamadas de Leis de Euler [30]. A equação (7) também é conhecida como Segunda lei de Newton.

Quando uma partícula estiver sob a influência de mais de uma força, a força resultante é dada pela soma vetorial destas forças, portanto:

\footnotetext{
${ }^{3}$ Neste texto, o termo "toque" é utilizado com maior frequência, em semelhança ao termo em inglês. Esta escolha é justificada com o intuito de evitar confusão com os termos "momento linear" e "momento angular" que também são bastante utilizados ao longo do texto.
} 


$$
\boldsymbol{f}=\sum_{\lambda=1}^{n} \boldsymbol{f}_{\lambda}
$$

\subsection{Mecânica do contato}

No MED, as partículas são consideradas indeformáveis. As forças tangentes e normais de contato são calculadas a partir de uma pseudo-penetração que utiliza alguma lei de contato para relacionar tal penetração a uma força. É fácil notar que a penetração é bem pequena quando comparada às dimensões da partícula. Entretanto, devido à possibilidade de deslizamento, os deslocamentos tangentes podem alcançar grandes dimensões, principalmente se comparados aos deslocamentos normais.

Os problemas de contato envolvem uma série de fatores que, isoladamente ou não, influenciam na resposta do problema, podendo tornar o estudo extremamente complexo. Fatores como a rugosidade, a variação de temperatura do meio ou resultante de alguma ação mecânica, os parâmetros individuais do material (ex.: fragilidade, plasticidade etc.), e a mudança geométrica no decorrer do processo são alguns exemplos que ilustram a diversidade de efeitos que podem ser analisados em problemas da mecânica do contato.

A superfície e o caminho por onde ocorre o contato são, a priori, desconhecidos. Eles são apresentados à medida que a simulação ocorre.

Uma vez que um contato é detectado, as relações entre os dois corpos obedecem algumas regras previamente definidas. Estas regras são definições matemáticas que representam algum fenômeno real como o atrito, coesão, amortecimento e a histerese, por exemplo. Em geral, o estudo é separado em duas partes, uma que estuda os efeitos na direção normal do contato e outra que analisa os efeitos a direção tangente. $\mathrm{O}$ estudo mais simples em uma simulação de contato é quando somente forças elásticas normais são consideradas.

Em um contato sem atrito, os sólidos podem deslizar uns sobre os outros sem que haja resistência na direção tangencial à superfície de contato. Portanto, o efeito do carregamento externo na interface de contato será somente de compressão normal. Sem atrito, a força tangencial será sempre igual à zero (Figura 2b). 


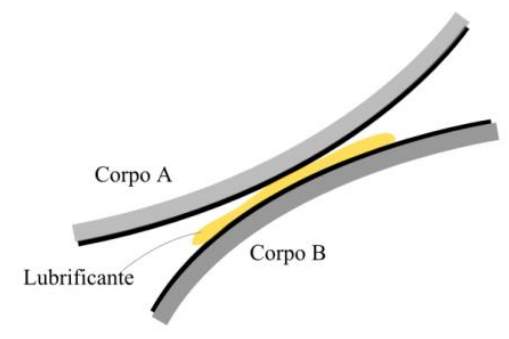

(a)

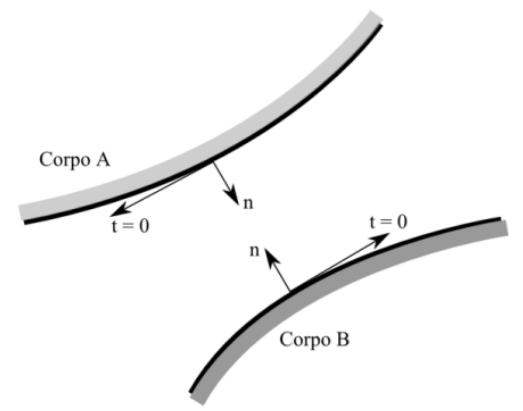

(b)

Figura 2 - Contato sem atrito. (a) contato com lubrificante. (b) forças na superfície de contato.

A aplicação prática deste tipo de contato é relativamente limitada. Em geral, este tipo de consideração é feito nos problemas envolvendo superfícies lisas e bem lubrificadas (Figura 2a).

Ao considerar o efeito de atrito, duas situações podem ocorrer: contato sem deslizamento tangencial (stick); e, contato com deslizamento tangencial (slip).

Na primeira situação, stick, o deslizamento é impedido pela força de atrito desenvolvida na superfície, que é a componente de resistência tangencial nos pontos de contato da superfície. Em outras palavras, quando houver stick, a componente tangencial que atua entre os sólidos é menor do que o limite de atrito. No segundo caso, slip, o limite da força de atrito é atingido e a componente tangencial da força na superfície de cada sólido será igual ao valor deste limite. A Figura 3 ilustra as forças atuantes nas superfícies de cada sólido.

Em ambos os casos, a força tangencial a ser desenvolvida depende da componente normal atuando no mesmo ponto e das características de cada sólido (como a rugosidade e a topologia).

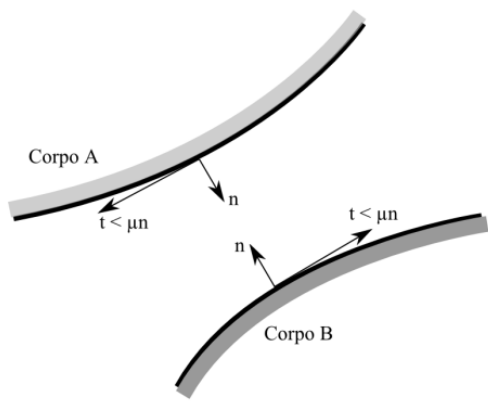

(a)

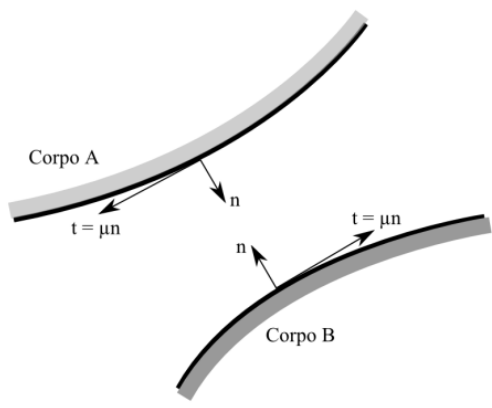

(b)

Figura 3 - Contato com atrito. (a) forças em situação tipo stick. (b) forças em situação tipo slip. 
O comportamento da fricção pode ser caracterizado por meio da "Lei Clássica da Fricção", também chamada de Lei de Atrito de Coulomb. Segundo esta teoria, o deslizamento relativo entre dois sólidos em contato irá acontecer quando a força tangencial em algum ponto da superfície exceder o produto da componente normal e uma constante de atrito [31].

A simplicidade desta formulação faz com que a teoria de Coulomb seja amplamente aplicada em modelos de contato.

Considerando o MED e duas partículas quaisquer $i$ e $j$, a força normal que atua na partícula $i$ depende da pseudo-penetração entre $i$ e $j$. O valor desta força pode ser calculado, por exemplo, a partir das relações de contato definidas por Hertz (ver [32]). Segundo esta teoria, a força normal é calculada pela expressão

$$
\boldsymbol{f}_{\text {Hertz }}^{N}=\left(k_{N} \delta_{N}^{3 / 2}\right) \boldsymbol{n},
$$

na qual $k_{N}$ é uma constante elástica resultante da propriedade equivalente de dois materiais e dos raios equivalentes das duas esferas, $k_{N}=\frac{4}{3} E_{e q} \sqrt{r_{e q}}$.

Outra maneira de se calcular a força normal é a partir de relações lineares que dependem apenas da penetração e de um coeficiente de rigidez normal, ou seja, $f^{N}=k^{N} \delta$. Este método é comumente chamado de método da penalidade. Em modelos que envolvem algum tipo de dissipação de energia mecânica, uma parcela viscosa é acrescentada na expressão da penalidade, tal que essa parcela depende da velocidade de penetração e de um coeficiente de dissipação que depende do material. Assim, a força normal pode ser calculada pela equação (10). Em comparação com o modelo de Hertz apresentado anteriormente, (9), é fácil notar que o método de penalidade possui maior simplicidade em sua formulação. Apesar disso, os resultados apresentados utilizando tal aproximação linear não são menos satisfatórios do que aqueles que utilizam Hertz em análises com o MED [33]. Uma das vantagens do método de Hertz é que, além de ser um método não linear, ele depende de grandezas conhecidas que relacionadas ao material da partícula.

$$
\boldsymbol{f}^{\mathrm{N}}=k^{N} \boldsymbol{\delta}^{N}+\gamma_{0} \dot{\boldsymbol{x}}^{\mathrm{N}}
$$


A existência do atrito faz com que existam forças tangentes que podem ser causadas tanto por colisões não centradas - quando a direção do deslocamento é diferente da direção do vetor normal de contato - quanto pela rotação relativa entre as partículas. É fácil perceber que o cálculo destas forças não pode ser feito diretamente a partir da penetração normal entre $i$ e $j$. Portanto, torna-se necessário o cálculo do deslizamento na direção tangente às superfícies das partículas, aqui chamado de gap tangente.

Uma partícula pode rolar, deslizar e também é possível rolar com a existência do deslizamento, criando uma combinação dos dois primeiros efeitos. $\mathrm{O}$ deslizamento puro acontece quando não há nenhuma rotação na partícula, porém, devido ao movimento de translação, a esfera se move tangencialmente, gerando uma força de atrito no sentido oposto ao deslizamento (exceto quando o atrito está sendo desprezado na análise). Por outro lado, no rolamento puro, o movimento de translação é acompanhado por uma rotação que faz a partícula se movimentar no mesmo sentido da translação. Neste caso, o comprimento do arco produzido na superfície da partícula pelo movimento de rotação é exatamente igual à distância percorrida pela partícula devido à sua velocidade linear, ou seja, $\Delta s=\Delta u$, conforme a Figura 4.

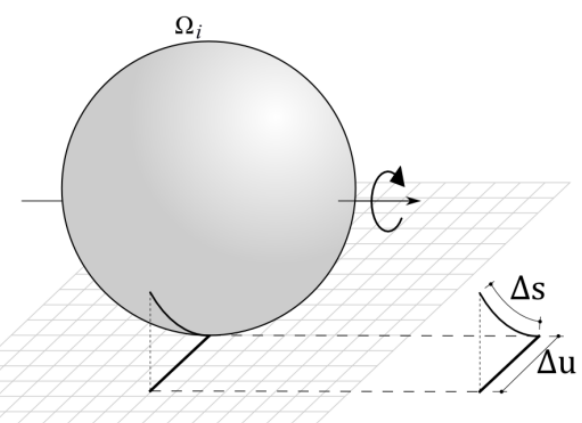

Figura 4 - Rolamento de uma partícula.

O deslizamento ocorrerá sempre que a força tangente ultrapassar o limite da força de atrito estático. Este limite pode ser definido por meio da Lei Coulomb. O valor desta força é dado por (11).

$$
\boldsymbol{f}_{\text {lim }}^{S}=\epsilon \boldsymbol{f}^{N}
$$

Sendo a constante $\epsilon$ o coeficiente de atrito estático, que neste trabalho possui o mesmo valor do coeficiente de atrito dinâmico. 


\subsection{Integração no tempo}

Seja $t$ um instante qualquer. Sendo $\Delta t$ a medida de um incremento de tempo, o instante consecutivo é igual a $t+\Delta t$. Adota-se nos capítulos seguintes a notação: $t \pm \Delta t=t \pm 1$ ou $t \pm 1 / 2 \Delta t=t \pm 1 / 2$.

\subsubsection{Método de Euler}

O método de integração explícita de Euler é utilizado para calcular determinada EDO a partir de informações atuais. O método também é chamado de Forward Euler. A sua formulação é extremamente simples e, por este motivo, pode ser facilmente implementada em algoritmos de programação e é extensamente utilizada no MED.

A solução dada pelo método de Euler é uma aproximação de primeira ordem, construída a partir do truncamento da expansão por série de Taylor da função principal, ou seja, se $h(t)$ é uma função qualquer, então $h(t+1)=h(t)+\frac{d}{d t} h(t) \Delta t$.

Utilizando o método de Euler, as forças são calculadas no instante atual, tal que a posição e a velocidade no instante consecutivo são dadas por

$$
\begin{aligned}
& x(t+\Delta t)=x(t)+\Delta t \dot{x}(t), \\
& \dot{\boldsymbol{x}}(t+\Delta t)=\dot{\boldsymbol{x}}(t)+\Delta t \ddot{\boldsymbol{x}}(t) .
\end{aligned}
$$

\subsubsection{Método leapfrog}

A integração no tempo com o método leapfrog recebe este nome devido ao fato de que as velocidades "saltam" o intervalo de tempo atual e são computadas "adiantadas" em meio instante de tempo. Portanto, a posição e a velocidade são conhecidas em instantes distintos. O método leapfrog é um método de segunda ordem. A integração com este método é dada pelas equações

$$
\boldsymbol{v}\left(t+\frac{\Delta t}{2}\right)=\boldsymbol{v}\left(t-\frac{\Delta t}{2}\right)+\Delta t \boldsymbol{a}(t)
$$




$$
x(t)=x(t)+\Delta t v\left(t+\frac{\Delta t}{2}\right)
$$

É importante notar que o método leapfrog, apesar de ser um método explícito, requer no início da simulação o uso de variáveis desconhecidas. Por exemplo, se o instante $t=0$ é o ins-

tante inicial da simulação, então $v\left(t \pm \frac{\Delta t}{2}\right)$ é desconhecido. Entretanto, considerando serem conhecidas as velocidades nos instantes intermediários anterior e posterior, a velocidade no instante $t$ pode ser calculada por

$$
\boldsymbol{v}(t)=\frac{1}{2}\left[\boldsymbol{v}\left(t-\frac{\Delta \mathrm{t}}{2}\right)+\boldsymbol{v}\left(t+\frac{\Delta \mathrm{t}}{2}\right)\right]
$$

No instante inicial, a informação de $\boldsymbol{v}\left(-\frac{\Delta t}{2}\right)$ ou $\boldsymbol{v}\left(+\frac{\Delta t}{2}\right)$ pode ser calculada pelo o método de Euler, mas considerando meio instante de tempo para trás ou para frente, respectivamente. Desta forma, todas as informações necessárias para iniciar a integração se tornam conhecidas.

\subsection{Transformação de Cayley}

A transformação de Cayley mostra que qualquer matriz ortogonal é uma função de uma matriz antissimétrica. Ou seja, um tensor ortogonal $\boldsymbol{R}$ pode ser calculado a partir de um tensor antissimétrico $\boldsymbol{A}$ (ver nota ${ }^{4}$ ), segundo a equação

$$
\boldsymbol{R}=(\boldsymbol{I}-\boldsymbol{A})^{-1} \cdot(\boldsymbol{I}+\boldsymbol{A})=(\boldsymbol{I}+\boldsymbol{A}) \cdot(\boldsymbol{I}-\boldsymbol{A})^{-1} .
$$

A equação (17) é chamada de "transformação de Cayley". A relação inversa pode ser obtida por:

$$
\boldsymbol{A}=(\boldsymbol{R}-\boldsymbol{I}) \cdot(\boldsymbol{R}+\boldsymbol{I})^{-1}=(\boldsymbol{I}+\boldsymbol{R}) \cdot(\boldsymbol{I}-\boldsymbol{R})^{-1} .
$$

\footnotetext{
${ }^{4}$ Somente nesta seção deste capítulo o tensor $\boldsymbol{A}$ representa um tensor antissimétrico qualquer. No restante do texto, este tensor representa o tensor antissimétrico da parametrização de Rodrigues. Esta nomenclatura foi utilizada propositalmente para criar certa analogia entre a transformação de Cayley, que é fundamental para as demonstrações da parametrização de Rodrigues, e o tensor das rotações de Rodrigues.
} 
Uma demonstração da transformação de Cayley pode ser feita a partir de uma descrição geométrica, conforme mostrado adiante. Seja $\mathcal{B}$ um corpo rígido e $C$ um ponto fixo pertencente ao corpo, pelo qual $\mathcal{B}$ gira. Seja $P_{0}$ um ponto arbitrário em $\mathcal{B}$ e seja o $\boldsymbol{v}$ o vetor que representa este ponto em algum sistema de referência. Uma transformação atuando em $\mathcal{B}$ é dada por

$$
\boldsymbol{v}^{\prime}=\boldsymbol{X} \cdot \boldsymbol{v}
$$

tal que $\boldsymbol{X}$ é o tensor ortogonal cuja a matriz que representa a transformação no sistema de referência é $[X]=X$.

O vetor resultante da transformação (19) possui a mesma norma do vetor original, portanto $\|\boldsymbol{v}\|=\left\|\boldsymbol{v}^{\prime}\right\|$. Esta igualdade pode ser reescrita na forma $\|\boldsymbol{v}\|^{2}-\left\|\boldsymbol{v}^{\prime}\right\|^{2}=0$, o que resulta em

$$
\|v\|^{2}-\left\|v^{\prime}\right\|^{2}=0=\left(\boldsymbol{v}^{\prime}-v\right) \cdot\left(\boldsymbol{v}^{\prime}+v\right)
$$

É fácil notar que $\left(\boldsymbol{v}^{\prime}-\boldsymbol{v}\right)$ e $\left(\boldsymbol{v}^{\prime}+\boldsymbol{v}\right)$ são ortogonais entre si. Usando (19) e nomeando os vetores resultantes das expressões entre parênteses, ou seja, $\boldsymbol{d}^{-}=\left(\boldsymbol{v}^{\prime}-\boldsymbol{v}\right)=(\boldsymbol{X}-\boldsymbol{I}) \cdot \boldsymbol{v}$ e $\boldsymbol{d}^{+}=\left(\boldsymbol{v}^{\prime}+\boldsymbol{v}\right)=(\boldsymbol{X}+\boldsymbol{I}) \cdot \boldsymbol{v}$. Agora, substituindo a segunda expressão na primeira e eliminando $\boldsymbol{v}$, obtêm-se a seguinte relação entre $\boldsymbol{d}^{+}$e $\boldsymbol{d}^{-}$

$$
d^{-}=(X-I) \cdot(X+I)^{-1} \cdot d^{+}
$$

Da expressão acima é extraído o operador $\boldsymbol{Y}$, tal que

$$
\boldsymbol{Y}=(\boldsymbol{X}-\boldsymbol{I}) \cdot(\boldsymbol{X}+\boldsymbol{I})^{-1}
$$

executa uma transformação que produz um vetor $\boldsymbol{d}^{-}$ortogonal a $\boldsymbol{d}^{+}$e que, portanto, está em conformidade com (20). É possível mostrar que $\boldsymbol{Y}$ é antissimétrico. Para isso, considere um vetor $\boldsymbol{m}$ qualquer pertencente ao sólido estudado. Considerando que $\boldsymbol{Y}$ é uma transformação que produz um vetor ortogonal, então deve ser válida a expressão 


$$
\boldsymbol{m} \cdot(\boldsymbol{Y} \cdot \boldsymbol{m})=0=\left[\begin{array}{lll}
m_{1} & m_{2} & m_{3}
\end{array}\right]\left[\begin{array}{lll}
y_{11} & y_{12} & y_{13} \\
y_{21} & y_{22} & y_{23} \\
y_{31} & y_{32} & y_{33}
\end{array}\right]\left[\begin{array}{l}
m_{1} \\
m_{2} \\
m_{3}
\end{array}\right]
$$

Com algum esforço algébrico é possível mostrar que a condição que torna a equação acima válida é que $\boldsymbol{Y}$ seja antissimétrico, ou seja,

$$
\left[Y_{i j}\right]=\left[\begin{array}{ccc}
0 & y_{12} & y_{13} \\
-y_{12} & 0 & y_{23} \\
-y_{13} & -y_{23} & 0
\end{array}\right]
$$

Portanto, a expressão $\boldsymbol{Y}$ em (22) representa uma relação entre um tensor ortogonal e um tensor antissimétrico (esta é exatamente a relação procurada). Fazendo $\boldsymbol{R} \equiv \boldsymbol{X}$ e $\boldsymbol{A} \equiv \boldsymbol{Y}$ em (22), a transformação de Cayley pode ser obtida resolvendo expressão $\boldsymbol{A}=(\boldsymbol{R}-\boldsymbol{I}) \cdot(\boldsymbol{R}+\boldsymbol{I})^{-1}$ de modo a isolar o tensor $\boldsymbol{R}$ do lado esquerdo da igualdade.

\subsection{Tensor das rotações}

A orientação de um corpo rígido $\mathcal{P}$ em relação a uma base ortogonal $\boldsymbol{e}_{i}$ pode ser definida pela orientação angular de uma base fixa ao corpo, $\hat{\boldsymbol{e}}_{i}$, em relação a essa base. Este pode ser, por exemplo, o cenário entre dois instantes de tempo consecutivos quando se observa um corpo que gira em torno de um eixo fixo, como uma partícula que gira. Sendo conhecidas as duas bases, a transformação linear que mapeia esta relação é dada pela equação (25).

$$
\hat{\boldsymbol{e}}_{i}=A_{i j} \boldsymbol{e}_{j}
$$

Os nove elementos da matriz $[A]$ são as coordenadas que descrevem a orientação do corpo na base $\boldsymbol{e}_{i}$. Cada componente da matriz $[A]$ representa o cosseno do ângulo entre os vetores da base $\hat{\boldsymbol{e}}_{i}$ e a base $\boldsymbol{e}_{i}$. Por este motivo, é muitas vezes chamada de "matriz dos cossenos diretores". A operação mostrada em (25) pode ser entendida como uma transformação linear, tal que $A: \mathbb{R}^{3} \rightarrow \mathbb{R}^{3}$. Portanto, a matriz de transformação possui nove componentes. O cálculo de todas estas coordenadas é inconveniente do ponto de vista computacional devido ao grande número de operações matemáticas que se fazem necessárias para realizar uma transformação entre as duas bases. Entretanto, sendo esta transformação uma rotação, podem-se utilizar for- 
mas diferentes daquela utilizada com o cálculo dos cossenos diretores para se conseguir os componentes da matriz de transformação. Conforme mostrado adiante.

A execução da rotação em um corpo que se encontra fixo por um ponto pertencente ao próprio corpo pode ser feita de diversas maneiras diferentes. Pode-se, por exemplo, executar certa sequência de rotações em torno dos eixos principais, até que se obtenha a posição procurada. Pode-se, também, executar a rotação por meio de um único passo, ao girar o corpo em torno de um eixo fixo que possui certa orientação e que passa pelo ponto fixo. Este segundo método descreve o teorema de Euler. Considerando estes dois cenários, é fácil notar que o segundo método exige menos operações para realizar a mesma tarefa.

O método dos ângulos de Euler é um dos mais conhecidos dentre aqueles que executam uma rotação por meio de rotações sucessivas. Neste método, a sequência de rotações sucessivas é definida por (3, 1', 3'’). Em que, 1' representa o vetor $\widehat{\boldsymbol{e}}_{1}$ após a primeira rotação; e 3'" representa o vetor $\hat{\boldsymbol{e}}_{3}$ após as duas rotações anteriores. Para cada rotação é definido um ângulo $\psi, \theta$ e $\phi$. A matriz de transformação resultante, o tensor das rotações, é igual a $\boldsymbol{R}=\boldsymbol{R}_{\phi} \cdot \boldsymbol{R}_{\theta}$. $\boldsymbol{R}_{\psi}$. Cada componente do tensor das rotações resultante é calculado por meio de longas expressões trigonométricas.

Outro método baseado em rotações sucessivas é o método dos ângulos de Cardan, também chamado de ângulos de Bryan. Pelo método de Cardan a posição final do corpo é dada após a execução da sequência $\left(1,2\right.$ ', 3''). Aqui, 2' representa o vetor $\hat{\boldsymbol{e}}_{2}$ após a primeira rotação; e 3 " representa o vetor $\hat{\boldsymbol{e}}_{3}$ após as duas rotações anteriores. Para cada rotação é definido um ângulo $\phi_{1}, \phi_{2}, \phi_{3}$. A matriz de transformação resultante, o tensor das rotações, é igual a $\boldsymbol{R}=\boldsymbol{R}_{\phi_{3}} \cdot \boldsymbol{R}_{\phi_{2}} \cdot \boldsymbol{R}_{\phi_{1}}$. Apesar de muito semelhante ao método dos ângulos de Euler, a principal vantagem dos ângulos de Cardan é a possibilidade de linearização dos componentes do tensor rotação para pequenas rotações, ou seja, quando $\left|\phi_{i} \ll 1\right|$. Uma descrição detalhada sobre estes dois métodos pode ser vista em [22].

Nota: Para evitar grandes desvios na proposta desta seção, as deduções do tensor das rotações mostrado nas definições seguintes, e alguns fundamentos matemáticos, foram colocados em um capítulo separado (ver apêndices A.I e A.II). 
Pelo lado das parametrizações vetoriais que se baseiam no teorema de Euler, a parametrização de Rodrigues, que é usada neste texto, é definida pelo tensor $\boldsymbol{Q}$ dado pela expressão (26). Note que as expressões abaixo se referem à parametrização de Rodrigues.

$$
\boldsymbol{Q}=\boldsymbol{I}+\frac{4}{4+\alpha^{2}} \boldsymbol{A}+\frac{2}{4+\alpha^{2}} \boldsymbol{A}^{2}
$$

Em (26), o tensor $\boldsymbol{A}$ é o tensor antissimétrico cuja matriz é igual a

$$
[A]=\left[\begin{array}{ccc}
0 & -\alpha_{3} & \alpha_{2} \\
\alpha_{3} & 0 & -\alpha_{1} \\
-\alpha_{2} & \alpha_{1} & 0
\end{array}\right]
$$

O vetor axial de $\boldsymbol{A}$ é o vetor $\boldsymbol{\alpha}=\operatorname{skew}(\boldsymbol{A})$ dado por

$$
\boldsymbol{\alpha}=\alpha_{i} \boldsymbol{e}=\left[\begin{array}{lll}
\alpha_{1} & \alpha_{2} & \alpha_{3}
\end{array}\right]^{T} .
$$

Na expressão acima, o vetor $\boldsymbol{e}$ é um vetor unitário na direção do eixo de rotação. O vetor $\boldsymbol{\alpha}$ não possui uma representação física e a sua norma é igual a.

$$
\|\alpha\|=\alpha=2 \tan \left(\frac{\theta}{2}\right)
$$

tal que $\theta$ representa o ângulo de rotação em torno do eixo $\boldsymbol{e}$. Note que o vetor axial é paralelo ao eixo de rotação.

É importante observar que o tensor das rotações de Rodrigues $\boldsymbol{Q},(26)$, é representado somente por três componentes, que são as coordenadas do vetor $\boldsymbol{\alpha}$.

Sejam duas rotações sucessivas representadas pelos tensores $\boldsymbol{Q}_{1}$ e $\boldsymbol{Q}_{2}$, parametrizados pelos respectivos vetores axiais $\boldsymbol{\alpha}_{1}$ e $\boldsymbol{\alpha}_{2}$. O tensor das rotações que representa esta composição é dado pelo produto $\boldsymbol{Q}_{(1+2)}=\boldsymbol{Q}_{2} \cdot \boldsymbol{Q}_{1}$. O vetor axial que parametriza tais rotações sucessivas é dado por 


$$
\alpha_{(1+2)}=\frac{4}{4-\alpha_{2} \cdot \alpha_{1}}\left(\alpha_{1}+\alpha_{2}-\frac{1}{2} \alpha_{1} \times \alpha_{2}\right)
$$

A expressão (30) permite escrever $\boldsymbol{Q}_{(1+2)}$ sem precisar resolver o produto entre os tensores $\boldsymbol{Q}_{1}$ e $\boldsymbol{Q}_{2}$, conforme mostra a Figura 5. Mas, é importante notar que esta equação só é válida quando o tensor das rotações utiliza a parametrização de Rodrigues dada em (26) e (29) [7] [16] [17].

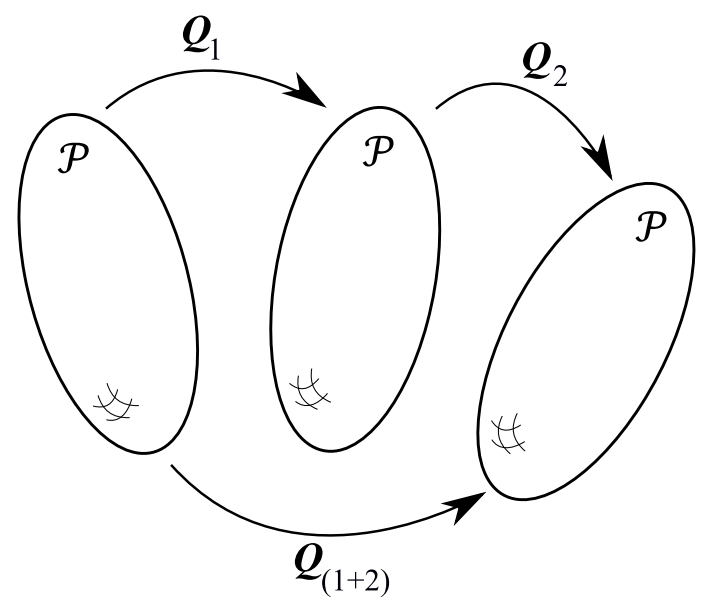

Figura 5 - Representação das rotações sucessivas.

Agora, sejam dois vetores $\boldsymbol{a}$ e $\boldsymbol{b}$ pertencentes a um mesmo sólido. Após uma rotação, estes vetores devem preservar os seus comprimentos e posições relativas. Portanto, nenhuma distorção deve ser observada entre eles ao final da transformação, tal que a forma do sólido permanecerá inalterada. Isto implica que $\|\boldsymbol{R} \cdot \boldsymbol{a}\|=\|\boldsymbol{a}\|$ e $\|\boldsymbol{R} \cdot \boldsymbol{b}\|=\|\boldsymbol{b}\|$. Além disso, $\boldsymbol{a} \cdot \boldsymbol{b}=$ $(\boldsymbol{R} \cdot \boldsymbol{a}) \cdot(\boldsymbol{R} \cdot \boldsymbol{b})=\boldsymbol{a} \cdot\left(\boldsymbol{R}^{T} \cdot \boldsymbol{R}\right) \cdot \boldsymbol{b}$ e, portanto:

$$
\boldsymbol{R}^{T} \cdot \boldsymbol{R}=\boldsymbol{I}
$$

A equação (31) mostra que um tensor rotação é ortogonal.

Neste trabalho é proposta a utilização do tensor das rotações (26) em duas situações: $i$ - para definir a nova orientação da partícula e, $i i$ - para o cálculo do deslocamento tangente relativo em um par de partículas em contato. A primeira situação ocorre ao final de um incremento de tempo, quando já foram calculadas todas as forças atuando na partícula. Neste caso, as forças externas resultantes definem o momento angular da partícula que é usado para o cálculo da 
velocidade angular atualizada, a qual que é usada para calcular o movimento à partícula. No segundo caso, para o cálculo dos deslocamentos tangentes relativos, o tensor rotação contêm as informações da partícula no início do passo de tempo. Assim, uma função especial, mostrada adiante, é utilizada para calcular o movimento do ponto de contato das partículas. Pelo estudo do movimento deste ponto de contato são calculadas as forças tangentes de interação na partícula, as quais são usadas para a composição do momento angular descrito acima.

Seja conhecida a velocidade angular $\boldsymbol{\omega}$ de uma partícula. Com base no que foi exposto, um vetor $\boldsymbol{a}$ que gira em torno de um eixo $\boldsymbol{e}$ terá sua nova posição, $\boldsymbol{a}^{\prime}$, dada pela transformação (32).

$$
\boldsymbol{a}^{\prime}=\boldsymbol{Q} \cdot \boldsymbol{a}
$$

Por meio de uma expressão simples é possível calcular o vetor de rotação $\boldsymbol{\alpha}$ em função da velocidade angular $\boldsymbol{\omega}$. Sendo assim, o vetor que define o incremento de rotação pode ser calculado utilizando-se somente a velocidade angular. Estas expressões são mostradas nos capítulos seguintes.

Aqui é utilizada a notação apresentada por [17], que utiliza o símbolo $\Delta$ para representar o incremento de rotação. Assim, o tensor das rotações associado a este vetor incremental é escrito na forma $\boldsymbol{Q}_{\Delta}$. Da mesma forma, o respectivo vetor axial é escrito por $\boldsymbol{\alpha}_{\Delta}$.

\subsection{Superelipsóide}

Os superelipsóides, também chamados de superquádricas, formam uma família de geometrias 3D com representação analítica. Em 1981, os superelipsóides foram generalizados por Barr [34] como um grupo de objetos sólidos 3D baseados em superfícies quádricas como elipsoides e hiperboloides, sendo estes dois últimos geometrias 2D. Os superelipsóides são parametrizados por três variáveis de dimensão e duas variáveis de curvatura, Figura 6.

Partículas superelipsóides são frequentemente utilizadas com o método dos elementos discretos. Assim como esferas, superelipsóides são representados por uma função paramétrica suave, e esta característica é desejável em formulações da mecânica computacional. Entretanto, um dos principais desafios em se utilizar este tipo de partícula em simulações com o MED está em descrever formulações matemática que permitam montar algoritmos eficientes para detecção do contato inter-partículas. Este tema tem sido estudado por diversos autores conforme pode ser visto em [10], [11], [28], [35], [36], [37] e [38]. Em todos estes trabalhos, os autores relatam que o tempo gasto na detecção do contato representa a maior parte do tempo total da simulação. 
Esta seção descreve a geometria de partículas superelipsóides. As equações mostradas aqui são utilizadas nos demais capítulos deste texto.

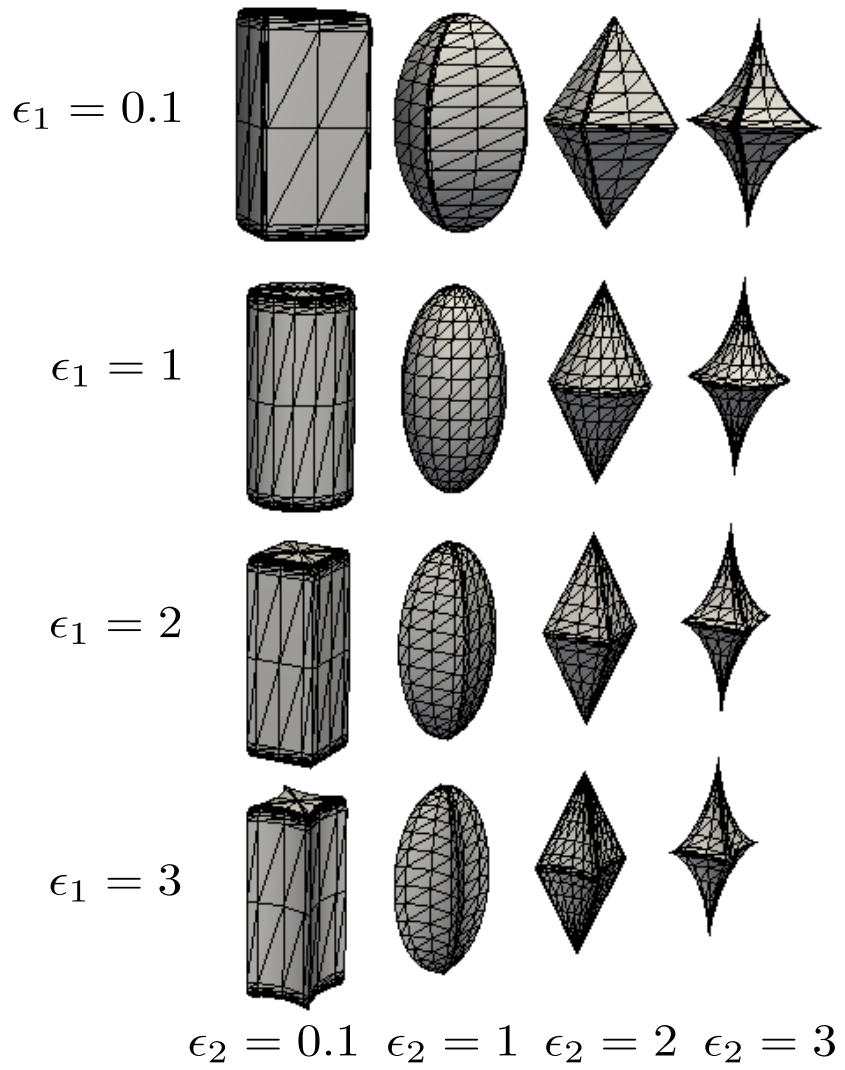

Figura 6 - Superelipsóides com diferentes parâmetros de curvatura e dimensões constantes $R_{1}=R_{2}=$ $R_{3} / 2$.

A equação (33) define a hipersuperfície de um superelipsóide [34] [39]. Assim, valores negativos de $F$ indicam que um ponto $\boldsymbol{x}$ pertence ao interior do superelipsóide, $F(\boldsymbol{x}) \leq 1$, e os pontos tal que $F(\boldsymbol{x})=1$ estão localizados na superfície da partícula.

$$
F(\boldsymbol{x})=\left(\left|\frac{x_{1}}{R_{1}}\right|^{\frac{2}{\epsilon_{1}}}+\left|\frac{x_{2}}{R_{2}}\right|^{\frac{2}{\epsilon_{1}}}\right)^{\epsilon_{1} / \epsilon_{2}}+\left|\frac{x_{3}}{R_{3}}\right|^{2 / \epsilon_{2}}
$$

Em (33), os expoentes $\epsilon_{1}$ e $\epsilon_{2}$ controlam a curvatura, definindo o quão cuboide é a geometria da partícula no plano $x_{1}, x_{2}$ e na direção $x_{3}$, respectivamente, tal que as variáveis $x_{i}$ são as coordenadas do vetor $\boldsymbol{x}$ no sistema local da partícula. Sendo que $\epsilon_{i}<1$ define formas mais quadradas, $\epsilon_{i} \sim 1$ define formas arredondadas, $\epsilon_{i} \sim 2$ define formas de bisel, e $\epsilon_{i}>2$ define formas comprimidas (apertadas). As equações apresentadas neste trabalho são válidas somente para geometrias convexas, portanto é assumido que $\epsilon_{i} \in(0,2)$, tal que $\epsilon_{1} \rightarrow 0$ leva a um cuboide e $\epsilon_{2} \rightarrow 2$ leva a um octaedro, conforme mostrado na Figura 7. 

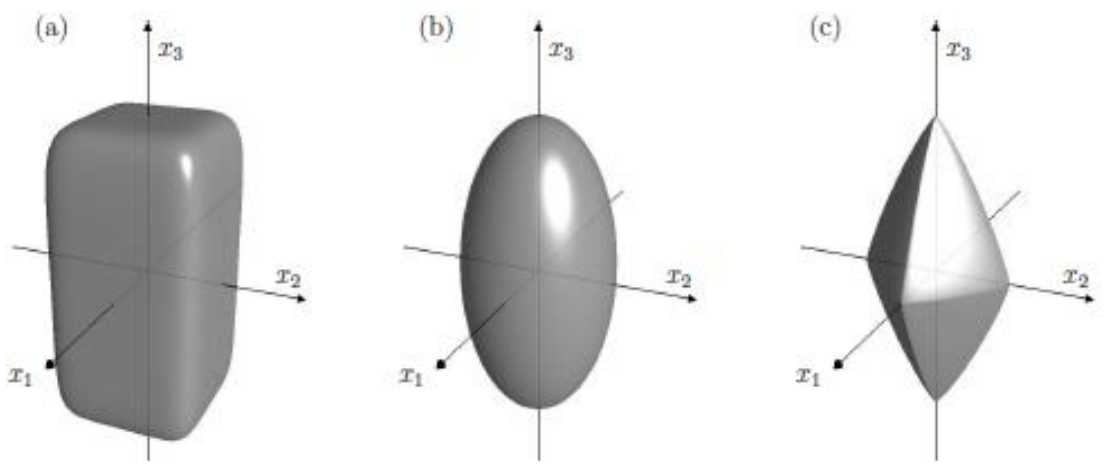

Figura 7 - Superelipsóides com $R_{1}=R_{2}=R_{3} / 2$ e: (a) $\epsilon_{\mathrm{i}}=0.3$; (b) $\epsilon_{\mathrm{i}}=1$; (c) $\epsilon_{\mathrm{i}}=1.7$. Fonte: [10]

Um ponto pertencente à superfície do superelipsóide pode ser descrito em coordenadas curvilíneas segundo o conjunto de equações (34).

$$
\boldsymbol{x}\left(\phi_{1}, \phi_{2}\right)=\left[\begin{array}{c}
\operatorname{sgn}\left(\cos \phi_{1}\right) R_{1}\left|\cos \phi_{1}\right|^{\epsilon_{1}}\left|\cos \phi_{2}\right|^{\epsilon_{2}} \\
\operatorname{sgn}\left(\operatorname{sen} \phi_{1}\right) R_{2}\left|\operatorname{sen} \phi_{1}\right|^{\epsilon_{1}}\left|\cos \phi_{2}\right|^{\epsilon_{2}} \\
\operatorname{sgn}\left(\operatorname{sen} \phi_{2}\right) R_{3}\left|\operatorname{sen} \phi_{2}\right|^{\epsilon_{2}}
\end{array}\right]
$$

Tal que $-\pi \leq \phi_{1}<\pi$ e $-\frac{\pi}{2} \leq \phi_{2}<\frac{\pi}{2}$.

Considerando que a densidade do material da partícula, $\rho$, é constante em todo elemento discreto, a massa de um superelipsóide dada pela equação (35).

$$
m=\rho R_{1} R_{2} R_{3} \epsilon_{1} \epsilon_{2} g_{1}^{1} g_{2}^{1}
$$

Na equação (35) $g_{j}^{i}$ são funções dos parâmetros exponenciais definidos por:

$$
\begin{aligned}
& g_{1}^{1}=\frac{\Gamma^{2}\left(\frac{\epsilon_{1}}{2}\right)}{\Gamma\left(\epsilon_{1}\right)} \\
& g_{1}^{2}=\frac{\Gamma\left(\frac{\epsilon_{1}}{2}\right) \Gamma\left(\frac{3 \epsilon_{1}}{2}\right)}{\Gamma\left(2 \epsilon_{1}\right)}
\end{aligned}
$$




$$
\begin{aligned}
& g_{2}^{1}=\frac{\Gamma\left(\frac{\epsilon_{2}}{2}\right) \Gamma\left(\epsilon_{2}+1\right)}{\Gamma\left(\frac{3 \epsilon_{2}}{2}+1\right)} \\
& g_{2}^{2}=\frac{\Gamma\left(\frac{\epsilon_{2}}{2}\right) \Gamma\left(2 \epsilon_{2}+1\right)}{\Gamma\left(\frac{5 \epsilon_{2}}{2}+1\right)} \\
& g_{2}^{3}=\frac{\Gamma\left(\frac{3 \epsilon_{2}}{2}\right) \Gamma\left(\epsilon_{2}+1\right)}{\Gamma\left(\frac{5 \epsilon_{2}}{2}+1\right)}
\end{aligned}
$$

tal que $\Gamma$ denota a função Gama 5 .

Usando as equações (36), os momentos de inércia principais são expressos por:

$$
\begin{aligned}
& J_{1}=\frac{1}{2} \rho R_{1} R_{2} R_{3} \epsilon_{1} \epsilon_{2}\left(R_{2}^{2} g_{1}^{2} g_{2}^{2}+2 R_{3}^{2} g_{1}^{1} g_{2}^{3}\right) \\
& J_{2}=\frac{1}{2} \rho R_{1} R_{2} R_{3} \epsilon_{1} \epsilon_{2}\left(R_{1}^{2} g_{1}^{2} g_{2}^{2}+2 R_{3}^{2} g_{1}^{1} g_{2}^{3}\right) \\
& J_{3}=\frac{1}{2} \rho R_{1} R_{2} R_{3} \epsilon_{1} \epsilon_{2}\left(R_{1}^{2}+R_{2}^{2}\right) g_{1}^{2} g_{2}^{2} .
\end{aligned}
$$

O tensor de inércia é dado, no sistema de coordenadas local da partícula, por:

$$
\boldsymbol{J}=J_{1} \hat{\boldsymbol{e}}_{1} \otimes \hat{\boldsymbol{e}}_{1}+J_{2} \hat{\boldsymbol{e}}_{2} \otimes \hat{\boldsymbol{e}}_{2}+J_{3} \hat{\boldsymbol{e}}_{3} \otimes \hat{\boldsymbol{e}}_{3} .
$$

\footnotetext{
${ }^{5}$ Uma função Gama é definida tal que $\Gamma(n)=(n-1)$ !, onde $n \in \mathbb{Z}_{+}$.
} 
MÉTODO PROPOSTO

\section{MÉTODO PROPOSTO}

Neste capítulo, o método dos elementos discreto é descrito conforme proposto neste trabalho.

As formulações apresentadas são aplicadas tanto para partículas esféricas quanto superelipsóide. Apesar disso, a formulação para as rotações poder ser usada para qualquer forma geométrica, desde que a partícula seja parametrizada em uma base fixada a ela, visto que a rotação é definida pela orientação da base da partícula, conforme mostrado nas seções 2.3, 2.7 e 3.1.4.

\subsection{Formulação proposta}

A parametrização de Rodrigues permite resolver com simplicidade problemas formulados segundo uma descrição incremental das rotações. Em uma vasta busca na bibliografia, tal parametrização não foi encontrada em aplicações com o MED. Esta parametrização tem sido objeto de estudo do grupo de pesquisa orientado pelo Prof. Pimenta em aplicações para o MEF, principalmente em formulações para as teoria de barras e cascas, como pode ser visto em [40] [41] [17] [42] [18] [43] [44], dentre outros.

Conforme mencionado, três etapas principais descrevem o MED: detecção de contato, tratamento das forças, e integração do movimento. Neste trabalho, o método de detecção de contato se baseia na proposta apresentada por [10] e não há nenhuma contribuição nova nesta etapa. O tratamento das forças é feito segundo teorias clássicas de contato, mas novas definições são apresentadas para o cálculo dos deslocamentos que são utilizados para obtenção das forças tangenciais. A integração dos deslocamentos é feita com o método leapfrog e, em situações específicas, pelo método de Euler. Para integração das rotações é apresentada uma nova abordagem do método leapfrog, a qual utiliza as equações da parametrização de Rodrigues. As três etapas são descritas individualmente nas seções seguintes deste capítulo.

No presente trabalho, são considerados os mesmos princípios definidos por [3] quanto à propagação dos efeitos causados por alguma perturbação no sistema. Ou seja, o passo de tempo deve ser pequeno o suficiente ao ponto que, durante um único passo de tempo, as forças devido ao incremento de deslocamento não se propaguem além da vizinhança imediata da partícula. Assim, em todos os instantes a força resultante em uma partícula é determinada exclusivamente pela interação das partículas com as quais ela está em contato. 


\subsubsection{Detecção de contato}

A busca por contatos deve acontecer em cada passo da simulação ${ }^{6}$. Este processo geralmente é executado em duas etapas, uma global (também chamada de busca espacial) e outra local. A busca local é quem define se o contato existe e é nesta etapa que é consumida a maior parte do esforço computacional do MED, pois na maioria das vezes requer a solução de diversas equações e/ou de algum tipo de processo iterativo. Sem um método de busca global, a detecção local deveria ser feita entre todas as partículas do modelo e o número de buscas seria da ordem de $O\left(n^{2}\right)$. Para minimizar a quantidade de vezes que o algoritmo de busca local é executado, são implementados alguns métodos de busca global que garantem a inexistência de contato por meio de regras simples. Assim, a busca local é feita somente entre partículas potencialmente em contato.

Os métodos de busca global normalmente se baseiam na divisão do domínio em algumas células (Figura 8). Diferentes autores propõem regras específicas para a divisão do domínio e, atreladas a estas regras, também são propostas algumas diretrizes a serem seguidas para a implementação da busca local, como pode ser viso em [45], [46] e [47]. Em geral, um método de busca global visa atender algum objetivo específico que pode ser, por exemplo, a redução do uso de memória ou a criação de divisões mais adequadas para determinada granulometria ou, ainda, para atender certa disposição espacial das partículas. Isso significa que um método deve ser melhor do que outro em algum cenário, mas não necessariamente em todos os cenários.

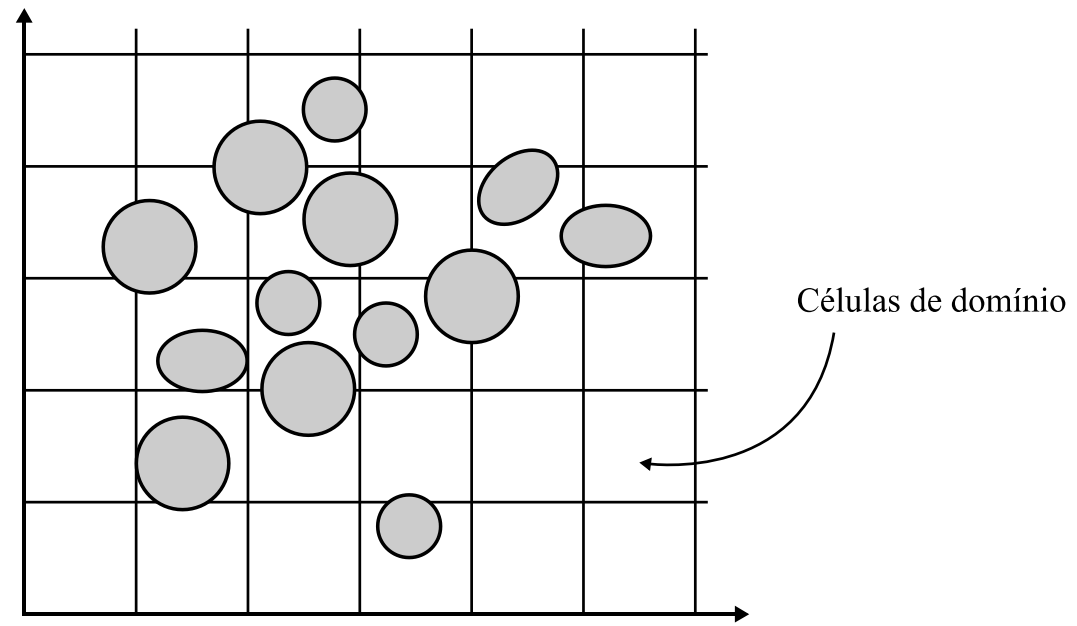

Figura 8 - Divisão do domínio em células para detecção de possíveis contatos.

\footnotetext{
${ }^{6}$ Apesar da busca local ser feita em todos os passos de tempo, alguns autores definem regras para atualização da busca global em intervalos maiores.
} 
O método de divisão de domínio mais simples consiste em dividir o domínio em células iguais. A dimensão das células é equivalente ao tamanho da maior partícula do modelo, que pode ser calculada pelo diâmetro ou pela maior dimensão do elemento discreto. A posição das partículas é dada pelo seu centro e este ponto é usado para mapear a localização das partículas em relação às células de domínio. A busca global termina quando todas as partículas estão listadas nos respectivos domínios. Na sequência, a busca local é feita da seguinte forma: para cada partícula considera-se a célula a qual ela pertence e mais as 26 células vizinhas. O contato é, portanto, verificado entre esta partícula e as partículas pertencentes às listas das 27 células potenciais.

A busca local depende da geometria da partícula. Geralmente, as regras são restritas a certo grupo geométrico ou estão condicionadas a certos limites de precisão. A busca local entre partículas esféricas, por exemplo, pode ser feita por meio de uma regra simples que avalia a distância entre os centros dos elementos discretos e a soma dos seus raios (Figura 9). Entretanto, testes como este não podem ser utilizados entre partículas com outros formatos, como é o caso dos superelipsóides. Neste trabalho, como somente estes dois grupos geométricos são considerados, as definições adiante são feitas separadamente para esferas e superelipsóides.

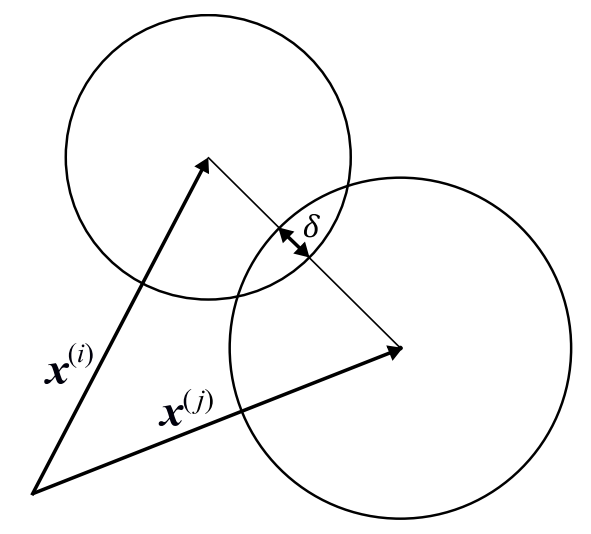

Figura 9 - Esferas em contato.

O contato entre duas partículas esféricas de raio $r^{(i)}$ e $r^{(j)}$ existe se a distância entre os seus centros, $\boldsymbol{x}^{(i)}$ e $\boldsymbol{x}^{(j)}$, for menor do que a soma dos seus raios, ou seja:

$$
\left|\left(\boldsymbol{x}^{(j)}-\boldsymbol{x}^{(i)}\right) \cdot \boldsymbol{n}\right|<\left(r^{(j)}+r^{(i)}\right)
$$


Na equação (41) o vetor unitário normal $\boldsymbol{n}$ é calculado para cada par de partículas em contato e pode ser dado por:

$$
\boldsymbol{n}=\boldsymbol{n}^{(i j)}=\frac{\boldsymbol{x}^{(j)}-\boldsymbol{x}^{(i)}}{\left\|\boldsymbol{x}^{(j)}-\boldsymbol{x}^{(i)}\right\|}
$$

Em $(42), \boldsymbol{n}^{(i j)}$ representa o vetor perpendicular à partícula $i$, apontando do centro de $i$ para $\mathrm{o}$ centro de $j$.

A equação (41) é válida somente para partículas esféricas e, portanto, não pode ser usada para superelipsóides. Logo, outras regras precisam ser definidas para este grupo geométrico. As técnicas de detecção de contato entre partículas superelipsóides podem ser divididas em dois grupos principais: aquelas que fazem a busca por meio das funções analíticas (33) e (34); ou por meio de técnicas que aproximam a superfície da partícula por uma malha de pontos ou outras curvas. No primeiro caso, duas abordagens são possíveis: resolver o sistema de equações em (34) simultaneamente para as duas partículas; ou utilizar alguma técnica de minimização. A solução por meio do sistema de equações possui como desvantagem a existência de mais de uma solução e há a necessidade de se usar outras regras que identifiquem o ponto de contato por alguma aproximação. Por outro lado, os métodos de minimização se baseiam na ideia de encontrar a menor distância entre as duas superfícies analíticas e usar esta informação para identificar o contato. O segundo grupo, que utiliza pontos na superfície da partícula, pode ser usado para detecção de contato entre qualquer tipo de partícula, convexas ou não, e a detecção é feita verificando se os pontos da superfície da partícula $\mathcal{P}^{(i)}$ pertencem ao domínio da partícula $\mathcal{P}^{(j)}$. A precisão deste método depende da quantidade de pontos utilizada.

Neste trabalho o contato é detectado por meio de uma função objetivo que minimiza a distância entre duas partículas. O método pertence a um grupo chamado de "abordagem por normal comum" (common-normal approach). Este método foi usado com sucesso em [10] e se baseia na ideia de que existe um único vetor normal à superfície de cada partícula que atenda às condições mostradas em (46). Na mecânica do contato, em relação ao cálculo das forças de contato, é preferível que a obtenção dos pontos de contato seja baseada nos vetores normais comuns às duas superfícies [31] [32]. 
Uma das propriedades fundamentais das funções analíticas do superelipsóide convexo é que para cada ponto da superfície existe somente um vetor normal; e, para cada direção normal existe somente um ponto na superfície. Esta relação permite um mapeamento bijetor entre estas duas propriedades e isto é explorado no método utilizado neste trabalho. As funções de mapeamento são detalhadas na seção A.III.

Sejam dois pontos quaisquer pertencentes às superfícies de dois superelipsóides, $\boldsymbol{p}^{(i)}$ e $\boldsymbol{p}^{(j)}$. A distância entre estes dois pontos é calculada por $\|\boldsymbol{d}\|=\boldsymbol{p}^{(j)}-\boldsymbol{p}^{(i)}$. O objetivo é minimizar esta função para encontrar a menor distância entre as duas partículas. Assim, o vetor distância é avaliado para identificação do contato. A minimização da função distância pode ser feita por qualquer método de otimização. Neste trabalho é utilizado o método de LevembergMarquardt (ver A.IV). Portanto, são necessárias as derivadas primeira e segunda da função objetivo.

$\mathrm{O}$ vetor distância $\boldsymbol{d}$ deve ser paralelo a ambos os vetores normais que representam o ponto de contato em cada uma das duas partículas, Figura 10. Seja $\boldsymbol{c}$ um vetor qualquer, escrito em coordenadas esféricas, cuja base $\tilde{\boldsymbol{e}}_{i}$ forma um sistema ortogonal definido a partir dos centros das duas partículas, ou seja:

$$
\begin{aligned}
& \boldsymbol{c}\left(\zeta_{1}, \zeta_{2}\right)=\cos \zeta_{1} \cos \zeta_{2} \tilde{\boldsymbol{e}}_{1}+\operatorname{sen} \zeta_{1} \cos \zeta_{2} \tilde{\boldsymbol{e}}_{2}+\operatorname{sen} \zeta_{2} \tilde{\boldsymbol{e}}_{3} \\
& \zeta_{1} \in(-\pi, \pi], \zeta_{2} \in\left[-\frac{\pi}{2}, \frac{\pi}{2}\right] \\
& \tilde{\boldsymbol{e}}_{1}=\frac{\boldsymbol{x}^{(2)}-\boldsymbol{x}^{(1)}}{\left\|\boldsymbol{x}^{(2)}-\boldsymbol{x}^{(1)}\right\|}, \tilde{\boldsymbol{e}}_{i} \cdot \tilde{\boldsymbol{e}}_{j}=\delta_{i j}
\end{aligned}
$$

Escrevendo os vetores $\boldsymbol{p}^{(i)}$ e $\boldsymbol{p}^{(j)}$ com a parametrização de $\boldsymbol{c}$ e utilizando as funções de mapeamento do superelipsóide (ver anexo A.III), o vetor distância se torna uma função de $\zeta_{1}$ e $\zeta_{2}$. Assim, a função objetivo é dada por (45).

$$
\min _{\zeta_{1}, \zeta_{2}} f\left(\zeta_{1}, \zeta_{2}\right)=\left\|\boldsymbol{d}\left(\zeta_{1}, \zeta_{2}\right)\right\|^{2}
$$

A condição de mínimo global é atendida quando 


$$
\begin{aligned}
& \boldsymbol{c}=\frac{\boldsymbol{n}^{(i)}}{\left\|\boldsymbol{n}^{(i)}\right\|}=-\frac{\boldsymbol{n}^{(j)}}{\left\|\boldsymbol{n}^{(j)}\right\|} \\
& \boldsymbol{d} \times \boldsymbol{c}=\mathbf{0}
\end{aligned}
$$

onde $\boldsymbol{n}^{(i)}$ e $\boldsymbol{n}^{(j)}$ são os vetores normais nos pontos $\boldsymbol{p}^{(i)}$ e $\boldsymbol{p}^{(j)}$. Note que $\boldsymbol{c}$ é paralelo à direção normal de contato.

A solução de (45) fornece os ângulos $\zeta_{1}$ e $\zeta_{2}$ que definem a direção dos vetores normais. Por meio das funções de mapeamento, os pontos $\boldsymbol{p}^{(i)}$ e $\boldsymbol{p}^{(j)}$ são calculados. O vetor distância $\boldsymbol{d}$ é parte da solução do problema de minimização. Note que a condição (46)a é atendida automaticamente devido à construção dos pontos da superfície. Além disso, a condição (46)b é atendida quando um mínimo global é atingido em (45) sempre que a penetração for pequena quando comparada ao tamanho das partículas e ao raio de curvatura mínimo da superfície das partículas. Portanto, o mínimo global de (45) fornece as direções de contato que são usadas para o cálculo do restante do processo.

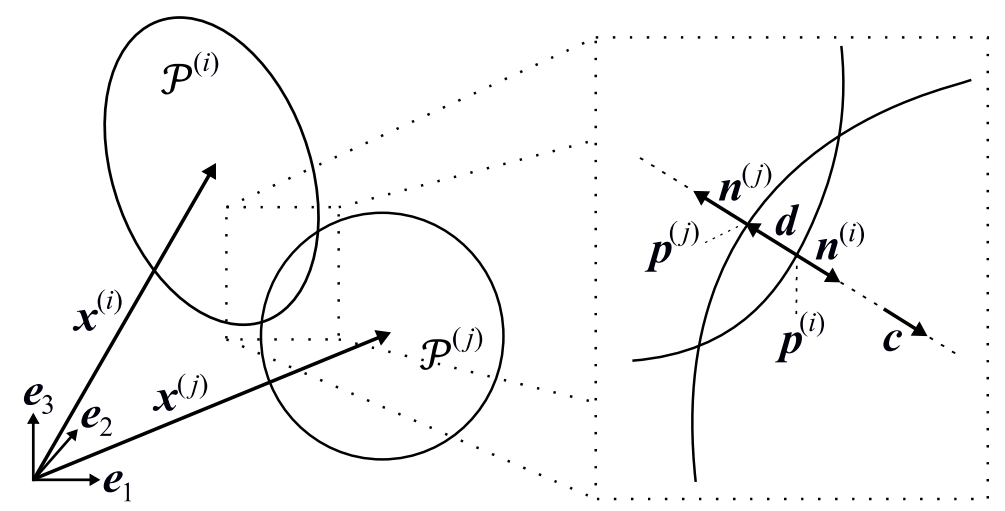

Figura 10 - Detecção de contato entre superelipsóides.

O algoritmo de Levemberg-Marquardt utiliza as duas primeiras derivadas da função $f$. Estas derivadas são dadas por

$$
\begin{aligned}
& f_{, i}=2(\boldsymbol{d} \cdot \boldsymbol{d}) \\
& f_{, i j}=2\left(\boldsymbol{d}_{, i} \cdot \boldsymbol{d}_{, j}+\boldsymbol{d} \cdot \boldsymbol{d}_{, i j}\right)
\end{aligned}
$$


onde $(\cdot)_{, i}=\frac{\partial(\cdot)}{\partial \zeta_{i}} \mathrm{e}(\cdot)_{, i j}=\frac{\partial^{2}(\cdot)}{\partial \zeta_{i} \partial \zeta_{j}},(i, j=1,2)$. A derivada do vetor distância é calculada pela derivada dos pontos da superfície. As derivadas dos pontos em relação a $\zeta_{1}$ e $\zeta_{2}$ são dadas pela regra da cadeia para derivadas, ou seja:

$$
\begin{aligned}
\boldsymbol{p}_{, i}^{(\beta)}= & \frac{\partial \boldsymbol{p}^{(\beta)}}{\partial \phi_{\gamma}} \frac{\partial \phi_{\gamma}}{\partial c_{k}} \frac{\partial c_{k}}{\partial \zeta_{i}} \\
\boldsymbol{p}_{, i j}^{(\beta)}= & \frac{\partial^{2} \boldsymbol{p}^{(\beta)}}{\partial \phi_{\gamma} \partial \phi_{\delta}} \frac{\partial \phi_{\gamma}}{\partial c_{k}} \frac{\partial \phi_{\delta}}{\partial c_{l}} \frac{\partial c_{k}}{\partial \zeta_{i}} \frac{\partial c_{l}}{\partial \zeta_{j}} \\
& +\frac{\partial \boldsymbol{p}^{(\beta)}}{\partial \phi_{\gamma}}\left(\frac{\partial^{2} \phi_{\gamma}}{\partial c_{k} \partial c_{l}} \frac{\partial c_{k}}{\partial \zeta_{i}} \frac{\partial c_{l}}{\partial \zeta_{j}}+\frac{\partial \phi_{\gamma}}{\partial c_{k}} \frac{\partial^{2} c_{k}}{\partial \zeta_{i} \partial \zeta_{j}}\right)
\end{aligned}
$$

Índices gregos denotam soma de 1 a 2 e índices latins denotam soma de 1 a 3 (exceto $i$ e $j$, que nestas equações assumem os valores 1 e 2 , referentes aos ângulos $\zeta_{1}$ e $\zeta_{2}$ ).

As derivadas parciais das equações (48) e (49) são detalhadas nos apêndices. Note que estas expressões são dadas pelo produto de diversas matrizes cujos componentes são obtidos pela solução de longas expressões. Isto mostra alguns indícios de que esta é a tarefa mais cara em termos computacionais.

Os critérios de parada para o algoritmo de minimização precisam ser definidos. A busca é iniciada com o vetor $\boldsymbol{c}$ apontando do centro da partícula $\mathcal{P}^{(i)}$ para o centro da partícula $\mathcal{P}^{(j)}$. Entretanto, esta estratégia deve ser usada somente quando o contato entre as duas partículas não foi registrado no passo anterior, ou seja, quando o contato acontece pela primeira vez. Caso contrário, a solução do passo anterior é usada como ponto de partida, visto que o ponto de contato atual está na vizinhança do ponto anterior (considerando que pequenos passos de tempo são utilizados). É fácil notar que o número de iterações para minimizar a função objetivo é menor em um contato já existente.

Em cada iteração a equação (50) é verificada. Se esta condição for satisfeita, então o algoritmo termina e o contato é descartado. Note que esta verificação é feita antes mesmo do algoritmo convergir para um mínimo de $f$. Apesar de acrescentar mais uma operação no processo, esta verificação aumenta significantemente a velocidade da simulação. 


$$
\boldsymbol{n}^{(i)} \cdot \boldsymbol{d}>0 \Leftrightarrow \boldsymbol{c} \cdot \boldsymbol{d}>0
$$

No caso de penetração, o algoritmo converge para um mínimo de $f$. Para garantir que o mínimo encontrado é global, duas condições precisam ser satisfeitas. Primeiro, a condição (46)b deve ser satisfeita. Neste caso, um mínimo local só existiria se os pontos de contato $\boldsymbol{p}^{(i)}$ e $\boldsymbol{p}^{(j)}$ estiverem fora dos domínios de $\mathcal{P}^{(j)}$ e $\mathcal{P}^{(i)}$, respectivamente. Em casos como este, a segunda condição precisa ser avaliada, ou seja, $\boldsymbol{p}^{(i)} \in \mathcal{P}^{(j)}$ e $\boldsymbol{p}^{(j)} \in \mathcal{P}^{(i)}$. Estas duas últimas condições são verificadas pela equação (33).

A busca por contatos é a primeira etapa do processo que inicia um incremento de tempo. Apesar da busca global reduzir drasticamente a quantidade de buscas locais, algum esforço ainda pode ser poupado se, antes de iniciar a busca local descrita acima, for usada uma técnica de busca chamada de bounding sphere. Por esta técnica, as partículas são consideradas esféricas e a equação (41) pode ser usada para descartar um contato. Neste caso, a esfera é construída considerando a maior dimensão do superelipsóide. Outra técnica semelhante é a chamada bounding box, onde a partícula é aproximada por um paralelepípedo. Em partículas superelipsóides achatadas, a aproximação por bounding box é mais eficiente. Note que nenhuma das duas técnicas é usada para detectar o contato, mas sim para descartar o contato, pois a detecção deve ser feita com o método descrito anteriormente.

A detecção de contato entre uma partícula e uma condição de contorno (parede) pode ser feita de maneira simples tanto para esfera quanto para superelipsóide.

Um plano no espaço pode ser definido a partir de um vetor unitário e um escalar. O vetor, que será sempre normal à superfície, define a orientação do plano e o escalar define a posição da parede no espaço e indica a distância entre o plano e a origem. O vetor normal que define o plano é chamado de $\boldsymbol{n}^{p}$, tal que $\left\|\boldsymbol{n}^{p}\right\|=1$ e a constante escalar é chamada de $\lambda^{p}$, tal que o plano é definido por $\lambda^{p} \boldsymbol{n}^{p}$. 


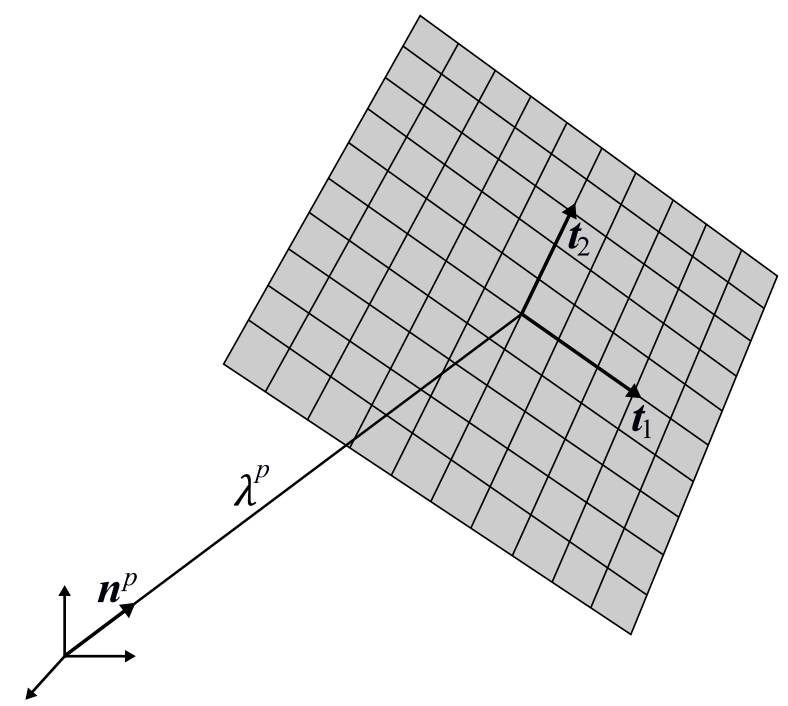

Figura 11 - Plano que define uma condição de contorno.

Em complemento à definição do plano mostrada acima, são definidos dois vetores tangentes, que são paralelos ao plano e ortogonais entre si. Estes vetores são utilizados para decompor as forças tangentes de interação entre partícula e superfície, e podem ser calculados por (55) e (56).

Uma partícula esférica está em contato com um plano quando

$$
\boldsymbol{x} \cdot \boldsymbol{n}^{p}-\lambda^{p}<r
$$

onde $r$ é o raio da esfera.

A força de contato atua na direção do vetor normal $\boldsymbol{n}^{p}$, tanto em partículas esféricas quanto superelipsóides. Sendo assim, e considerando que em um superelipsóide a força de contato atua na direção perpendicular ao ponto de contato, para verificação do contato com uma partícula superelipsóide, aplica-se o vetor $\boldsymbol{n}^{p}$ na função de mapeamento do superelipsóide e encontra-se o respectivo ponto da superfície da partícula. Desta forma, o contato existe quando

$$
\boldsymbol{p} \cdot \boldsymbol{n}^{p}-\lambda^{p}<0
$$

onde $\boldsymbol{p}$ é o vetor que representa o ponto na superfície da partícula. É importante observar que estas operações devem ser feitas nos respectivos sistemas de coordenadas. Portanto, sendo $\boldsymbol{n}^{p}$ escrito no sistema global, deve-se transportar $\boldsymbol{n}^{p}$ para a base local da partícula para utilizar a 
função de mapeamento e encontrar o ponto na superfície da partícula. O ponto $\boldsymbol{p}$ é o ponto da superfície já transportado para a base global.

\subsubsection{Deslocamento tangente}

Nesta seção é detalhada a proposta deste trabalho para o cálculo do deslocamento tangente (gap tangente). Conforme mencionado, este cálculo é feito com base no tensor das rotações de Rodrigues. O deslocamento tangente é usado para o cálculo das forças que atuam na partícula e que produzem o movimento.

A técnica comumente utilizada no MED para o cálculo do deslocamento tangente se baseia na velocidade linear instantânea do ponto de contato [3] [6]. Usando esta técnica, com a ajuda do método de integração no tempo, $\operatorname{leapfrog}^{7}$, é feita uma predição do movimento do ponto de contato e o deslocamento tangente é a projeção no plano tangente do vetor que representa o movimento o ponto de contato. Logo, a predição é feita na direção paralela ao vetor velocidade instantânea. O cálculo da velocidade do ponto de contato é a soma da velocidade linear do centro da partícula com a velocidade produzida no ponto de contato devido à velocidade angular. No presente trabalho, a parcela do deslocamento tangente devido à rotação é calculada pela mudança de posição do ponto de contato após uma rotação causada pela velocidade angular.

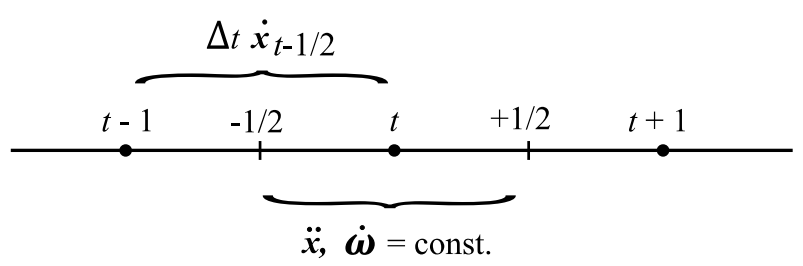

Figura 12 - Integração com leapfrog.

Considera-se que as acelerações são constantes no intervalo de $(t-\Delta t)$ até $(t+\Delta t)$ [3] [6], conforme mostra a Figura 12. As acelerações são calculadas em função dos deslocamentos normal e tangente, utilizando as leis de Euler para translação e rotação. A penetração normal é calculada pelo algoritmo de detecção de contato. O cálculo dos deslocamentos tangentes é mostrado adiante.

\footnotetext{
${ }^{7}$ Alguns autores mencionam o método utilizado por Cundall como sendo do tipo leapfrog e alguns o consideram do tipo velocity Verlet. O próprio autor menciona que as equações da integração no tempo representam um método do tipo "time-centered system". Visto que o método velocity Verlet pode ser considerado uma pequena variação do método leapfrog, ambos condizem com o método apresentado por Cundall.
} 
Seja o vetor $\boldsymbol{\delta}$ o vetor dos deslocamentos tangentes do ponto de contato, tal que

$$
\boldsymbol{\delta}=\Delta \boldsymbol{u}+\Delta \boldsymbol{s}
$$

onde $\Delta \boldsymbol{u}$ é o deslocamento tangente do ponto de contato devido à translação, e $\Delta \boldsymbol{s}$ é o deslocamento do mesmo ponto devido à rotação.

A Figura 13 mostra os vetores normais $\boldsymbol{n}^{(i)}$ e $\boldsymbol{n}^{(j)}$ de duas partículas em contato e o plano de contato $\mathcal{T}$, que é definido para cada par de partículas em contato e que é atualizado a cada incremento de tempo. Note que $\boldsymbol{n}^{(i)}$ e $\boldsymbol{n}^{(j)}$ são dois vetores antiparalelos, eq. (54). Em esferas, os vetores normais são facilmente calculados a partir das informações das posições dos centros das esferas, conforme (42) e (54). Em superelipsóides, o vetor normal é o resultado do problema de otimização que foi resolvido para a detecção de contato (ver seção 3.1.1), e que atende a condição (54). O plano de contato, ou plano tangente, é o plano perpendicular aos vetores normais, conforme (55).

$$
\boldsymbol{n}^{(j)}=-\boldsymbol{n}^{(i)}
$$

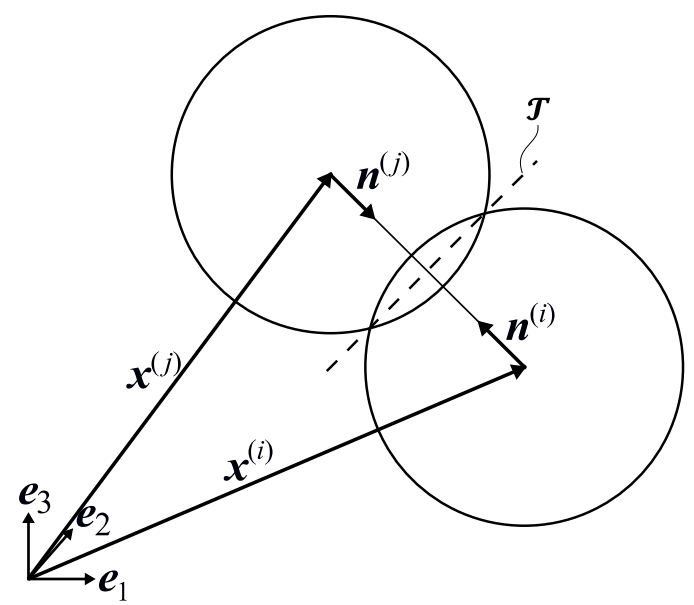

Figura 13 - Partículas esféricas $i$ e $j$ em contato.

O plano de contato $\mathcal{T}$ é definido por dois vetores $\boldsymbol{t}_{1}$ e $\boldsymbol{t}_{2}$, ortogonais entre si e perpendiculares ao vetor normal, tal que $\left\|\boldsymbol{t}_{1}\right\|=\left\|\boldsymbol{t}_{2}\right\|=1$, conforme mostra a Figura 14. 

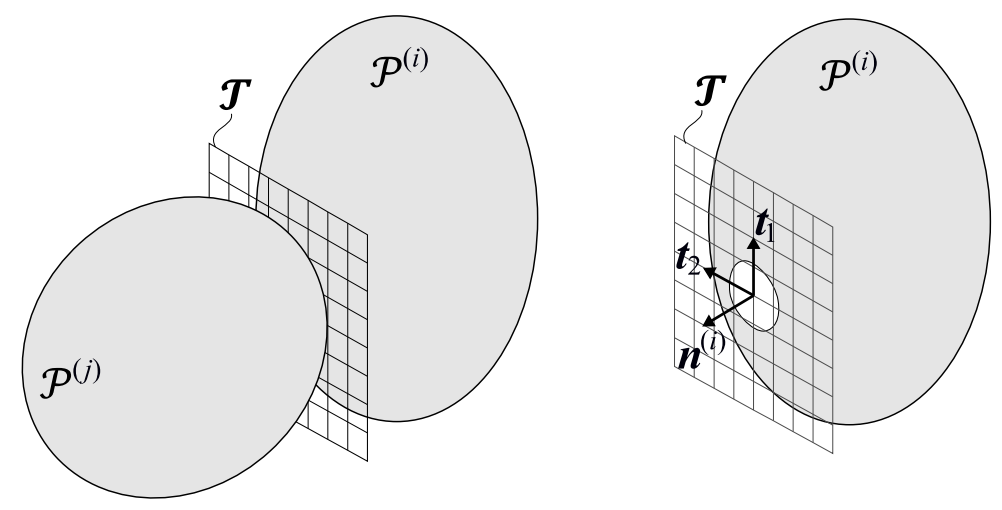

Figura 14 - Vetores $\boldsymbol{t}_{1}$ e $\boldsymbol{t}_{2}$ que definem o plano de contato.

Os vetores $\boldsymbol{t}_{1}$ e $\boldsymbol{t}_{2}$ podem ser calculados analiticamente uma vez que $\boldsymbol{n}^{(i)}$ seja conhecido. Ou seja:

$$
\begin{aligned}
& \boldsymbol{n}^{(i)} \cdot \boldsymbol{t}_{1}=0 \\
& \boldsymbol{n}^{(i)} \times \boldsymbol{t}_{1}=\boldsymbol{t}_{2}
\end{aligned}
$$

A equação (55) permite infinitas soluções, das quais se pode utilizar (56) para calcular $\boldsymbol{t}_{1}$. Assim, o plano tangente fica definido ao calcular $\boldsymbol{t}_{2}$ pela substituição de (56) em (55)b.

$$
\begin{array}{ll}
{\left[t_{1}\right]=\left[\begin{array}{lll}
0 & -n_{3} & n_{2}
\end{array}\right],} & \text { se } n_{2}, n_{3} \neq 0 \\
{\left[t_{1}\right]=\left[\begin{array}{lll}
-n_{3} & 0 & n_{1}
\end{array}\right], \quad \text { senão. }}
\end{array}
$$

Na equação (56), os escalares $n_{k}$ correspondem aos componentes do vetor normal $\left[n^{(i)}\right]=$ $\left[\begin{array}{lll}n_{1} & n_{2} & n_{3}\end{array}\right]$.

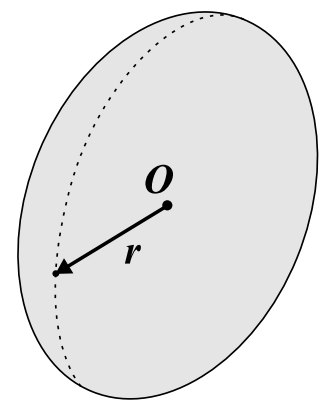

Figura 15 - Definição do vetor raio. 
Seja $C$ um ponto na superfície da partícula e seja $\boldsymbol{r}$ um vetor que vai do centro da partícula até o ponto $C,(57)$, conforme mostra a Figura 15. Em partículas esféricas, a norma de $\boldsymbol{r}$ é igual ao raio da partícula, conforme mostra a equação (57)a. Em partículas superelipsóides, o vetor $\boldsymbol{r}$ é calculado com a ajuda das funções de mapeamento (ver A.III) e é dado por (57)b, onde $\boldsymbol{x}^{c}$ o vetor que representa o ponto $C$.

$$
\begin{aligned}
& \boldsymbol{r}=r \boldsymbol{n} \\
& \boldsymbol{r}=\boldsymbol{x}^{c}-\boldsymbol{x}
\end{aligned}
$$

O incremento de deslocamento de $\boldsymbol{r}$ causado pela velocidade angular é calculado pelo tensor $\boldsymbol{Q}_{\Delta}$ mostrado em (26), tal que nesta equação $\boldsymbol{Q}:=\boldsymbol{Q}_{\Delta}$. Portanto,

$$
\boldsymbol{r}^{\prime}=\boldsymbol{Q}_{\Delta} \cdot \boldsymbol{r}
$$

A distância que o ponto de contato percorre durante $\Delta t$ é aproximada pela diferença entre $\boldsymbol{r}^{\prime}$ e $\boldsymbol{r}$, que representa uma corda, ou seja,

$$
\Delta \boldsymbol{s}=\boldsymbol{r}^{\prime}-\boldsymbol{r}
$$

Substituindo (57) e (58) em (59) o deslocamento do ponto é escrito em função do tensor das rotações $\boldsymbol{Q}_{\Delta}$. Note que (60) ainda não representa o vetor que deve ser usado em (53). A expressão (60) foi proposta por [18] e, na passagem seguinte, é apresentada uma nova abordagem para a mesma. Mais adiante, algumas modificações são apresentadas.

$$
\Delta s=Q_{\Delta} \cdot r-r=\left(Q_{\Delta}-I\right) \cdot r
$$

Rearranjando a equação (26) de forma a isolar $\left(\boldsymbol{Q}_{\Delta}-\boldsymbol{I}\right)$ do lado esquerdo da expressão e substituindo o lado direito na equação (60), o deslocamento causado pela rotação pode ser escrito por $4 /\left(4+\alpha_{\Delta}^{2}\right)\left(\boldsymbol{A}_{\Delta}+\frac{1}{2} \boldsymbol{A}_{\Delta}^{2}\right) \cdot \boldsymbol{r}$. Mas, sendo $\boldsymbol{A}_{\Delta}$ um tensor antissimétrico, pode-se usar a relação $\boldsymbol{A}_{\Delta} \cdot(\cdot)=\boldsymbol{\alpha}_{\Delta} \times(\cdot)$, onde $(\cdot)$ é um vetor qualquer. Assim, é possível eliminar o tensor 
de segunda ordem em (60) e o deslocamento pode ser descrito por uma expressão livre de tensores de segunda ordem, conforme mostra a equação (61).

$$
\Delta s=\frac{4}{\left(4+\alpha_{\Delta}^{2}\right)}\left(\alpha_{\Delta} \times r+\frac{1}{2} \alpha_{\Delta} \times\left(\alpha_{\Delta} \times r\right)\right)
$$

Note que o vetor deslocamento mostrado nas equações (60) e (61) não é paralelo ao plano tangente, mas representa o comprimento que o ponto $C$ se desloca durante $\Delta t$. É desejado utilizar este comprimento para calcular a força tangente. Portanto, utilizando este comprimento e a direção de $\Delta \boldsymbol{s}$ projetada no plano tangente $\left(\Delta \boldsymbol{s}^{\prime}=\left(\Delta \boldsymbol{s} \cdot \boldsymbol{t}_{1}\right) \boldsymbol{t}_{1}+\left(\Delta \boldsymbol{s} \cdot \boldsymbol{t}_{2}\right) \boldsymbol{t}_{2}\right)$ pode-se escrever o vetor $\Delta \boldsymbol{s}$ por

$$
\Delta s:=\|\Delta s\| \frac{\Delta s^{\prime}}{\left\|\Delta s^{\prime}\right\|}
$$

As características do contato descritas em 2.4 são definidas pelo movimento relativo dos pontos de contato das duas partículas. As parcelas da rotação que causam o deslocamento dos pontos de contato das partículas $i$ e $j$ são, portanto, calculadas pelas equações (61) e (62).

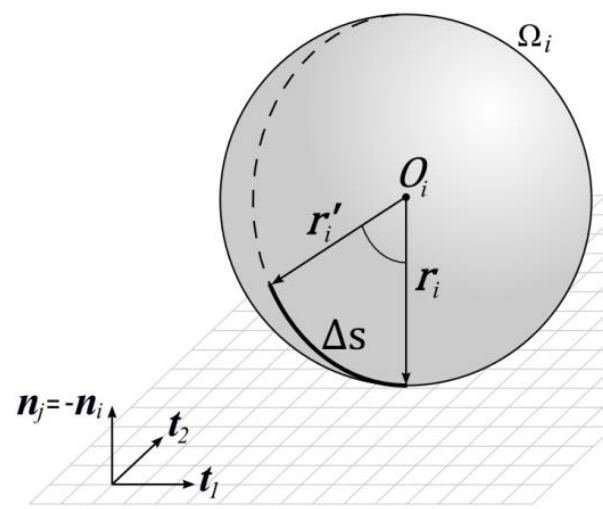

Figura 16 - Descrição da rotação.

Por outro lado, o movimento do ponto de contato devido à translação é igual ao deslocamento do centro da partícula durante $\Delta t$. Utilizando o método de integração mostrado na seção 2.5 , o deslocamento do ponto $C$ devido à translação, $\Delta \boldsymbol{u}$, pode ser calculado por 


$$
\Delta \boldsymbol{u}=\left[\left(\dot{\boldsymbol{x}} \cdot \boldsymbol{t}_{1}\right) \boldsymbol{t}_{1}+\left(\dot{\boldsymbol{x}} \cdot \boldsymbol{t}_{2}\right) \boldsymbol{t}_{2}\right] \Delta t
$$

Com a ajuda de (53), (61), (62) e (63), a diferença entre os gaps tangentes das duas partículas é calculada por (64).

$$
\boldsymbol{g}^{\prime}=\boldsymbol{\delta}^{(j)}-\boldsymbol{\delta}^{(i)}
$$

Em (64), $\boldsymbol{g}^{\prime}$ representa o incremento do deslocamento relativo que é utilizado para verificar a existência de deslizamento entre as partículas. Conforme mostrado na seção 2.4, um deslizamento relativo ocorre quando a força tangente atinge o limite de atrito de Coulomb. Um teste é feito para avaliar se a força gerada pelo deslocamento tangente acumulado desde o início do contato é maior do que a força limite. Portanto, considerando duas partículas em contato, o deslocamento tangente total é dado por (65). O cálculo da força de teste é mostrado na seção 3.1.3 seguinte.

$$
\boldsymbol{g}^{\text {teste }}=\left[\left(\boldsymbol{g}^{s} \cdot \boldsymbol{t}_{1}\right) \boldsymbol{t}_{1}+\left(\boldsymbol{g}^{s} \cdot \boldsymbol{t}_{2}\right) \boldsymbol{t}_{2}\right]+\boldsymbol{g}^{\prime}
$$

Na equação (65), $\boldsymbol{g}^{S}$ é o gap elástico tangente acumulado desde o início do contato e $\boldsymbol{g}^{\text {teste }}$ é o vetor usado para o teste da condição de atrito. O gap elástico pode ser entendido como o alongamento da mola do mecanismo que simula o atrito entre duas partículas. O valor de $\boldsymbol{g}^{s}$ é igual à zero no início do contato e é válido para o contato entre $i$ e $j$, devendo ser guardado individualmente para cada par de contatos até que o contato seja desfeito.

\subsubsection{Forças de interação}

As forças de interação entre as partículas dependem do modelo de contato escolhido. Este trabalho utiliza o modelo de contato elástico linear amortecido, tal que as forças elásticas obedecem à lei de Hooke e a dissipação da força é dada por meio de um amortecimento viscoso.

A força total que ocorre em um evento de contato é dada pela soma das forças normal e tangente naquele contato. Portanto, é dada por (66). 


$$
\boldsymbol{f}=\boldsymbol{f}^{n}+\boldsymbol{f}^{s}
$$

A força normal de contato é calculada pela expressão

$$
\boldsymbol{f}^{n}=k^{n} \boldsymbol{d}+D \boldsymbol{v}^{n}
$$

onde $\boldsymbol{d}$ é o vetor penetração calculado durante a detecção de contato, $k^{n}$ é o fator de penalidade que também pode ser interpretado como sendo o coeficiente elástico de uma mola, $D$ é o coeficiente de amortecimento e $\boldsymbol{v}^{n}$ é a velocidade de penetração na direção normal.

Em todo incremento de tempo, antes da aplicação da força tangente na partícula, é necessário verificar se o incremento de deslizamento tangente faz com que o contato viole o critério de Coulomb. A força tangente de teste, utilizada para verificar a existência de deslizamento, é dada por pelo produto de (65) com um coeficiente de rigidez tangente $k^{s}$.

$$
\boldsymbol{f}_{\text {teste }}^{s}=k^{s} \boldsymbol{g}^{\text {teste }}
$$

A força de teste $\boldsymbol{f}_{\text {teste }}^{S}$ deverá ser sempre menor ou igual à relação entre o coeficiente de atrito e a força normal de contato, isto é, (69). Caso contrário, haverá deslizamento e a força de atrito deverá ser substituída pela força limite de atrito. Caso a força $\boldsymbol{f}_{\text {teste }}^{S}$ seja menor do que a força limite de atrito, então a força de atrito será igual à força de teste.

$$
\left\|\boldsymbol{f}_{\text {teste }}^{S}\right\| \leq \epsilon\left\|\boldsymbol{f}^{n}\right\|
$$

A direção da força de atrito, que é igual à direção do deslizamento, pode ser calculada por

$$
\boldsymbol{s}=\frac{\boldsymbol{g}^{\text {teste }}}{\left\|\boldsymbol{g}^{\text {teste }}\right\|}
$$

Note que, quando há deslizamento, a mola que representa o mecanismo de atrito (gap elástico) permanece alongada em seu limite máximo, e este limite é proporcional à força normal existente em cada instante. 
O total de deslizamento é calculado com base na diferença entre a força limite de contato e a força de teste, portanto igual a (71).

$$
\boldsymbol{\delta}^{s}=\frac{1}{k^{s}}\left(\left\|\boldsymbol{f}_{\text {teste }}^{s}\right\|-\epsilon\left\|\boldsymbol{f}^{n}\right\|\right) \boldsymbol{s}
$$

É importante observar que a expressão (71) só deve ser utilizada quando o limite de Coulomb for ultrapassado. O gap elástico é atualizado subtraindo o deslizamento do deslocamento total, ou seja

$$
\boldsymbol{g}^{s}=\boldsymbol{g}^{\text {teste }}-\boldsymbol{\delta}^{s}
$$

Portanto, a força de atrito é dada por (73).

$$
\boldsymbol{f}^{s}=k^{s} \boldsymbol{g}^{s}
$$

O torque resultante na partícula $i$ é o resultado da soma das forças de interação com outras partículas e paredes, conforme (74). Note que em partículas não esféricas a força normal também contribui para o momento, o que não ocorre com partículas esféricas, pois $\boldsymbol{r}$ é paralelo a $\boldsymbol{f}^{n}$ e, portanto, nulo.

$$
\dot{\boldsymbol{\mu}}^{(i)}=\sum \boldsymbol{r}^{(i j)} \times \boldsymbol{f}^{(i j)}
$$

Note em (74) que a somatória representa cada contato que ocorre na partícula $i$ em um mesmo instante, seja ele proveniente de outra partícula ou de alguma condição de contorno, $j$.

\subsubsection{Movimento da partícula}

O movimento das partículas é descrito nesta seção. Neste trabalho, a integração do movimento é feita pelo método leapfrog, conforme apresentado na seção 2.5.2. Uma vez que a rotação e a translação são movimentos independentes, aqui eles são ser resolvidos separadamente. Descrições detalhadas do método leapfrog para translação podem ser facilmente encontradas na literatura e são baseadas nos mesmos princípios [15] [48] [3]. Para as rotações, ainda usan- 
do leapfrog, alguns trabalhos apresentam soluções que se aplicam aos quatérnions, como pode ser visto em [49], [50] e, mais recentemente, em [51]. Porém, uma vez que as rotações podem ser tratadas de maneiras diferentes, o uso destes algoritmos não pode ser aplicado para este trabalho. A formulação proposta neste trabalho mantêm todas as características do método leapfrog, sendo idêntico para translação, mas sem utilizar os quatérnions para rotação. Em vez disso, é usado o vetor das rotações de Rodrigues e suas propriedades.

A simulação é iniciada no instante zero. Entretanto, o método leapfrog requer a velocidade no instante $\frac{\Delta t}{2}$, que é desconhecida (ver seção 2.5.2). Para obter a velocidade nesse instante, o método explícito de Euler é utilizado para calcular $\dot{\boldsymbol{x}}(\Delta t / 2)$. O restante da simulação é feito com o método de leapfrog, conforme descrito abaixo. Note que o uso do método de Euler é necessário somente uma vez, no início da simulação.

O movimento de translação de uma partícula $i$ é dado por

$$
\boldsymbol{x}_{(t+1)}^{(i)}=\boldsymbol{x}_{(t)}^{(i)}+\Delta t \dot{x}_{(t+1 / 2)}^{(i)}
$$

Onde $(t+1 / 2)=(t+\Delta t / 2)$ é usado para simplificar a notação. O cálculo da velocidade linear em $(t+1 / 2)$ utiliza as forças externas que atuam no instante atual $(t)$. O cálculo dessas forças é mostrado em 3.1.3. Dessa forma, a velocidade é dada por

$$
\dot{\boldsymbol{x}}_{(t+1 / 2)}^{(i)}=\dot{\boldsymbol{x}}_{(t-1 / 2)}^{(i)}+\Delta t \ddot{\boldsymbol{x}}_{(t)}^{(i)}
$$

onde $\ddot{\boldsymbol{x}}_{(t)}^{(i)}$ é a aceleração linear da partícula causada pelas forças externas. Ou seja, $\ddot{\boldsymbol{x}}_{(t)}^{(i)}=$ $\frac{1}{m^{(i)}} \boldsymbol{f}_{(t)}^{(i)}$. Esta nova velocidade $\dot{\boldsymbol{x}}_{(t+1 / 2)}^{(i)}$ é usada para movimentar a partícula para o instante seguinte e o ciclo de cálculo é repetido até o final da simulação. A integração da rotação é mostrada adiante.

Conforme mostrado na seção 2.2, cada elemento discreto possui uma base cartesiana fixa cuja origem coincide com o centro da partícula. Assim, para executar a rotação em uma partícula é suficiente atualizar a orientação da base local em relação ao sistema inercial. A relação geral entre o sistema de referência e a posição atual da base fixa é dada pela matriz dos cossenos di- 
retores, mostrada na expressão (25), tal que cada um dos nove componentes dessa matriz deveria ser calculado por meio de diversas operações matemáticas. Entretanto, conforme mostrado nas seções 2.7 e A.II, quando se trata de uma rotação, esta relação pode ser feita por meio de um tensor rotação cujos componentes são funções de poucos parâmetros.

A configuração de referência de uma partícula é apresentada na seção 2.3 e algumas definições são reescritas aqui, por conveniência. Na configuração de referência, o sistema local é paralelo ao sistema global. Portanto, considera-se que no início da simulação são conhecidas as posições e orientações (geradas por algum critério) das partículas, tal que a orientação da base $\underline{\hat{\boldsymbol{e}}}_{t=0}^{(i)}$ de certa partícula $i$ em relação ao sistema inercial é dada pelo tensor da rotações $\boldsymbol{Q}_{t=0}^{(i)}$. No instante consecutivo, $(t=1)$, após certa perturbação no sistema, a orientação da base dessa partícula é calculada pela expressão $\underline{\hat{\boldsymbol{e}}}_{t=1}^{(i)}=\boldsymbol{Q}_{t=1}^{(i)} \cdot \underline{\hat{\boldsymbol{e}}}_{t=0}^{(i)}$. Logo, pode-se dizer que a orientação de $i$ é obtida pelas rotações sucessivas dos instantes $t=0$ e $t=1$; e a expressão que leva a partícula da configuração de referência para a configuração $(t=1)$ é igual a $\underline{\hat{\boldsymbol{e}}}_{t=1}^{(i)}=\left(\boldsymbol{Q}_{t=1}^{(i)} \cdot \boldsymbol{Q}_{t=0}^{(i)}\right) \cdot \underline{\hat{\boldsymbol{e}}}^{(i)}$. É importante notar que no instante atual $(t=0)$ o tensor que representa a orientação da partícula é conhecido. Além disso, o tensor que representa a rotação da partícula para o instante seguinte $(t=1)$ reproduz um acréscimo de rotação da partícula em relação ao instante atual. Note, também, que o tensor $\boldsymbol{Q}_{t=0}^{(i)}$ representa a rotação acumulada da partícula até o instante inicial.

Um ponto importante deste trabalho é a utilização da configuração de referência das partículas paralelas ao sistema global (ver Figura 17). Nesta configuração, o tensor de inércia do superelipsóide é diagonal. Esta característica favorece operações matemáticas e também o cálculo da energia cinética, quando for necessário (a energia cinética é calculada por $T=\frac{1}{2} \hat{J}_{1} \widehat{\omega}_{1}^{2}+$ $\left.\frac{1}{2} \hat{J}_{2} \widehat{\omega}_{2}^{2}+\frac{1}{2} \hat{J}_{3} \widehat{\omega}_{3}^{2}\right)$. Entretanto, é importante notar que a configuração no instante zero poderia ser, por exemplo, tomada como sendo a configuração de referência. Nesta situação, a mesma formulação aqui apesentada poderia ser usada sem grandes modificações. Mas, ainda para este caso, deve-se dar atenção para o fato de que o tensor de inércia não mais será diagonal. 

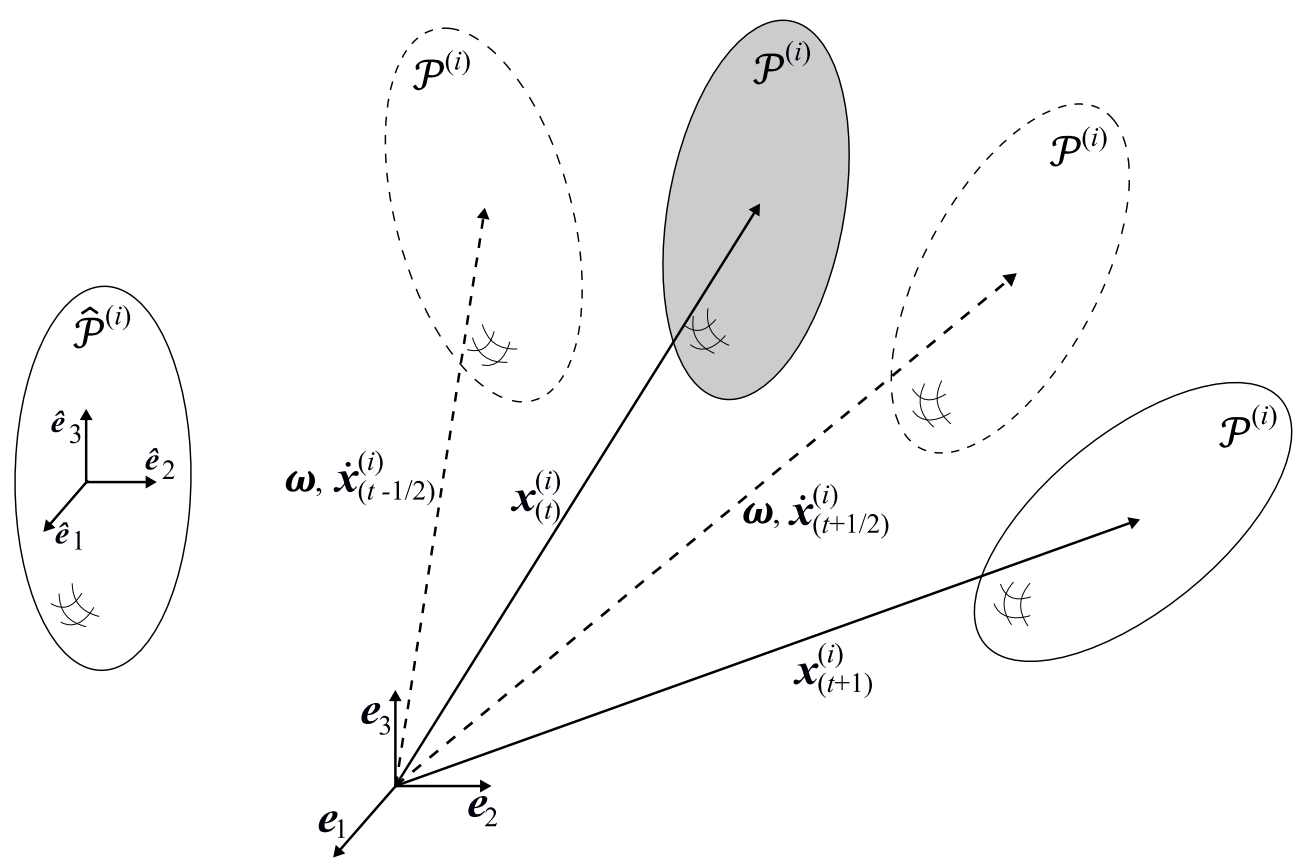

Figura 17 - Mapeamento das variáveis velocidades linear e angular e posição com o método leapfrog.

A integração das rotações deve seguir o mesmo princípio utilizado para integração das translações com o método leapfrog. Ou seja, as forças no instante atual são usadas para calcular a velocidade no instante $(t+1 / 2)$ e esta velocidade é usada para calcular o incremento de rotação que gira a partícula do instante $(t)$ para o instante seguinte $(t+1)$. A Figura 17 ilustra a relação entre as grandezas vetoriais, tal que as velocidades angular e linear são conhecidas em instantes diferentes da posição e orientação. Neste trabalho, propõe-se que a velocidade angular seja calculada por meio do momento angular, semelhante ao que foi proposto em [49] e [50]. O momento angular é obtido pela integração do torque.

A equação (5) permite relacionar a velocidade angular às forças externas por meio do momento angular. O momento angular no instante $(t+1 / 2)$ é obtido a partir das forças no instante atual, que geram o torque, ou seja:

$$
\boldsymbol{\mu}_{(t+1 / 2)}=\boldsymbol{\mu}_{(t-1 / 2)}+\Delta t \dot{\boldsymbol{\mu}}_{(t)}
$$

O momento angular (77) é transformado para as coordenadas da configuração de referência da partícula pelo tensor das rotações $\boldsymbol{Q}_{(t+1 / 2)}$, portanto: 


$$
\boldsymbol{\mu}_{(t+1 / 2)}^{r}=\boldsymbol{Q}_{(t+1 / 2)}^{T} \cdot \boldsymbol{\mu}_{(t+1 / 2)}
$$

Note que $\boldsymbol{Q}_{(t+1 / 2)}$ é desconhecido, entretanto ele pode ser facilmente calculado por um valor médio. Esta aproximação é mostrada no final desta seção.

A velocidade angular na configuração de referência é calculada pela equação de Euler que relaciona o momento angular e a velocidade angular. Logo,

$$
\boldsymbol{\omega}_{(t+1 / 2)}^{r}=\boldsymbol{J}^{-1} \cdot \boldsymbol{\mu}_{(t+1 / 2)}^{r}
$$

Onde $\boldsymbol{J}$ é o tensor de inércia da partícula na configuração de referência (portanto, diagonal). Esta passagem justifica o uso da configuração de referência para o cálculo da velocidade angular, pois não seria possível calcular o tensor de inércia na configuração intermediária visto que a orientação da partícula é desconhecida em $(t+1 / 2)$, ver Figura 17. Usando $\boldsymbol{\omega}_{(t+1 / 2)}^{r}$ é possível calcular o vetor rotação incremental de Rodrigues, visto que o tensor de inércia é sempre constante nesta configuração. A relação entre a velocidade angular e o vetor rotação de Rodrigues $\boldsymbol{\alpha}_{\Delta}^{r}$ pode ser conseguida de maneira simples usando a definição apresentada em [17], convenientemente reescrita aqui:

$$
\boldsymbol{\alpha}_{\Delta}^{r}=\Delta t \boldsymbol{\omega}_{(t+1 / 2)}^{r}
$$

A transformação da equação (80) para o sistema de coordenadas global é dada por

$$
\boldsymbol{\alpha}_{\Delta}=\boldsymbol{Q}_{(t+1 / 2)} \cdot \boldsymbol{\alpha}_{\Delta}^{r}
$$

Note que $\alpha_{\Delta}=\left\|\boldsymbol{\alpha}_{\Delta}\right\|=\left\|\boldsymbol{\alpha}_{\Delta}^{r}\right\|$. Da seção 2.7, a expressão (30) permite representar duas rotações sucessivas por meio de um único vetor $\boldsymbol{\alpha}$. Assim, utilizando $\boldsymbol{\alpha}_{\Delta}$ e (30), define-se o vetor orientação da partícula: 


$$
\alpha_{(t+1)}=\frac{4}{4-\alpha_{\Delta} \cdot \alpha_{(t)}}\left(\alpha_{(t)}+\alpha_{\Delta}-\frac{1}{2} \alpha_{(t)} \times \alpha_{\Delta}\right)
$$

Na expressão (82), o vetor $\boldsymbol{\alpha}_{(t)}$ é o vetor axial associado ao tensor $\boldsymbol{Q}_{(t)}$ e o vetor $\boldsymbol{\alpha}_{\Delta}$ é o vetor axial associado ao tensor $\boldsymbol{Q}_{\Delta}$. O vetor $\boldsymbol{\alpha}_{(t+1)}$ permite escrever o tensor que representa a orientação da partícula no instante seguinte $(t+1)$.

Utilizando (26), o tensor das rotações que transforma a orientação da partícula para o instante $(t+1)$ é definido por

$$
\boldsymbol{Q}_{(t+1)}=\boldsymbol{I}+\frac{4}{4+\alpha_{(t+1)}^{2}} \boldsymbol{A}_{(t+1)}+\frac{2}{4+\alpha_{(t+1)}^{2}} \boldsymbol{A}_{(t+1)}^{2},
$$

onde $\boldsymbol{A}_{(t+1)}$ é o tensor antissimétrico associado ao vetor axial $\boldsymbol{\alpha}_{(t+1)}$.

Portanto, dada uma partícula $i$, e sendo conhecida a sua velocidade angular $\boldsymbol{\omega}^{(i)}$ no instante $(t)$, a aplicação que leva $i$ para o instante consecutivo $(t+1)$ é dada por

$$
\underline{\hat{\boldsymbol{e}}}_{(t+1)}^{(i)}=\boldsymbol{Q}_{(t+1)} \cdot \underline{\hat{\boldsymbol{e}}}^{(i), r}
$$

O cálculo de $\boldsymbol{Q}_{(t+1 / 2)}$, que foi adiado no início desta dedução, pode ser executado ao utilizar a metade de um instante de tempo com o método de Euler explícito, isto é

$$
\boldsymbol{\mu}_{(t)}=\boldsymbol{\mu}_{(t-1 / 2)}+\frac{\Delta t}{2} \dot{\boldsymbol{\mu}}_{(t)}
$$

Assim, e utilizando o tensor das rotações $\boldsymbol{Q}_{(t)}$, que é conhecido, o momento angular é transformado para o sistema de coordenadas da partícula:

$$
\boldsymbol{\mu}_{(t)}^{r}=\boldsymbol{Q}_{(t)}^{T} \cdot \boldsymbol{\mu}_{(t)}
$$

Com isso, a velocidade angular no instante atual $t$ é calculada: 


$$
\boldsymbol{\omega}_{(t)}^{r}=\boldsymbol{J}^{-1} \cdot \boldsymbol{\mu}_{(t)}^{r}
$$

tal que $\boldsymbol{J}$ é o tensor de inércia da partícula na configuração de referência.

A equação (80) pode ser reescrita na forma

$$
\boldsymbol{\alpha}_{\Delta / 2}^{r}=\frac{\Delta t}{2} \boldsymbol{\omega}_{(t)}^{r}
$$

A equação (88) pode agora ser transformada de volta para o sistema global, ou seja, $\boldsymbol{\alpha}_{\Delta / 2}=$ $\boldsymbol{Q}_{(t)} \cdot \boldsymbol{\alpha}_{\Delta / 2}^{r}$. Usando $\boldsymbol{\alpha}_{\Delta / 2}^{r}$, a equação (30) pode ser calculada, tal que $\boldsymbol{\alpha}_{1}:=\boldsymbol{\alpha}_{(t)}$. Assim, o tensor rotação no instante intermediário $\boldsymbol{Q}_{(t+1 / 2)}$ é calculado substituindo o resultado de (30) em (26).

\subsection{Algoritmo}

A rotina de cálculo proposta neste trabalho é semelhante àquela usada tradicionalmente com o MED (detecção de contato, cálculo das forças de contato e integração do movimento). A integração das rotações é feita por meio de uma série de transformações nas grandezas vetoriais que descrevem a cinemática das partículas, alternando entre o sistema espacial (global) e o sistema local da partícula (ver seção 3.1.4). A Figura 18 mostra a sequência de cálculos que deve ser feita para realizar a integração das rotações utilizando a formulação proposta (na figura, os itens com preenchimento indicam que a grandeza é calculada no sistema de referência). Note que no início da sequência mostrada na Figura 18 os contatos já foram detectados e as forças de contato foram calculadas para cada partícula. 


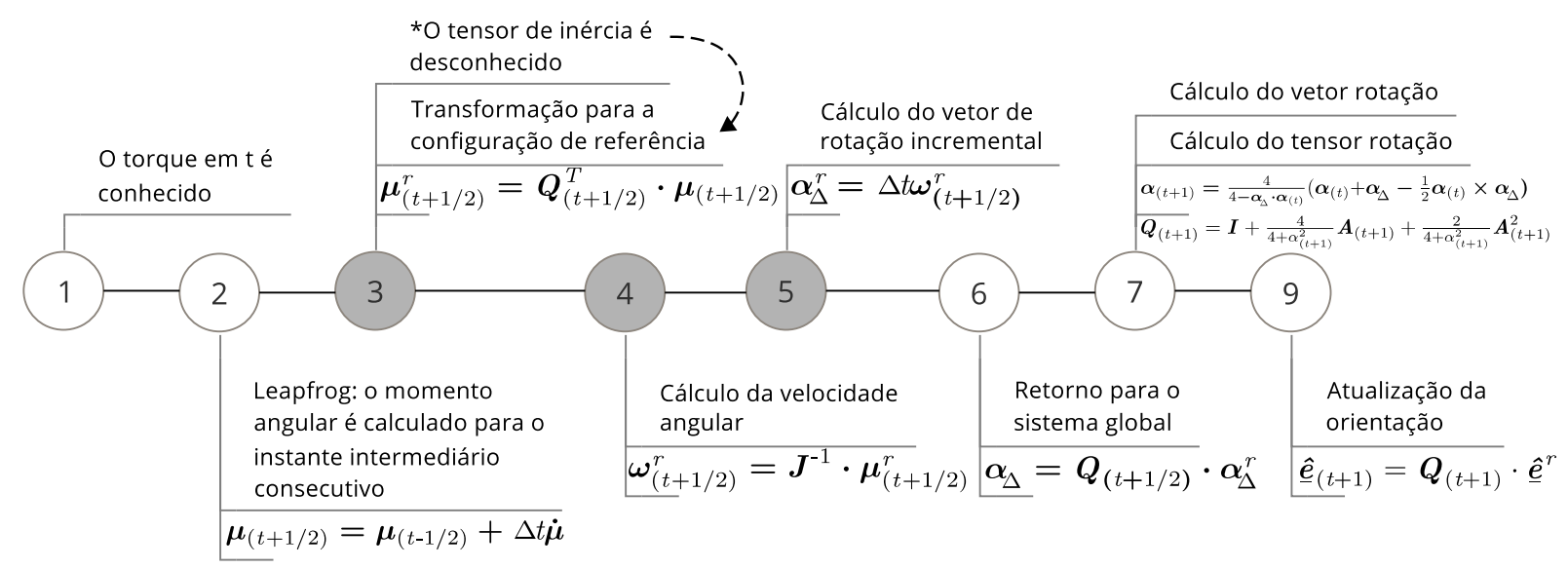

Figura 18 - Sequência proposta para integração das rotações. 


\section{RESULTADOS E ANÁLISES}

Os exemplos numéricos apresentados neste capítulo têm como objetivo verificar o algoritmo e as formulações propostas neste trabalho. Embora simulações com o MED possam envolver milhares de partículas, optou-se por utilizar exemplos simplórios que permitam avaliar numericamente o comportamento das partículas quanto à rotação, à integração no tempo e à interação de contato.

Em nenhum dos exemplos buscou-se avaliar o desempenho do processamento da simulação. Pois, objetivos como este fazem parte de uma linha de pesquisa específica sobre alto desempenho de processamento com o MED, tanto usando paralelismo de CPUs quanto de GPUs. Para maiores detalhes sobre este tema, recomendamos a leitura de [52] [53] [54].

Toda teoria apresentada nesta tese foi escrita em um código fonte em linguagem FORTRAN 2003, para que fossem realizados os exemplos numéricos mostrados neste capítulo. Durante a revisão bibliográfica, o autor observou que a detecção do contato com o MED requer grande esforço computacional. Além disso, notou-se também que diferentes métodos podem ser empregados em diferentes partes do MED como métodos de integração no tempo, de detecção de contato e de aplicação das rotações. E, o uso de tipos geométricos diferentes requer tratamento específico em situações restritas como a detecção do contato e a caracterização geométrica, porém sem modificar a parte central do código. Por estes motivos, o autor optou pelo uso desta linguagem de programação, visto que ela permite a implementação em uma abordagem orientada a objetos (POO), e também por ser historicamente uma linguagem com bom desempenho computacional. Uma das principais vantagens observadas com o uso da POO é a possibilidade de expansão do código utilizando heranças e polimorfismo. Para o leitor com interesse em utilizar Fortran 2003 com POO, recomendamos [55], [56] e [57].

\subsection{Cilindro em superfície plana}

Para avaliar a rotação e o cálculo do deslocamento tangencial, uma simulação com uma única partícula é resolvido. Este problema foi proposto por [18] e permite avaliar com precisão a formulação proposta, pois possui solução analítica.

O problema consiste em um cilindro de comprimento unitário apoiado em uma superfície plana, Figura 19. As velocidades angular e linear iniciais da partícula são diferentes de zero e de- 
finidas de modo que a relação entre a rotação e a translação cause um comportamento de slip de rotação no início da simulação (velocidade angular muito alta). Devido ao efeito do atrito, se espera que após certo instante a velocidade angular diminua. Consequentemente, a velocidade linear aumenta ao ponto que as duas velocidades se tornam constantes e apenas um comportamento de rolamento puro permanece.

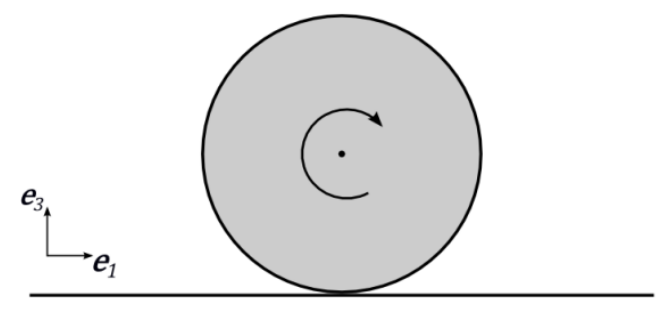

Figura 19 - Ilustração do exemplo numérico.

As condições iniciais do problema são:

$\omega_{2}=127,03$

$\dot{x}_{1}=2,355$

$m=1000$

$r=0,2$

$\mu=0,25$

$g=9,81$

$k_{n}=E+08$

$k_{s}=E+07$

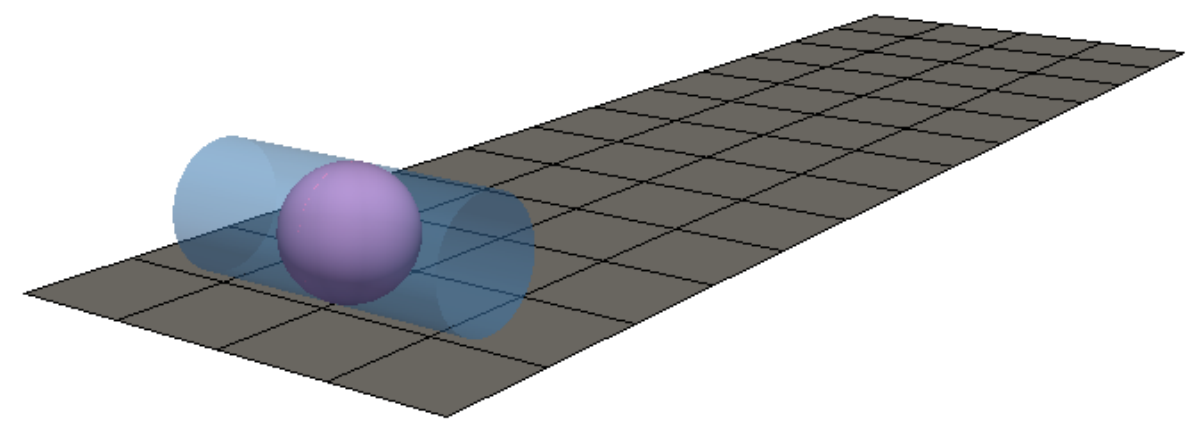

Figura 20 - Elemento esférico representando cilindro.

Note que a partícula em questão é um cilindro, diferentemente daquelas apresentadas neste trabalho (esfera e superelipsóide), Figura 20. Para tornar este problema equivalente à formulação aqui apresentada, duas situações são adotadas: modificar o momento de inércia do elemento discreto esférico para um valor equivalente ao de um cilindro de comprimento unitário; e utilizar um superelipsóide com geometria cilíndrica (cilindroide). Para os três casos, é im- 
portante notar que o contato acontece em um único ponto (apesar de se tratar um cilindro e de se esperar o contato ao longo de uma linha, a solução analítica resolve um disco e, portanto, o contato é descrito para um único ponto). Por este motivo, o modelo da esfera pode ser usado desde que a orientação do eixo $\boldsymbol{e}_{2}$ permaneça constante em toda simulação. Dois modelos de superelipsóides são utilizados, Figura 21, cujas geometrias são dadas por $r_{1}=0,2 ; r_{2}=$ 0,$2 ; r_{3}=0,5$ e $\epsilon_{1}=1,0 ; \epsilon_{2}=0,2 \vee 0,3$. Em ambos superelipsóides são mantidos seus próprios momentos de inércia. Devido às curvaturas nos polos dos cilindroides, a massa das partículas deve ser levemente menor do que aquela utilizada nos cilindros. Por este motivo, as massas dos superelipsóides são calculadas segundo o peso específico obtido pela relação entre massa e volume do cilindro. $\mathrm{O}$ eixo $\boldsymbol{e}_{2}$ deve ser mantido constante.

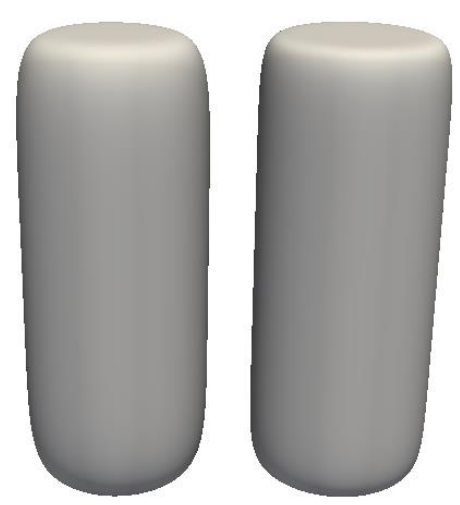

Figura 21 - Superelipsóides parametrizados para formar cilindroides (esq.: $\epsilon_{2}=0$,3, dir.: $\epsilon_{2}=0,2$ ).

Para avaliar a estabilidade do método de integração, foram realizadas simulações utilizando valores diferentes de incremento de tempo, porém constantes durante cada simulação.

A solução analítica mostra que o equilíbrio deve ser estabelecido no instante $t=3,13$ e com velocidades iguais a $\omega_{2}=50,27$ e $\dot{x}_{1}=10,03$. 

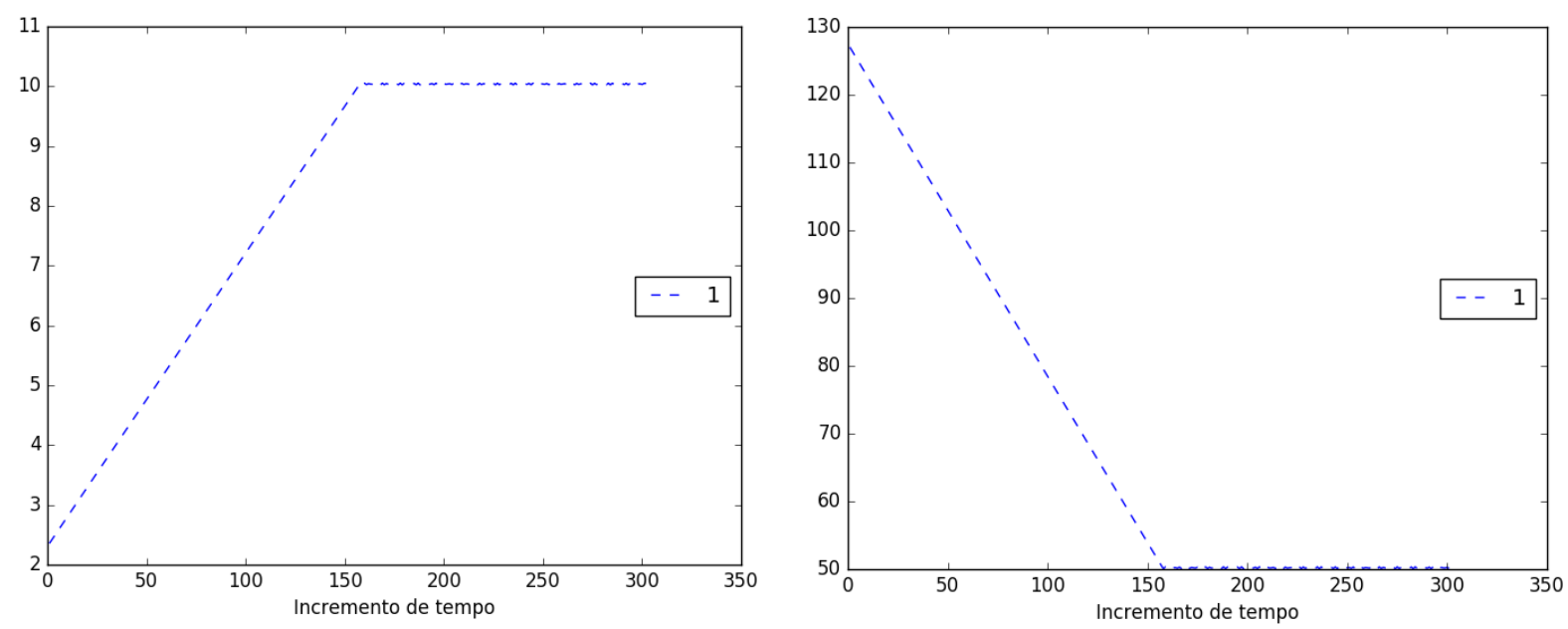

Figura 22 - Velocidades linear e angular para simulação com partículas esféricas (esq.: vel. linear; dir: vel. Angular).

Os resultados das análises com a partícula esférica coincidem com os valores analíticos para incrementos de tempo menores ou iguais a E-03, Figura 22. Os resultados para os modelos dos superelipsóides são mostrados na Tabela 1.

Tabela 1 - Resultado da simulação com superelipsóides em superfície plana.

\begin{tabular}{|c|c|c|}
\hline Geometria & Velocidade linear & Velocidade angular \\
\hline$\epsilon_{2}=0,3$ & $\dot{x}_{1}=9,83$ & $\omega_{2}=49,07$ \\
\hline$\epsilon_{2}=0,2$ & $\dot{x}_{1}=9,92$ & $\omega_{2}=49,73$ \\
\hline
\end{tabular}

Conforme esperado, a simulação com os superelipsóides mostrou resultados muito próximos da solução analítica. Valores menores eram esperados para estas partículas, visto que os superelipsóides são mais leves devido à curvatura de seus polos. Por este motivo, dentre os modelos de cinlindróide, o que possui maior proximidade geométrica de um cilindro $\left(\epsilon_{2}=0,2\right)$ foi o que apresentou resultados mais próximos do analítico.

O gráfico da Figura 23 mostra a velocidade angular da partícula ao longo do tempo. São avaliadas as integrações no tempo com o método de Euler e com leapfrog. Somente dois valores de incremento de tempo são mostrados $\left(\Delta t=10^{-3}\right.$ e $\left.\Delta t=71 \cdot 10^{-2}\right)$. A diferença nos valores para incrementos menores ou iguais a $\Delta t=10^{-3}$ é muito pequena em relação à solução analítica e, por este motivo, não são mostrados. 


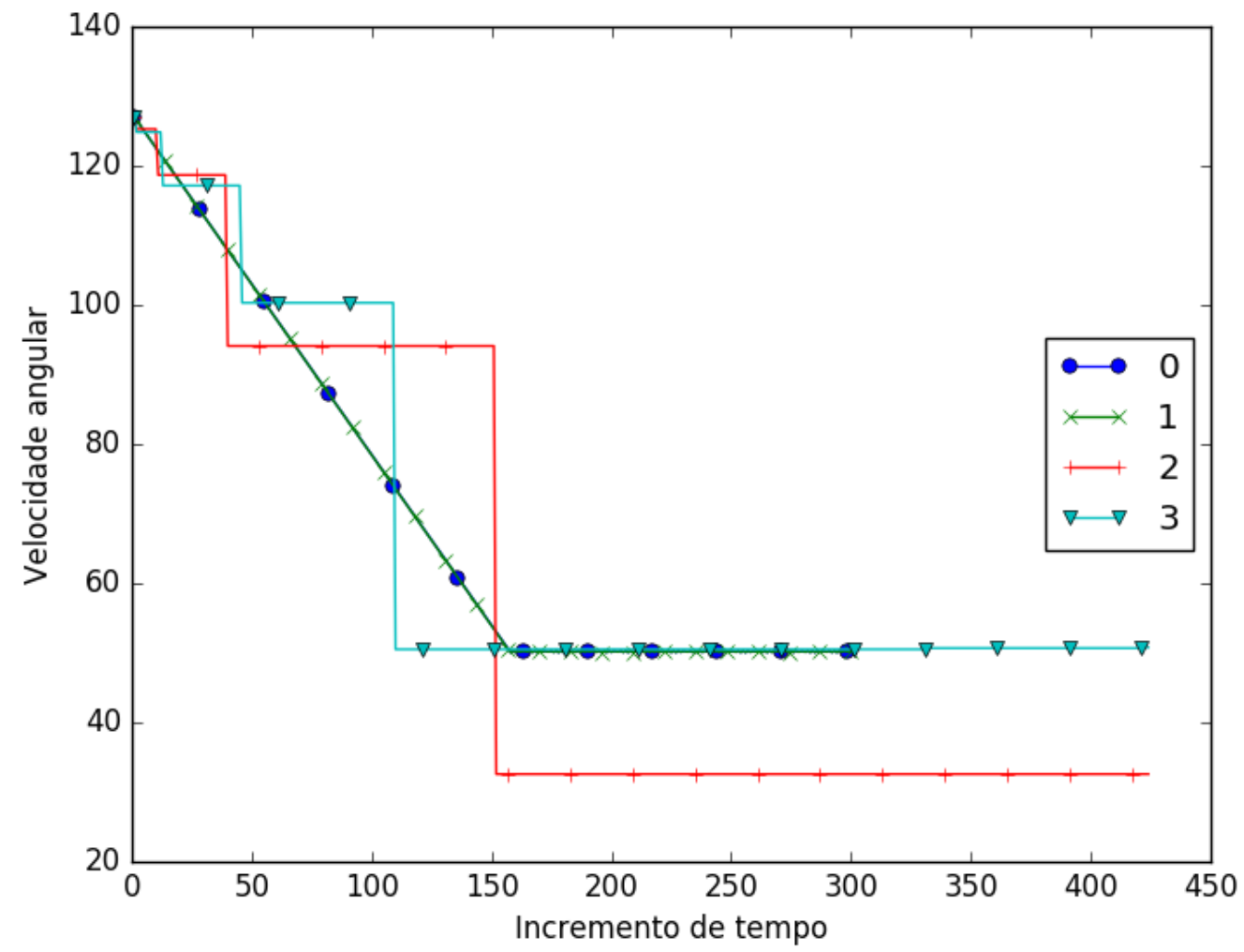

Figura 23 - Variação do incremento de tempo usando Euler e leapfrog $\left(0\right.$ - Euler com $\Delta t=10^{-3} ; 1$ leapfrog com $\Delta t=10^{-3} ; 2$ - Euler com $\Delta t=71 \cdot 10^{-2} ; 3$ - leapfrog $\operatorname{com} \Delta t=71 \cdot 10^{-2}$ ).

Duas observações podem ser feitas a partir do gráfico da Figura 23. A primeira delas é que o erro apresentado para solução com $\Delta t=71 \cdot 10^{-2}$ utilizando leapfrog (gráfico “3”) é menor do que o erro para a simulação com o mesmo incremento de tempo utilizando Euler (gráfico “2”). Também é possível observar que esta mesma simulação com leapfrog converge para o valor analítico da velocidade angular após estabilização da partícula. Estes resultados condizem com o que é relatado na literatura quanto ao uso do método leapfrog em comparação com o método de Euler explícito. Valores de incremento de tempo maiores do que $\Delta t=71 \cdot 10^{-2}$ resultaram em erros muito grandes em relação ao resultado analítico.

\subsection{Superelipsóides em simetria}

Este exemplo numérico tem como objetivo avaliar a rotação e o contato entre superelipsóides. Três superelipsóides são posicionados nos vértices de um triângulo equilátero, em mesma cota vertical. Um quarto superelipsóide é posicionado verticalmente acima das três demais partícu- 
las, tal que o centro da partícula se projeta no baricentro do triângulo, conforme mostra a Figura 24.

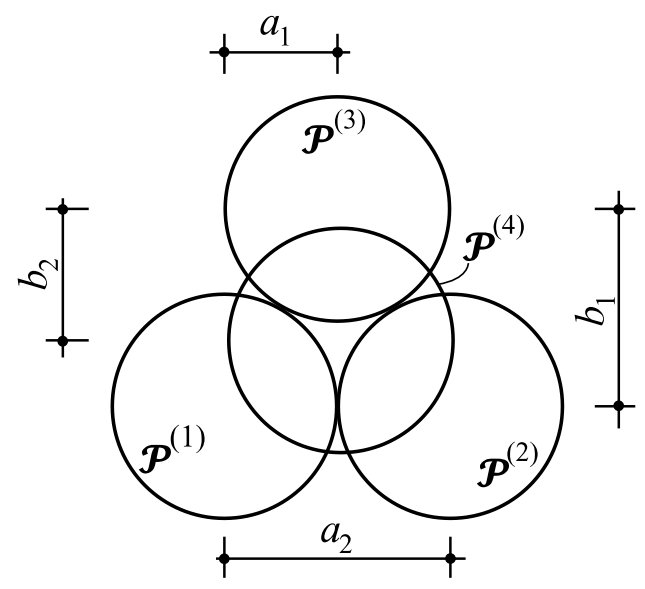

Figura 24 - Configuração inicial da simulação com quatro superelipsóides.

Para esta simulação, as dimensões mostradas na Figura 24 são $a_{1}=1, a_{2}=2, b_{1}=\sqrt{3}$, $b_{2}=2 / 3 \sqrt{3}$. As três partículas coplanares possuem velocidade inicial igual à zero. A quarta partícula possui velocidade inicial igual a $\left[\begin{array}{c}v_{t=0}^{(4)}\end{array}\right]=\left[\begin{array}{lll}0 & 0 & -1\end{array}\right]^{T}$. Todas as velocidades angulares iniciais são iguais a zero e a aceleração da gravidade é desprezada. Note a existência de um plano imaginário de simetria entre cada par de partículas, dentre $\mathcal{P}^{(1)}, \mathcal{P}^{(2)}$ e $\mathcal{P}^{(3)}$.

Na configuração inicial, as três partículas coplanares se tocam, mas sem nenhuma penetração. Ou seja, a distância entre elas é exatamente igual à zero. Conforme esperado, nesta situação, o algoritmo de contato não mostrou nenhuma inconsistência, visto que arredondamentos de máquina poderiam induzir o algoritmo para erros em números muito pequenos. A colisão ocorre simultaneamente entre a partícula em queda e as três demais partículas. O avanço da simulação é ilustrado na Figura 25.
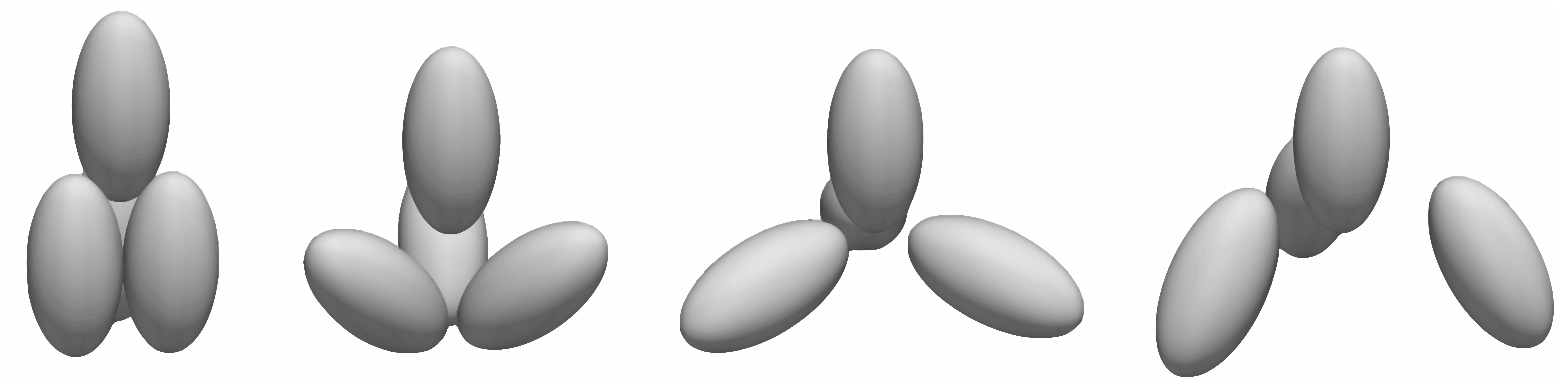

Contato inicial

Avanço da simulação

Figura 25 - Avançado da simulação com quatro superelipsóides. 
Para avaliar o movimento das partículas, propõe-se analisar o afastamento relativo entre duas partículas e o plano de simetria entre elas. Assim, tanto as forças de contato, que devem ser idênticas em termos absolutos para as três partículas, quanto o algoritmo de integração no tempo com a parametrização das rotações são avaliados.

O gráfico da Figura 26 mostra o afastamento absoluto das partículas $\mathcal{P}^{(1)}$ e $\boldsymbol{P}^{(2)}$ em relação ao plano de simetria, que é paralelo ao plano $\left(\boldsymbol{e}_{2}, \boldsymbol{e}_{3}\right)$ e que passa pelo ponto médio de $a_{2}$ (ver Figura 24).

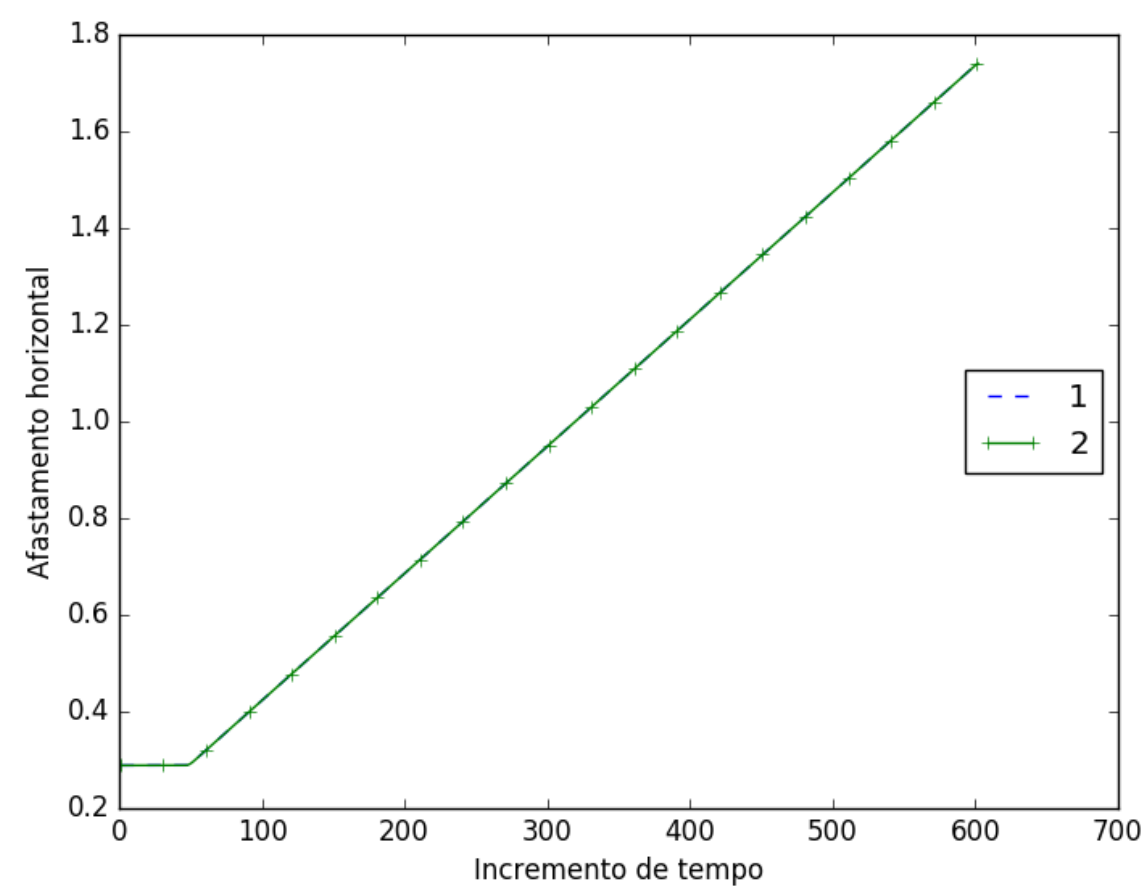

Figura 26 - Avaliação do afastamento horizontal relativo entre as partículas $\mathcal{P}^{(1)}$ e $\mathcal{P}^{(2)}$.

Conforme esperado, os afastamentos absolutos são equivalentes.

\subsection{Verificação dos pontos de singularidade}

Na equação (A.31) é apresentada uma solução para um problema de singularidade presente nas equações de mapeamento do superelipsóide. A singularidade acontece sobre as linhas de interseção dos quadrantes dos superelipsóides. Para avaliar a solução apresentada, foi proposto um problema onde o contato ocorre na linha de singularidade durante toda simulação, tanto entre superelipsóide-superelipsóide quanto entre superelipsóide-parede. 
Duas partículas são colocadas de tal maneira a colidir exatamente sobre a linha de singularidade. O centro das duas partículas está localizado em um mesmo plano vertical, sendo que em cotas verticais diferentes. A velocidade inicial de ambas as partículas é igual a zero e somente a gravidade atua no modelo. Não há atrito. Um amortecimento viscoso é utilizado.

Logo após o início da simulação, a partícula localizada mais acima entra em contato com a outra partícula, deslizando uma sobre a outra na região da curva de singularidade. $\mathrm{O}$ contato com as paredes do modelo também ocorre ao longo da região de singularidade. Espera-se que nenhuma mudança de posição seja vista na direção perpendicular ao plano vertical onde estão localizados os centros das partículas. A Figura 27 mostra a configuração inicial das partículas. Utilizando como referência as linhas de grade das paredes, é possível observar o plano vertical que as partículas devem se manter.
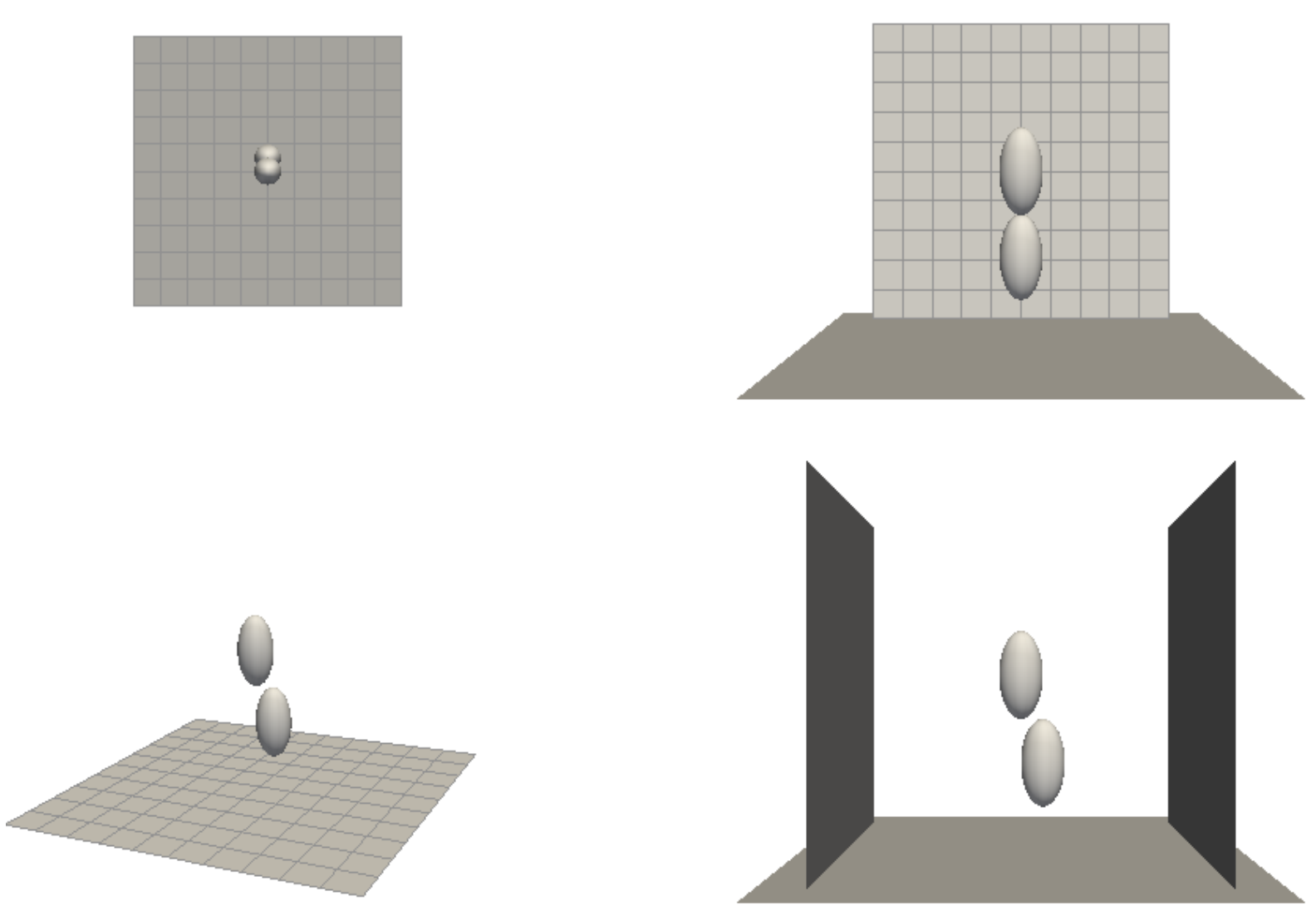

Figura 27 - Deslizamento na zona de singularidade: configuração inicial.

A Figura 28 mostra o cenário depois do início da simulação, no momento em que as partículas estão em contato entre si e com a parede simultaneamente. 

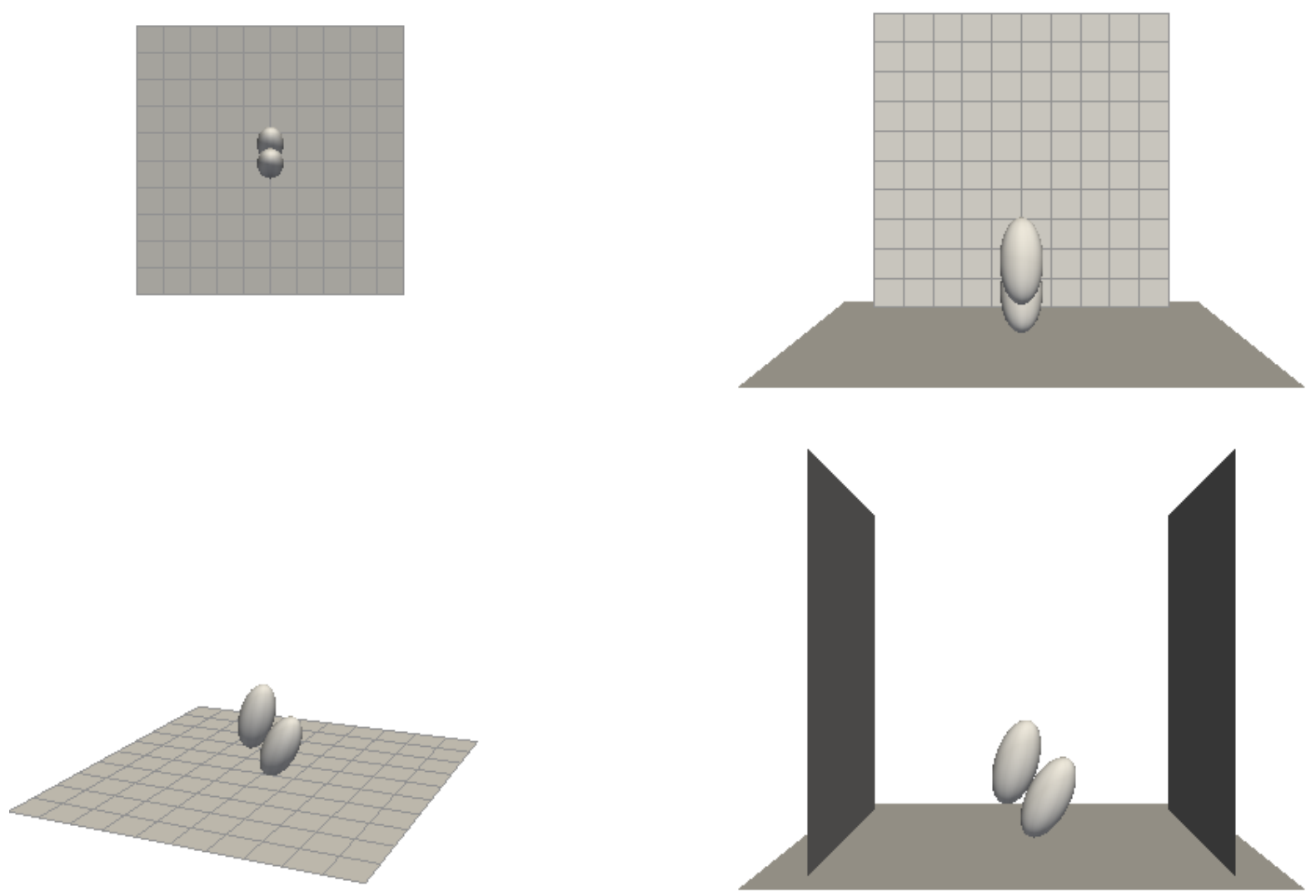

Figura 28 - Deslizamento na zona de singularidade: condição com contatos ativos.

À medida que a simulação acontece, as partículas continuam a deslizar sobre a parede horizontal do modelo, e sucessivas colisões acontecem contra as paredes laterais. Após certo tempo de simulação, a posição das partículas é observada novamente. É avaliado se ocorreu alguma perturbação na direção perpendicular ao movimento. Nenhum desvio é encontrado, conforme mostra a Figura 29. 

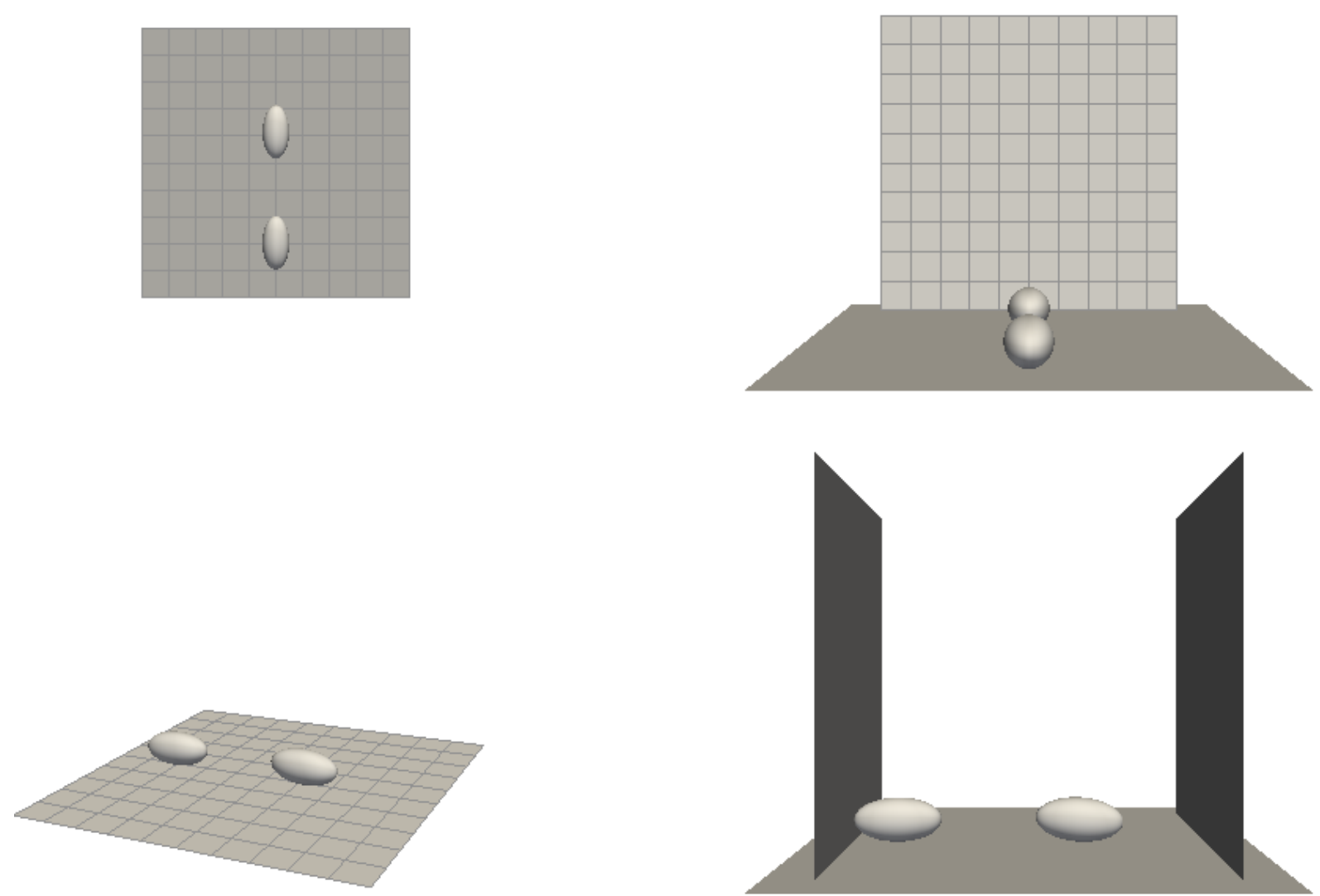

Figura 29 - Deslizamento na zona de singularidade: configuração final.

Apesar de sugerir um arredondamento, a solução para o problema de singularidade das funções de mapeamento não gerou nenhum erro significativo após sucessivos ciclos de contato, apesar de não haver o equilíbrio perfeito. O desvio observado foi menor do que $10^{-12}$.

\subsection{Múltiplas partículas}

Um exemplo com múltiplas partículas foi proposto para avaliar qualitativamente o comportamento do algoritmo em situações mais complexas, tanto em termos de detecção de contato quanto de rotações. Um conjunto de 360 partículas superelipsóides dispostas regularmente em um cubo é gerado. Todas as partículas possuem velocidade inicial igual a zero e não há conato inicial entre as partículas entre si e nem com os contornos. As partículas caem sob a ação da gravidade em direção a uma calha rígida que possui um anteparo na extremidade final (Figura 30). Atrito e amortecimento estão presentes nos contatos. 


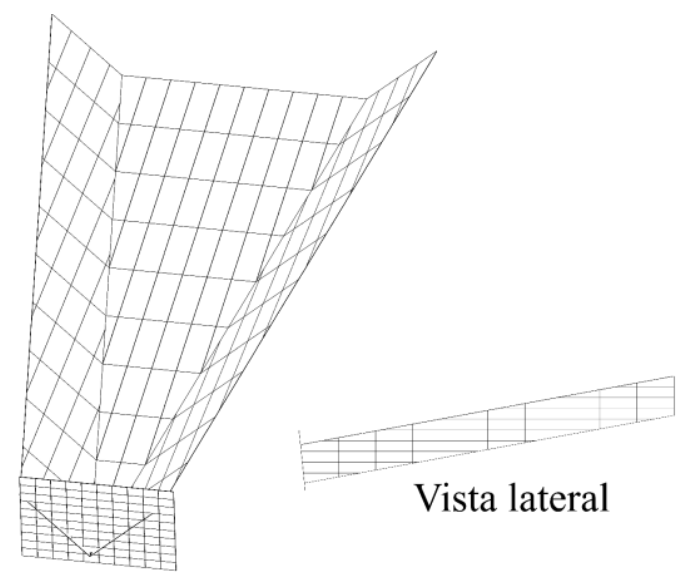

Figura 30 - Condições de contorno da simulação com múltiplas partículas.

A simulação possui duração de 20 segundos. Todas as partículas são configuradas com as dimensões $r_{1}=r_{2}=0,4, r_{3}=0,9, \epsilon_{1}=\epsilon_{2}=1$ e possuem orientação inicial paralela ao sistema espacial. O material das partículas é definido por $E=10^{8}, G=10^{7}, \rho=29841,55$, $\epsilon=0,15$ e $D=0,4$, onde $D$ é o coeficiente de amortecimento. A Figura 31 mostra a evolução do modelo ao longo do tempo (as superfícies do contorno foram omitidas para facilitar a apresentação das partículas). O intervalo de tempo utilizado na simulação foi de $\Delta t=10^{-6}$.

O número de iterações executado pelo algoritmo de busca de contatos foi avaliado em cada passo de tempo. Foi observado que, na maioria das vezes, um mínimo é atingido em um número de iterações que varia entre 2 e 9 para detecção do primeiro contato. Em menos de 5\% das buscas foram necessários mais do que 20 iterações para detecção do primeiro contato. A detecção de contato consumiu entre $52 \%$ e $72 \%$ do tempo da simulação ${ }^{8}$.

Para efeito de comparação, a mesma simulação foi feita com partículas esféricas. O tempo consumido para esta simulação representou menos de $1 \%$ do tempo consumido para simulação com superelipsóides. Esta observação mostra que o esforço para detecção de contato depende da geometria das partículas. Sabe-se que geometrias esféricas são aquelas que demandam menor esforço computacional para detecção do contato. Apesar da relação aqui apresentada mostrar grande diferença de tempo, há ainda possibilidade de melhorar o desempenho para detecção de contato entre superelipsóides. Neste caso, a solução seria em termos de algoritmo de programação e/ou pela escolha de métodos diferentes daquele aqui utilizado.

\footnotetext{
${ }^{8}$ É importante mencionar que o código fonte deste trabalho não foi elaborado com propósito de se obter alto desempenho. Por este motivo, não faz sentido serem colocados tempos de simulação computacional. Para detalhes sobre a ordem de grandeza de tempo em termos de detecção de contato com superelipsóides, recomendamos [10] e [38].
} 


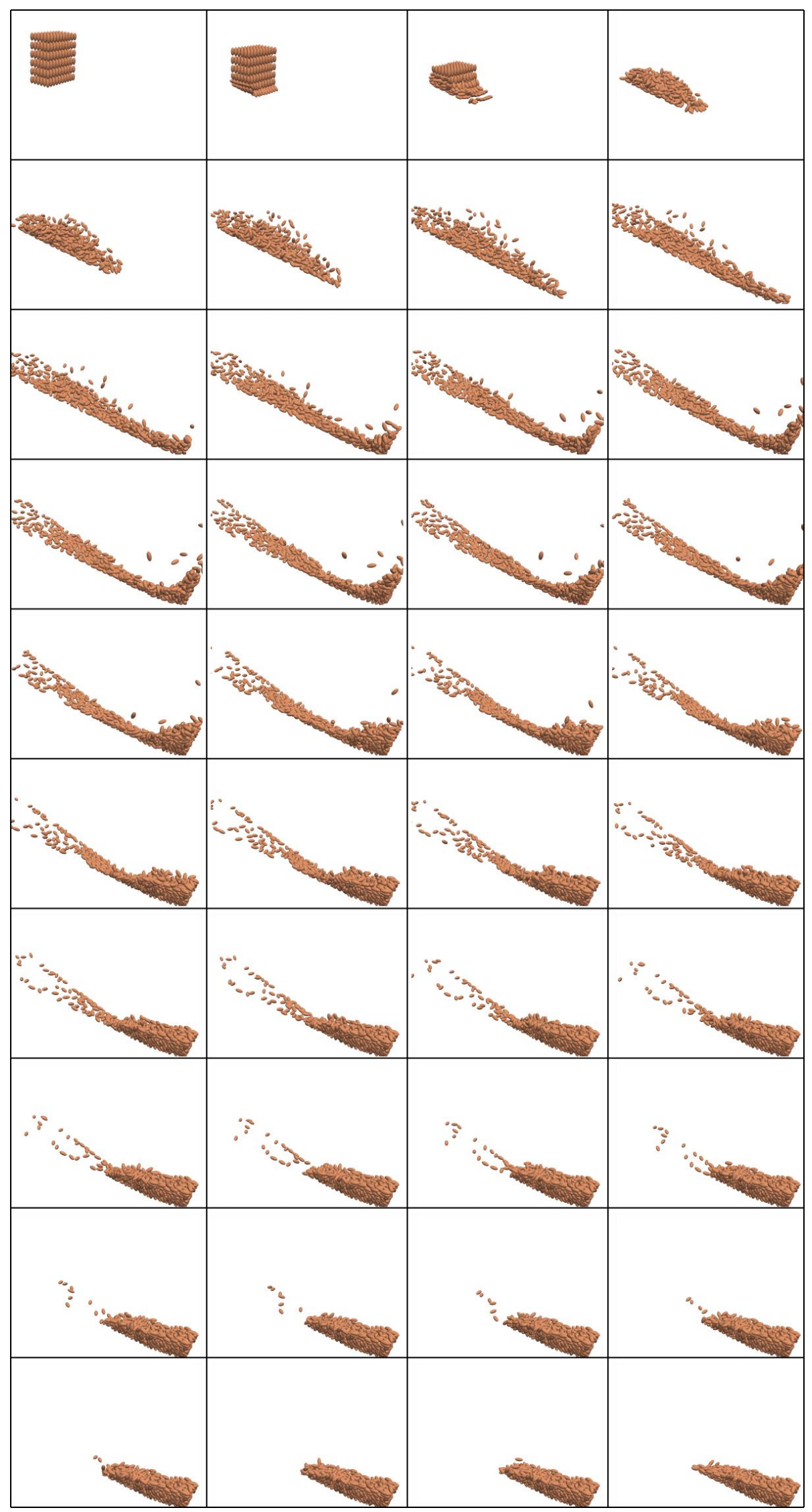

Figura 31 - Sequencia da simulação com múltiplos superelipsóides. 


\section{CONCLUSÃO}

O MED possui grande aplicação na mecânica computacional e pode ser considerado um dos principais métodos da mecânica dos meios descontínuos. A parametrização de Rodrigues, apesar de não ter sido encontrada na literatura em problemas com o método dos elementos discretos, possui algumas características que a tornam atrativas para este tipo de simulação. Além disso, esta parametrização foi utilizada com sucesso nas teorias de barras e cascas do método dos elementos finitos.

Uma das suas principais características da parametrização escolhida é permitir descrever, por meio de vetores, e de maneira exata, duas rotações sucessivas. Esta característica foi explorada neste trabalho, onde se propõe, com resultados satisfatórios, o uso de uma fórmula livre de tensores de segunda ordem para o cálculo dos deslocamentos tangentes em um evento de contato. A mesma expressão também é usada para uma nova formulação da integração no tempo com o método leapfrog.

Apesar de não ser uma parametrização livre de singularidades, e de esperar grandes rotações durante uma simulação - que induziriam a atingir tais pontos de singularidade, os resultados obtidos mostram que a parametrização de Rodrigues pode ser utilizada com o Método dos Elementos Discretos quando se utiliza uma descrição lagrangiana atualizada. Nenhuma restrição de singularidade foi encontrada, conforme se esperava, visto que os incrementos de rotação são muito pequenos quando comparados com o limite necessário para se atingir tais singularidades. Mostrou-se que a sua aplicação no MED pode ser feita não somente para execução das rotações, mas também para o cálculo de grandezas que envolvem este tipo de movimento como o cálculo dos deslocamentos tangentes.

Verificou-se, conforme já descrito na literatura, que a detecção de contato ocupa a maior parte absoluta do tempo de processamento de uma simulação.

Para que este trabalho possa ser ampliado, são sugeridas algumas pesquisas futuras:

- Desenvolvimento de modelos matemáticos para gerar partículas superelipsóides em um volume pré-definido e que atenda certo critério de granulometria;

- Desenvolvimento de leis constitutivas mais robustas que se apliquem a problemas com coesão e critérios de falha. 


\section{APÊNDICE}

Neste capítulo são colocadas algumas demonstrações e propriedades matemáticas utilizadas ao longo do texto. O objetivo é complementar as informações contidas no desenvolvimento principal, para evitar longos parênteses no decorrer do texto.

Todos os símbolos utilizados adiante são limitados a este capítulo.

\section{A.I Matriz antissimétrica e tensores de segunda ordem}

Seja a matriz quadrada $[L]_{n \times n}$. Qualquer matriz semelhante a $[L]$ pode ser decomposta em duas partes, uma simétrica e outra antissimétrica, tal que:

$$
[L]=\frac{1}{2}\left([L]-[L]^{T}\right)+\frac{1}{2}\left([L]+[L]^{T}\right)=[S]+[A]
$$

As matrizes $[S]$ e $[A]$ representam a parte simétrica e antissimétrica de $[L]$, respectivamente, e são representadas por $[S]=\operatorname{Sym}([L])$ e $[A]=\operatorname{Skew}([L])$.

Sejam dois vetores $\boldsymbol{a}$ e $\boldsymbol{b}$. O "produto diádico", ou "produto tensorial" entre dois vetores, produz um tensor de segunda ordem, com nove componentes, dado por:

$$
\boldsymbol{a} \boldsymbol{b}^{T} \equiv \boldsymbol{a} \boldsymbol{b} \equiv \boldsymbol{a} \otimes \boldsymbol{b}=\left[\begin{array}{l}
a_{1} \\
a_{2} \\
a_{3}
\end{array}\right]\left[\begin{array}{lll}
b_{1} & b_{2} & b_{3}
\end{array}\right]
$$

A expressão $\boldsymbol{a} \boldsymbol{b}^{T}$ é chamada de produto diádico ou produto tensorial e também é comumente escrita na forma $\boldsymbol{a} \otimes \boldsymbol{b}$ ou $\boldsymbol{a} \boldsymbol{b}$ (note que o produto diádico $\boldsymbol{a} \boldsymbol{b}$ se diferencia do produto vetorial $\boldsymbol{a} \cdot \boldsymbol{b}$ pelo símbolo “." colocado entre os dois vetores). O resultado de um produto diádico é um tensor de segunda ordem representado por uma matriz de dimensão (3x3).

Sobre o produto diádico, ou tensorial, é importante notar que o produto vetorial de um vetor $\boldsymbol{c}$ com o produto diádico $\boldsymbol{a} \boldsymbol{b}$ resulta em um vetor com a direção de $\boldsymbol{b}$ e é válida a igualdade $\boldsymbol{c} \cdot \boldsymbol{a} \boldsymbol{b}=(\boldsymbol{c} \cdot \boldsymbol{a}) \boldsymbol{b}$. Invertendo a ordem do produto vetorial, a expressão é escrita na forma $\boldsymbol{a} \boldsymbol{b} \cdot \boldsymbol{c}=\boldsymbol{a}(\boldsymbol{b} \cdot \boldsymbol{c})$ e, neste caso, o vetor resultante tem a direção de $\boldsymbol{a}$. 
Seja o produto vetorial $\boldsymbol{a} \times \boldsymbol{b}$. O tensor $\boldsymbol{A}_{\boldsymbol{a}}$ formado pelos componentes $a_{i}$, tal que $\boldsymbol{A}_{\boldsymbol{a}} \cdot \boldsymbol{b}=$ $\boldsymbol{a} \times \boldsymbol{b}$, é definido como sendo o tensor antissimétrico associado ao vetor axial $\boldsymbol{a}$. O vetor $\boldsymbol{a}$ também é chamado de vetor dual. Este tensor é igual a:

$$
\boldsymbol{A}_{\boldsymbol{a}}=\left[\begin{array}{ccc}
0 & -a_{3} & a_{2} \\
a_{3} & 0 & -a_{1} \\
-a_{2} & a_{1} & 0
\end{array}\right]
$$

Note que o tensor antissimétrico substitui um produto vetorial entre dois vetores por um produto escalar entre um tensor e um vetor.

Seja agora o vetor $\boldsymbol{c}$ obtido pelo produto de dois vetores $\boldsymbol{a} \times \boldsymbol{b}=\boldsymbol{c}$. O tensor antissimétrico $\boldsymbol{A}_{\boldsymbol{c}}$ pode ser calculado a partir dos seguintes produtos diádicos:

$$
A_{c}=A_{a \times b}=b a-a b
$$

Abaixo são colocadas algumas propriedades dos tensores antissimétricos.

$$
\begin{aligned}
& A_{\alpha a}=\alpha A_{a} \\
& A_{a+b}=A_{a}+A_{b} \\
& A_{a} \cdot a=0 \\
& A_{b} \cdot a=b \cdot A_{a} \\
& A_{a} \cdot A_{b}=b a-(a \cdot b) I \\
& A_{a \times b}=b a-a b=A_{a} \cdot A_{b}-A_{b} \cdot A_{a} \\
& A_{-a}=A_{a}^{T} \\
& A_{a} \cdot A_{b}=\left(A_{a} \cdot A_{b}\right)^{T} \\
& A_{a} \cdot b=-b \cdot A_{a}
\end{aligned}
$$


Nas expressões acima $\alpha$ é um escalar e $\boldsymbol{I}$ é a matriz identidade. $\mathrm{O}$ símbolo $(\cdot)^{T}$ indica o transposto de $(\cdot)$. Em um tensor antissimétrico é implícita a existência de um vetor axial e o índice é comumente omitido, ou seja, $\boldsymbol{A}_{\boldsymbol{a}} \equiv \boldsymbol{A}$.

Seja agora o produto vetorial duplo $(\boldsymbol{a} \times \boldsymbol{b}) \times \boldsymbol{v}$. Para esta expressão é válida a igualdade $(\boldsymbol{a} \times \boldsymbol{b}) \times \boldsymbol{v}=(\boldsymbol{b} \boldsymbol{a}-\boldsymbol{a} \boldsymbol{b}) \cdot \boldsymbol{v}$. Utilizando as considerações acima, o tensor formado por $(\boldsymbol{b a}-\boldsymbol{a b})$ é igual a:

$$
(\boldsymbol{b a}-\boldsymbol{a b})=\left[\begin{array}{ccc}
0 & b_{1} a_{2}-b_{2} a_{1} & b_{1} a_{3}-a_{3} b_{1} \\
\text { antissimétrico } & 0 & b_{2} a_{3}-a_{3} b_{2} \\
\text { antis } & & 0
\end{array}\right]
$$

Analisando a expressão de $(\boldsymbol{b} \boldsymbol{a}-\boldsymbol{a} \boldsymbol{b})$ e a definição de tensor antissimétrico feita no início desta seção, pode-se concluir que $(\boldsymbol{b} \boldsymbol{a}-\boldsymbol{a b}) \cdot \boldsymbol{v}$ equivale a $\boldsymbol{c} \times \boldsymbol{v}$ tal que $\boldsymbol{C}=(\boldsymbol{b} \boldsymbol{a}-\boldsymbol{a} \boldsymbol{b})$. Assim, a expressão acima pode ser escrita na forma:

$$
\boldsymbol{C}=\left[\begin{array}{ccc}
0 & -c_{3} & c_{2} \\
c_{3} & 0 & -c_{1} \\
-c_{2} & c_{1} & 0
\end{array}\right]
$$

\section{A.II Rotações}

Do ponto de vista algébrico, uma rotação finita pode ser representada de duas formas:

a. Como uma matriz real ortogonal $[R]$ de dimensão 3x3, tal que o tensor $\boldsymbol{R}$ representado por esta matriz é chamado de tensor rotação;

b. Como uma matriz real antissimétrica $[A]$ de dimensão $3 \times 3$, tal que o tensor $\boldsymbol{A}$ representado por esta matriz é chamado de tensor spin [58] [21].

Os componentes do tensor spin podem ser relacionados diretamente aos parâmetros mencionados no teorema de Euler para as rotações finitas e, por este motivo, possui grande importância do ponto de vista das rotações. Sendo assim, o tensor $\boldsymbol{A}$ pode ser representado por três pa- 
râmetros escalares. Estes números representam as coordenadas de um vetor axial ${ }^{9} \boldsymbol{a}$. É possível relacionar estes três componentes - vetor axial, tensor spin e tensor rotação - de modo a ser possível se calcular um a partir do outro, conforme mostra a Figura 32.

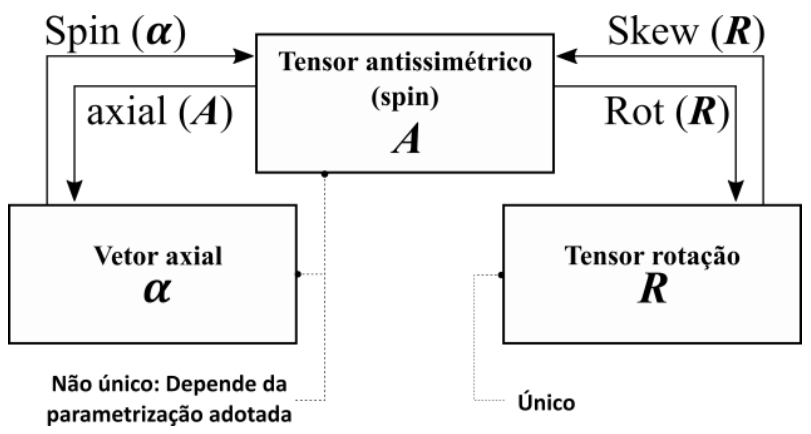

Figura 32 - Formas de representações das rotações.

Para as definições a seguir, seja considerado um corpo rígido $\mathcal{B}$ e um ponto fixo $C$ pertencente a este sólido.

Seja uma base ortogonal $\boldsymbol{e}_{i}$ e um sólido qualquer que possui, fixo a ele, outra base ortogonal $\hat{\boldsymbol{e}}_{i}$. Lembrando que a orientação do sólido na base $\boldsymbol{e}_{i}$ é dada pela orientação da base $\hat{\boldsymbol{e}}_{i}$ em relação à $\boldsymbol{e}_{i}$. Supondo um vetor rotação unitário $\boldsymbol{a}$, a cada ângulo de rotação em torno deste eixo está associada uma orientação entre as duas bases. Entretanto, independente do ângulo, as coordenadas de $\boldsymbol{a}$ serão sempre a mesmas em ambas as bases. Esta observação está diretamente relacionada ao problema de autovalores da álgebra linear. Ou seja, $\boldsymbol{R} \cdot \boldsymbol{a}=\lambda \boldsymbol{a}$, onde $\boldsymbol{R}$ é o tensor rotação que representa a rotação do sólido em torno do eixo de rotação $\boldsymbol{a}$ e $\lambda$ é um escalar qualquer. Neste caso, é fácil perceber que o eixo de rotação é um dos autovetores do tensor rotação. Com base nestas observações, é importante investigar o tensor rotação quanto aos seus autovalores e autovetores.

Seja a matriz ortogonal $[B]$ a matriz dos cossenos diretores que representa uma transformação de coordenadas. Os componentes desta matriz são dados por $b_{i j}$, tal que:

\footnotetext{
${ }^{9}$ Apesar do vetor axial ser chamado de "vetor", ele viola as propriedades de um vetor tal como as regras da álgebra linear. Por este motivo o termo pseudovetor é muitas vezes usado para descrevê-lo. Neste texto, em menção a este tipo de pseudovetor, será usado o termo vetor, permanecendo válida esta ressalva.
} 


$$
[B] \equiv B=\left[\begin{array}{lll}
b_{11} & b_{12} & b_{13} \\
b_{21} & b_{22} & b_{23} \\
b_{31} & b_{32} & b_{33}
\end{array}\right]
$$

Os autovalores de $B$ podem ser determinados a partir das raízes do polinômio característico

$$
\operatorname{det}(B-\lambda I)=0
$$

onde $I$ representa a matriz identidade $[I]=\delta_{i j}$, tal que $\delta_{i j}$ é o delta de Kronecker. A resolução deste polinômio leva a

$$
\begin{aligned}
\operatorname{det}(B-\lambda I)= & -\lambda^{3}+\lambda^{2}\left(b_{11}+b_{22}+b_{33}\right) \\
& -\lambda\left[\operatorname{cof}\left(b_{11}\right)+\operatorname{cof}\left(b_{22}\right)+\operatorname{cof}\left(b_{33}\right)\right]+\operatorname{det}(B) \\
& =0 .
\end{aligned}
$$

Na equação (A.10), $\operatorname{cof}\left(b_{i i}\right)$ é o cofator de $b_{i i}$, isto é, o determinante da matriz (2x2) formada pela eliminação da i-ésima linha e i-ésima coluna de $B$. Uma vez que $B$ é uma matriz própria ortogonal, então o seu determinante vale +1 . Sendo assim, os cofatores são idênticos ao elemento da diagonal $\left(b_{i i}=\operatorname{cof}\left(b_{i i}\right)\right)$. A equação (A.10) resulta em

$$
\operatorname{det}(B-\lambda I)=-\lambda^{3}+\lambda^{2} \operatorname{tr}(B)-\lambda \operatorname{tr}(B)+1=0 .
$$

A solução desta equação grau três fornece os autovalores de $B$, ou seja:

$$
\begin{aligned}
& \lambda_{1}=+1 \\
& \lambda_{2,3}=\frac{\operatorname{tr}(B)-1}{2} \pm i\left(\sqrt{1-\left(\frac{\operatorname{tr}(B)-1}{2}\right)^{2}}\right) .
\end{aligned}
$$


Observando a equação (A.12) é fácil notar que o primeiro autovalor está relacionado ao eixo de rotação, visto que ele preserva o comprimento do vetor resultante. Nota-se também que os outros dois autovalores configuram um par de números complexos conjugados. Sabendo que $\cos \phi=\frac{\operatorname{tr}(B)-1}{2}$, pode-se reescrever $\lambda_{2,3}$ da seguinte forma:

$$
\lambda_{2,3}=\cos \phi \pm i \operatorname{sen} \phi
$$

Sejam os vetores $\boldsymbol{n}_{i}$ os autovetores associados aos autovalores $\lambda_{i}$ da equação (A.12), ou seja, $B \boldsymbol{n}_{i}=\lambda_{i} \boldsymbol{n}_{i}$. Conforme mencionado anteriormente, o primeiro autovalor está relacionado ao eixo de rotação e, consequentemente, isto leva a concluir que o eixo de rotação é o primeiro autovetor. Resta agora encontrar o ângulo de rotação em torno deste eixo. Conforme mostrado abaixo, este ângulo é o ângulo $\phi$ que aparece nas expressões dos autovalores $\lambda_{2,3}$.

Para mostrar que $\phi$ corresponde ao ângulo de rotação em torno de $\boldsymbol{n}_{1}$ são escolhidos dois vetores quaisquer $\boldsymbol{c}_{2}$ e $\boldsymbol{c}_{3}$, dados a partir de uma combinação de $\boldsymbol{n}_{2}$ e $\boldsymbol{n}_{3}$ e ortogonais entre si. Portanto, $\boldsymbol{c}_{2}$ e $\boldsymbol{c}_{3}$ pertencem ao mesmo plano que $\boldsymbol{n}_{2}$ e $\boldsymbol{n}_{3}$.

$$
\begin{aligned}
& \boldsymbol{c}_{2}=\frac{1}{2}\left(\boldsymbol{n}_{2}+\boldsymbol{n}_{3}\right) \\
& \boldsymbol{c}_{3}=\frac{1}{2}\left(\boldsymbol{n}_{2}-\boldsymbol{n}_{3}\right)
\end{aligned}
$$

Ambos $\boldsymbol{c}_{2}$ e $\boldsymbol{c}_{3}$ são ortogonais a $\boldsymbol{n}_{1}$. Assim, $\boldsymbol{c}_{2}$ e $\boldsymbol{c}_{3}$ fazem parte do plano ortogonal ao eixo de rotação. Aplicando $B$ em $\boldsymbol{c}_{2}$ e $\boldsymbol{c}_{3}$ chega-se a:

$$
\begin{aligned}
B \boldsymbol{c}_{2}=\frac{1}{2} B\left(\boldsymbol{n}_{2}\right. & \left.+\boldsymbol{n}_{3}\right)=\frac{1}{2}\left(\lambda_{2} \boldsymbol{n}_{2}+\lambda_{3} \boldsymbol{n}_{3}\right) \\
& =\frac{1}{2}(\cos \phi+i \operatorname{sen} \phi) \boldsymbol{n}_{2}+\frac{1}{2}(\cos \phi-i \operatorname{sen} \phi) \boldsymbol{n}_{3} \\
& =\boldsymbol{c}_{2} \cos \phi+\boldsymbol{c}_{3} \operatorname{sen} \phi
\end{aligned}
$$




$$
B \boldsymbol{c}_{3}=\frac{i}{2} B\left(\boldsymbol{n}_{2}-\boldsymbol{n}_{3}\right)=-\boldsymbol{c}_{2} \operatorname{sen} \phi+\boldsymbol{c}_{3} \cos \phi
$$

As equações (A.15) e (A.16) mostram que a transformação de qualquer vetor perpendicular ao eixo de rotação resulta em na rotação destes vetores em um ângulo $\phi$ em torno deste eixo.

Pretende-se agora encontrar a matriz antissimétrica $[A] \equiv A$, cujo vetor axial seja $\boldsymbol{a}=$ skew $(A)$. Para isso, é utilizada a transformação de Cayley dada pela equação (17) e a matriz ortogonal $B$ mostrada acima. Sabendo que $\boldsymbol{n}_{i}$ é um autovetor associado ao autovalor $\lambda_{i}$, então $\left(B-\lambda_{i} I\right) \boldsymbol{n}_{i}=\mathbf{0}$. Aplicando a transformação de Cayley em ambos os lados desta equação, considerando que $i=1$ representa o eixo de rotação e que $\lambda_{1}=1$, então a equação resulta em: $(B-I) \boldsymbol{n}_{1}=\left[(I-A)^{-1}(I+A)-I\right] \boldsymbol{n}_{1}=0$. A multiplicação de ambos os lados por $(I-A)$ resulta em:

$$
2 A \boldsymbol{n}_{1}=0
$$

A equação acima implica que $\boldsymbol{a}$ seja paralelo (ou antiparalelo) a $\boldsymbol{n}_{1}$, ou seja, $\boldsymbol{a}= \pm c \boldsymbol{n}_{1}$, onde $c$ é uma constante a ser definida.

Seja $\mathcal{P}$ um plano perpendicular ao eixo de rotação $\boldsymbol{n}_{1}$ e que passa pelo ponto fixo de rotação. Uma vez que $\boldsymbol{a}$ é paralelo a $\boldsymbol{n}_{1}$, implica dizer que o plano $\mathcal{P}$ é também perpendicular ao vetor $\boldsymbol{a}$. Sejam dois vetores $\boldsymbol{v}_{0}^{*}$ e $\boldsymbol{v}_{1}^{*}$ as projeções em $\mathcal{P}$ dos vetores $\boldsymbol{v}_{0}$ e $\boldsymbol{v}_{1}$, respectivamente, tal que $\boldsymbol{v}_{1}=A \boldsymbol{v}_{0}$ e $\left\|\boldsymbol{v}_{0}\right\|=\left\|\boldsymbol{v}_{1}\right\|$. Destas duas últimas condições pode-se dizer que $\left(\boldsymbol{v}_{1}+\boldsymbol{v}_{0}\right)$ e $\left(\boldsymbol{v}_{1}-\boldsymbol{v}_{0}\right)$ são as diagonais de um losango cujos lados são paralelos a $\boldsymbol{v}_{0}$ e $\boldsymbol{v}_{1}$, portanto $\left(\boldsymbol{v}_{1}+\boldsymbol{v}_{0}\right)$ é ortogonal a $\left(\boldsymbol{v}_{1}-\boldsymbol{v}_{0}\right)$. Isto torna esta passagem idêntica ao que foi mostrado em (21) e (22). Considerando as propriedades de uma matriz antissimétrica (ver A.I), pode-se, portanto, escrever $\left(\boldsymbol{v}_{1}-\boldsymbol{v}_{0}\right)=\boldsymbol{a} \times\left(\boldsymbol{v}_{1}+\boldsymbol{v}_{0}\right)$. Isto implica dizer que também é válida a relação

$$
\left(v_{1}^{*}-v_{0}^{*}\right)=a \times\left(v_{1}^{*}+v_{0}^{*}\right)
$$

Agora, considerando que $\phi$ seja o ângulo entre $\boldsymbol{v}_{0}^{*}$ e $\boldsymbol{v}_{1}^{*}$, pode-se escrever 


$$
\tan \frac{\phi}{2}=\frac{\left\|v_{1}^{*}-\boldsymbol{v}_{0}^{*}\right\| / 2}{\left\|\boldsymbol{v}_{1}^{*}+\boldsymbol{v}_{0}^{*}\right\| / 2}=\frac{\left\|\boldsymbol{v}_{1}^{*}-\boldsymbol{v}_{0}^{*}\right\|}{\left\|\boldsymbol{v}_{1}^{*}-\boldsymbol{v}_{0}^{*}\right\|}
$$

Calculando a norma nos dois lados da equação (A.18) e sabendo que $\boldsymbol{a}$ é ortogonal a $\left(\boldsymbol{v}_{1}+\right.$ $\boldsymbol{v}_{0}$ ), e com a igualdade (A.19), resulta em

$$
\|a\|=\frac{\left\|v_{1}^{*}-v_{0}^{*}\right\|}{\left\|v_{1}^{*}-v_{0}^{*}\right\|}=\tan \frac{\phi}{2}
$$

Portanto, $\boldsymbol{a}=\tan \frac{\phi}{2} \boldsymbol{e}$, sendo $\boldsymbol{e}$ um vetor unitário paralelo ao vetor rotação e, consequentemente, um vetor axial. Substituindo este resultado na equação da transformação de Cayley e com algum esforço algébrico, chega-se a

$$
\boldsymbol{B}=\boldsymbol{I}+\operatorname{sen} \phi \boldsymbol{E}+(1-\cos \phi) \boldsymbol{E}^{2}
$$

A equação (A.21) mostra o tensor rotação parametrizado em termos do eixo e ângulo de rotação. Esta equação é chamada de fórmula de Rodrigues.

Utilizando algumas identidades trigonométricas é possível reescrever a equação (A.21) de diversas maneiras para criar as diversas parametrizações do tensor das rotações.

Conhecendo-se o tensor das rotações, é possível calcular o ângulo $\phi$ do teorema de Euler, e que é mostrado na equação (A.21). Este ângulo é dado tal que

$$
\cos \phi=\frac{1}{2}(\operatorname{tr}(\boldsymbol{B})-1),
$$

onde tr representa o traço da matriz.

A partir do tensor das rotações também é possível calcular o vetor que representa o eixo de rotação $\boldsymbol{e}$ do teorema de Euler, ou seja: 


$$
\boldsymbol{E}=\frac{\boldsymbol{B}-\boldsymbol{B}^{T}}{2 \operatorname{sen} \phi}
$$

sendo $\boldsymbol{e}=\operatorname{axial}(\boldsymbol{E})$.

Note que a expressão acima é singular quando $\phi=0$. Entretanto, neste caso, a rotação é nula e o tensor das rotações é igual a identidade.

\section{A.III Superelipsóide}

As equações mostradas abaixo derivam das equações mostradas na seção 2.8. As deduções foram omitidas e somente as expressões finais estão presentes.

\section{Pontos a partir de normais}

As funções de mapeamento são utilizadas para relacionar os pontos da superfície aos respectivos vetores normais.

Para evitar expressões muito grandes e considerando o reaproveitamento de partes repetidas no código computacional, algumas partes das expressões são abreviadas.

Seja um ponto na superfície do superelipsóide dado pelo vetor $\boldsymbol{x}=\left(x_{1}, x_{2}, x_{3}\right)$ escrito em coordenadas locais. A relação entre um vetor normal $\boldsymbol{n}=\left(n_{1}, n_{2}, n_{3}\right)$, no mesmo sistema de coordenadas, e o ponto $\boldsymbol{x}$ é dada por.

$$
\left(x_{1}, x_{2}, x_{3}\right)=x_{1}\left(1, \gamma_{21}, \gamma_{31}\right)
$$

tal que

$$
\begin{aligned}
& x_{1}=\left[s_{12}^{\epsilon_{1} / \epsilon_{2}}+\left(\frac{\gamma_{31}}{r_{3}}\right)^{2 / \epsilon_{2}}\right]^{-\epsilon_{2} / 2} \\
& s_{12}=\left(\frac{1}{r_{1}}\right)^{2 / \epsilon_{1}}+\left(\frac{\gamma_{21}}{r_{2}}\right)^{2 / \epsilon_{1}}
\end{aligned}
$$




$$
\begin{aligned}
& \gamma_{21}=\left(\frac{r_{2}}{r_{1}}\right)^{2 /\left(2-\epsilon_{1}\right)}\left(\frac{n_{2}}{n_{1}}\right)^{\epsilon_{1} /\left(2-\epsilon_{1}\right)} \\
& \gamma_{31}=\left(\frac{n_{3}}{n_{1}} \frac{r_{3}^{2 / \epsilon_{2}}}{r_{1}^{2 / \epsilon_{1}}} s_{12}^{\epsilon_{1} / \epsilon_{2}-1}\right)^{\epsilon_{2} /\left(2-\epsilon_{2}\right)}
\end{aligned}
$$

\section{Coordenadas curvilíneas a partir de normais}

O algoritmo de minimização utiliza as derivadas primeira e segunda das funções das coordenadas curvilíneas em relação ao vetor normal $\phi_{1}(\boldsymbol{n})$ e $\phi_{2}(\boldsymbol{n})$.

As equações que relacionam um vetor normal às coordenadas curvilíneas são dadas por

$$
\begin{aligned}
& \phi_{1}=\tan ^{-1}(\underbrace{s_{1}\left|r_{1} n_{1}\right|^{\delta_{1}}}_{\phi_{1}^{x}}, \underbrace{s_{2}\left|r_{2} n_{2}\right|^{\delta_{1}}}_{\phi_{1}^{y}}) \\
& \phi_{2}= \begin{cases}\tan ^{-1}(\underbrace{\left|r_{1} n_{1}\right|^{\delta_{2}}}_{\phi_{2}^{x}}, \underbrace{s_{3}\left|\left(r_{3} n_{3}\left|\cos \phi_{1}\right|^{\gamma_{1}}\right)\right|^{\delta_{2}}}_{\phi_{2}^{y}}) & \text { se }\left|r_{1} n_{1}\right|>\left|r_{2} n_{2}\right| \\
\tan ^{-1}(\underbrace{\left|r_{2} n_{2}\right|^{\delta_{2}}}_{\phi_{2}^{x}}, \underbrace{s_{3}\left|\left(r_{3} n_{3}\left|\cos \phi_{1}\right|^{\gamma_{1}}\right)\right|^{\delta_{2}}}_{\phi_{2}^{y}}) & \text { senão. }\end{cases}
\end{aligned}
$$

tal que $\tan ^{-1}(x, y)$ é igual ao arco tangente $(y / x)$, levando em consideração o quadrante que o ponto $(x, y)$ se encontra. E, $\gamma_{i}=2-\epsilon_{i}, \delta_{i}=1 / \gamma_{i}, s_{i}=\operatorname{sign}\left(n_{i}\right)$. Para evitar singularidades quando $n_{i}=0$, adota-se que

$$
\text { se }\left|n_{i}\right|<T O L \Rightarrow n_{i}=s_{i} T O L
$$

onde $T O L=10^{-20}$ é um número positivo pequeno.

As derivadas parciais $(\cdot)_{, i}=\partial(\cdot) / \partial n_{i}$ e $(\cdot)_{, i j}=\partial^{2}(\cdot) / \partial n_{i} \partial n_{i}$ são mostradas abaixo. Considera-se que $(\cdot)_{, i j}=(\cdot)_{, j i}$. As derivadas parciais iguais a zero são omitidas.

Nota: devido ao condicional definido na equação (A.30), as derivadas parciais de $\phi_{2}$ dependem desta condição. Portanto, nas expressões abaixo são mostradas as derivações para ambas 
as condições. Ou seja, as expressões abaixo são escritas para a condição $\left|r_{1} n_{1}\right|>\left|r_{2} n_{2}\right|$ e, nos casos onde a condição não é satisfeita, é utilizada uma chave superior no trecho da equação que é modificado, informando alteração da equação. Exemplo: $x+\stackrel{-2 y}{\tilde{y}}$ significa $x+y$, se $\left|r_{1} n_{1}\right|>\left|r_{2} n_{2}\right|$ ou $x-2 y$, senão.

Para o cálculo das derivadas de $\phi_{i}$ considera-se que

$$
\begin{aligned}
& \frac{\partial \tan ^{-1}(x, y)}{\partial x}=-\frac{y}{x^{2}+y^{2}} \\
& \frac{\partial \tan ^{-1}(x, y)}{\partial y}=\frac{x}{x^{2}+y^{2}} .
\end{aligned}
$$

As derivadas primeiras $\phi_{1, i}$ e $\phi_{2, i}$ são iguais a

$$
\begin{aligned}
& \phi_{1,1}=-\frac{1}{l_{1}} \phi_{1}^{y} \phi_{1,1}^{x}, \\
& \phi_{1,2}=\frac{1}{l_{1}} \phi_{1}^{x} \phi_{1,2}^{y}, \\
& \phi_{2, i}=\frac{1}{l_{2}}\left(\phi_{2}^{x} \phi_{2, i}^{y}-\phi_{2}^{y} \phi_{2, i}^{x}\right),
\end{aligned}
$$

tal que

$$
\begin{aligned}
& \phi_{1,1}^{x}=\frac{r_{1}}{\gamma_{1}}\left|r_{1} n_{1}\right|^{\eta_{1} / \gamma_{1}} \\
& \phi_{1,2}^{y}=\frac{r_{2}}{\gamma_{1}}\left|r_{2} n_{2}\right|^{\eta_{1} / \gamma_{1}} \\
& \eta_{i}=\epsilon_{i}-1 \\
& l_{1}=\left(\phi_{1}^{x}\right)^{2}+\left(\phi_{1}^{y}\right)^{2}
\end{aligned}
$$


e, introduzindo $q_{1}=\eta_{1} / \gamma_{1}^{2}$,

$$
\begin{aligned}
& \phi_{1,11}^{x}=\frac{q_{1} s_{1}}{n_{1}^{2}}\left|r_{1} n_{1}\right|^{\delta_{1}} \\
& \phi_{1,22}^{y}=\frac{q_{1} s_{2}}{n_{2}^{2}}\left|r_{2} n_{2}\right|^{\delta_{1}}
\end{aligned}
$$

calculam-se

$$
\begin{aligned}
& \phi_{1,11}=\frac{1}{l_{1}^{2}} \phi_{1}^{y}\left[2 \phi_{1}^{x}\left(\phi_{1,1}^{x}\right)^{2}-l_{1} \phi_{1,11}^{x}\right] \\
& \phi_{1,12}=\frac{1}{l_{1}^{2}} \phi_{1,1}^{x} \phi_{1,2}^{y}\left[\left(\phi_{1}^{y}\right)^{2}-\left(\phi_{1}^{x}\right)^{2}\right] \\
& \phi_{1,22}=\frac{1}{l_{1}^{2}} \phi_{1}^{x}\left[l_{1} \phi_{1,22}^{y}-2 \phi_{1}^{y}\left(\phi_{1,2}^{y}\right)^{2}\right]
\end{aligned}
$$

e, introduzindo

$$
\begin{aligned}
& l_{2}=\left(\phi_{2}^{x}\right)^{2}+\left(\phi_{2}^{y}\right)^{2}, \quad q_{2}=\left.\frac{1}{\gamma_{2}}\left|r_{3} n_{3}\right| \overbrace{\cos \phi_{1}}^{\sin \phi_{1}} \gamma^{\gamma_{1}}\right|^{\delta_{2}-1} \\
& q_{3}=-r_{3} n_{3} \gamma_{1}|\overbrace{\cos \phi_{1}}^{\sin \phi_{1}}|^{-\eta_{1}} \overbrace{\sin \phi_{1}}^{-\cos \phi_{1}} \overbrace{s_{1}}^{s_{1}} q_{2}
\end{aligned}
$$

chega-se às derivadas parciais 


$$
\begin{aligned}
& \phi_{2,1}^{x}=\overbrace{\frac{1}{\gamma_{2}} s_{1} r_{1}\left|r_{1} n_{1}\right|^{\delta_{2}-1}}^{0} \\
& \phi_{2,2}^{x}=\overbrace{\gamma_{2,1}}^{\frac{1}{\gamma_{2}} s_{2} r_{2}\left|r_{2} n_{2}\right|^{\delta_{2}-1}} \\
& \phi_{2,2}^{y}=q_{3} \phi_{1,1} \\
& \phi_{2,3}^{y}=q_{1,2} r_{3} \mid \overbrace{\cos \phi_{1}}^{\sin \phi_{1}}
\end{aligned}
$$

e, finalmente, chega-se a $\phi_{1, i}$ e $\phi_{2, i}$ acima.

As segundas derivadas $\phi_{2, i j}$ são dadas por

$$
\begin{gathered}
\phi_{2, i j}=\frac{1}{l_{2}}\left[\phi_{2, j}^{x} \phi_{2, i}^{y}-\phi_{2, j}^{y} \phi_{2, i}^{x}+\phi_{2}^{x} \phi_{2, i j}^{y}-\phi_{2}^{y} \phi_{2, i j}^{x}\right. \\
\left.-2 \phi_{2, i}\left(\phi_{2}^{x} \phi_{2, j}^{x}+\phi_{2}^{y} \phi_{2, j}^{y}\right)\right]
\end{gathered}
$$

tal que as seguintes abreviações são introduzidas:

$$
\begin{aligned}
& q_{4}:=\frac{1}{\gamma_{2}}\left|\left(r_{3} n_{3}|\overbrace{\cos \phi_{1}}^{\sin \phi_{1}}|^{\gamma_{1}}\right)\right|^{\delta_{2}-2} \\
& q_{5}:=-s_{3} \gamma_{1} q_{4}\left(r_{3} n_{3}\right)^{2}\left|\cos \phi_{1}\right|^{-2 \epsilon_{1}} \\
& q_{6}:=-\gamma_{2} \sin \phi_{1} \cos ^{3} \phi_{1} \\
& q_{7}:=\overbrace{\left(\eta_{1}-\eta_{2} \gamma_{1}\right)}^{\left(-\eta_{1}+\eta_{2} \gamma_{1}\right)} \overbrace{\sin ^{2} \phi_{1}}^{\cos ^{2} \phi_{1}} \overbrace{\cos ^{2} \phi_{1}}^{\sin ^{2} \phi_{1}}-\gamma_{2} \overbrace{\cos ^{4} \phi_{1}}^{\sin ^{4} \phi_{1}} \\
& q_{8}:=(\overbrace{\cos ^{2} \phi_{1}}^{\sin ^{2} \phi_{1}} \eta^{\eta_{1}}
\end{aligned}
$$




$$
q_{9}:=-\gamma_{1}\left|r_{3} n_{3}\right| r_{3} q_{4} q_{8} \overbrace{\sin \phi_{1}}^{\cos \phi_{1}} \overbrace{\cos \phi_{1}}^{\sin \phi_{1}}
$$

e, calculando-se

$$
\begin{aligned}
& \phi_{2,11}^{x}=\frac{1}{\gamma_{2}^{2}} r_{1}^{2} \eta_{2}\left|r_{1} n_{1}\right|^{\delta_{2}-2} \\
& \phi_{2,11}^{y}=q_{5}\left(q_{7} \phi_{1,1} \phi_{1,1}-q_{6} \phi_{1,11}\right) \\
& \phi_{2,12}^{y}=q_{5}\left(q_{7} \phi_{1,1} \phi_{1,2}-q_{6} \phi_{1,12}\right) \\
& \phi_{2,22}^{y}=q_{5}\left(q_{7} \phi_{1,2} \phi_{1,2}-q_{6} \phi_{1,22}\right) \\
& \phi_{2,13}^{y}=q_{9} \phi_{1,1} \\
& \phi_{2,23}^{y}=q_{9} \phi_{1,2} \\
& \phi_{2,33}^{y}=s_{3} r_{3}^{2} \eta_{2} q_{4} q_{8} \cos ^{2} \phi_{1}
\end{aligned}
$$

chega-se, finalmente, às derivadas segundas $\phi_{2, i j}$ acima.

Para o cálculo de $\partial \phi_{\gamma} / \partial c_{k}$ nas expressões (48) e (49), deve-se transformar o sistema de coordenadas do sistema de coordenadas de contato $\tilde{\boldsymbol{e}}_{i}$ para o sistema de coordenadas da partícula $\hat{\boldsymbol{e}}_{i}$, resultando em

$$
\frac{\partial \phi_{\gamma}}{\partial c_{k}}=\frac{\partial \phi_{\gamma}}{\partial n_{i}} \frac{\partial n_{i}}{\partial c_{k}}=\frac{\partial \phi_{\gamma}}{\partial n_{i}} T_{l i} R_{l k}
$$

tal que $T_{l i}=[T]$ é a matriz de mudança de base do sistema de contato para o sistema local da partícula, e $R_{l i}=[R]$ é a matriz de mudança de base do sistema global para o sistema de contato.

Da mesma maneira, a relação para a segunda partícula do par em contato, deriva da relação $\boldsymbol{n}^{(2)}=-\boldsymbol{c}$ é dada por 


$$
\frac{\partial \phi_{\gamma}}{\partial c_{k}}=-\frac{\partial \phi_{\gamma}}{\partial n_{i}} T_{l i} R_{l k}
$$

\section{Derivadas da superfície paramétrica}

Para o cálculo das derivadas dos pontos da superfície $\boldsymbol{x}\left(\phi_{1}, \phi_{2}\right)$ em relação aos parâmetros $\phi_{1}$ e $\phi_{2}$, considera-se a simetria do superelipsóide. Portanto, as expressões mostradas abaixo se referem aos pontos pertencentes ao primeiro quadrante do superelipsóide. Com isso, deve-se considerar algumas regras que transportam os pontos dos demais quadrantes para o primeiro quadrante. E, depois de resolvidas as derivações parciais, deve-se retornar os resultados para o quadrante original. Todas as regras utilizadas para estas transformações são descritas ao longo desta seção.

A equação (34) define os pontos $\boldsymbol{x}\left(\phi_{1}, \phi_{2}\right)$ da superfície do superelipsóide por meio de coordenadas curvilíneas, e são válidas para os oito quadrantes dos eixos coordenados. A equação (34) pode ser simplificada quando somente o primeiro quadrante é considerado, ou seja

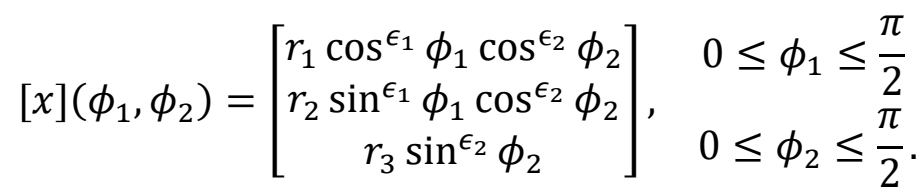

As derivadas parciais primeiras são dadas por

$$
\begin{aligned}
& {\left[\frac{\partial x}{\partial \phi_{1}}\right]=\left[h_{1}\right]=\left[\begin{array}{c}
-r_{1} \epsilon_{1} \operatorname{sen} \phi_{1} \cos ^{\epsilon_{1}-1} \phi_{1} \cos ^{\epsilon_{2}} \phi_{2} \\
r_{2} \epsilon_{1} \operatorname{sen}^{\epsilon_{1}-1} \phi_{1} \cos \phi_{1} \cos ^{\epsilon_{2}} \phi_{2} \\
0
\end{array}\right],} \\
& {\left[\frac{\partial x}{\partial \phi_{2}}\right]=\left[h_{2}\right]=\left[\begin{array}{c}
-r_{1} \epsilon_{2} \cos ^{\epsilon_{1}} \phi_{1} \operatorname{sen} \phi_{2} \cos ^{\epsilon_{2}-1} \phi_{2} \\
-r_{2} \epsilon_{2} \operatorname{sen}^{\epsilon_{1}} \phi_{1} \operatorname{sen} \phi_{2} \cos ^{\epsilon_{2}-1} \phi_{2} \\
r_{3} \epsilon_{2} \operatorname{sen}^{\epsilon_{2}-1} \phi_{2} \cos \phi_{2}
\end{array}\right] .}
\end{aligned}
$$

A equação acima deve ser utilizada após a identificação do quadrante do vetor. Para identificar o quadrante ao qual determinado vetor pertence, pode-se utilizar a tabela abaixo. 


\begin{tabular}{|l|c|c|c|c|c|c|c|c|}
\hline Quadrante: & 1 & 2 & 3 & 4 & 5 & 6 & 7 & 8 \\
\hline $\operatorname{sign}\left(x_{1}\right)=\operatorname{sign}\left(\sin \phi_{1}\right)$ & 1 & -1 & -1 & 1 & 1 & -1 & -1 & 1 \\
$\operatorname{sign}\left(x_{2}\right)=\operatorname{sign}\left(\cos \phi_{1}\right)$ & 1 & 1 & -1 & -1 & 1 & 1 & -1 & -1 \\
$\operatorname{sign}\left(x_{3}\right)=\operatorname{sign}\left(\sin \phi_{2}\right)$ & 1 & 1 & 1 & 1 & -1 & -1 & -1 & -1 \\
\hline
\end{tabular}

Uma vez identificado o quadrante, deve-se considerar nas equações de $\boldsymbol{h}_{1}$ e $\boldsymbol{h}_{2}$ os seguintes valores para os cossenos e senos:

$$
\operatorname{sen} \phi_{1}:=\left|\operatorname{sen} \phi_{1}\right|, \quad \operatorname{sen} \phi_{2}:=\left|\operatorname{sen} \phi_{2}\right|, \quad \cos \phi_{1}:=\left|\cos \phi_{1}\right| .
$$

Depois que as derivadas foram calculadas, os vetores tangentes resultantes devem ser remapeados para o quadrante original. O mapeamento reverso pode ser feito pela tabela abaixo.

\begin{tabular}{|c|c|c|c|c|c|c|c|}
\hline Quadrante: & 2 & 3 & 4 & 5 & 6 & 7 & 8 \\
\hline$\left[h_{1}\right]=$ & {$\left[R_{2}\right]\left[h_{1}^{*}\right]$} & {$\left[R_{12}\right]\left[h_{1}^{*}\right]$} & {$\left[R_{1}\right]\left[h_{1}^{*}\right]$} & {$\left[h_{1}^{*}\right]$} & {$\left[R_{2}\right]\left[h_{1}^{*}\right]$} & {$\left[R_{12}\right]\left[h_{1}^{*}\right]$} & {$\left[R_{1}\right]\left[h_{1}^{*}\right]$} \\
{$\left[h_{2}\right]=$} & {$\left[R_{1}\right]\left[h_{2}^{*}\right]$} & {$\left[R_{12}\right]\left[h_{2}^{*}\right]$} & {$\left[R_{2}\right]\left[h_{2}^{*}\right]$} & {$\left[R_{12}\right]\left[h_{2}^{*}\right]$} & {$\left[R_{2}\right]\left[h_{2}^{*}\right]$} & {$\left[h_{2}^{*}\right]$} & {$\left[R_{1}\right]\left[h_{2}^{*}\right]$} \\
{$[n]=$} & {$\left[R_{1}\right]\left[n^{*}\right]$} & {$\left[R_{12}\right]\left[n^{*}\right]$} & {$\left[R_{2}\right]\left[n^{*}\right]$} & {$\left[R_{3}\right]\left[n^{*}\right]$} & {$\left[R_{13}\right]\left[n^{*}\right]$} & {$\left[R_{123}\right]\left[n^{*}\right]$} & {$\left[R_{23}\right]\left[n^{*}\right]$} \\
\hline
\end{tabular}

Tal que $\left[h_{i}^{*}\right]$ e $\left[n^{*}\right]$ são os vetores calculados para o primeiro quadrante nas expressões mostradas acima. E, as matrizes da transformação são dadas por 


$$
\begin{aligned}
& {\left[R_{1}\right]=\left[\begin{array}{ccc}
-1 & 0 & 0 \\
0 & 1 & 0 \\
0 & 0 & 1
\end{array}\right],} \\
& {\left[R_{2}\right]=\left[\begin{array}{ccc}
1 & 0 & 0 \\
0 & -1 & 0 \\
0 & 0 & 1
\end{array}\right],} \\
& {\left[R_{3}\right]=\left[\begin{array}{ccc}
1 & 0 & 0 \\
0 & 1 & 0 \\
0 & 0 & -1
\end{array}\right],} \\
& {\left[R_{12}\right]=\left[R_{1}\right]\left[R_{2}\right],} \\
& {\left[R_{23}\right]=\left[R_{2}\right]\left[R_{3}\right],} \\
& {\left[R_{13}\right]=\left[R_{1}\right]\left[R_{3}\right],} \\
& {\left[R_{123}\right]=\left[R_{12}\right]\left[R_{3}\right] .}
\end{aligned}
$$

Os vetores normais à superfície põem ser calculados por $\boldsymbol{n}=\boldsymbol{h}_{1} \times \boldsymbol{h}_{2}$, resultando, em coordenadas locais, em

$$
[n]=\lambda\left[\begin{array}{c}
\frac{1}{r_{1}} \cos ^{2-\epsilon_{1}} \phi_{1} \cos ^{2-\epsilon_{2}} \phi_{2} \\
\frac{1}{r_{2}} \operatorname{sen}^{2-\epsilon_{1}} \phi_{1} \cos ^{2-\epsilon_{2}} \phi_{2} \\
\frac{1}{r_{3}} \operatorname{sen}^{2-\epsilon_{2}} \phi_{2}
\end{array}\right]
$$

onde $\lambda=r_{1} r_{2} r_{3} \epsilon_{1} \epsilon_{2} \operatorname{sen}^{\epsilon_{1}-1} \phi_{1} \cos ^{\epsilon_{1}-1} \phi_{1} \operatorname{sen}^{\epsilon_{2}-1} \phi_{2} \cos ^{2 \epsilon_{2}-1} \phi_{2}$ representa um fator de escala e pode ser ignorado quando somente a direção normal é requisitada. Entretanto, o mapeamento mostrado acima deve ser levado em consideração.

As derivadas parciais segundas são dadas por 


$$
\begin{aligned}
& {\left[x_{, 11}\right]=\left[\begin{array}{c}
-\frac{1}{2} r_{1} \epsilon_{1} \cos ^{\epsilon_{2}} \phi_{2} \cos ^{\epsilon_{1}-2} \phi_{1}\left(2-\epsilon_{1}+\epsilon_{1} \cos 2 \phi_{1}\right) \\
\frac{1}{2} r_{2} \epsilon_{1} \cos ^{\epsilon_{2}} \phi_{2} \sin ^{\epsilon_{1}-2} \phi_{1}\left(-2+\epsilon_{1}+\epsilon_{1} \cos 2 \phi_{1}\right) \\
0
\end{array}\right]} \\
& {\left[x_{, 12}\right]=\left[\begin{array}{c}
r_{1} \epsilon_{2} \epsilon_{1} \cos ^{\epsilon_{2}-1} \phi_{2} \sin \phi_{2} \cos ^{\epsilon_{1}-1} \phi_{1} \sin \phi_{1} \\
-r_{2} \epsilon_{2} \epsilon_{1} \cos ^{\epsilon_{2}-1} \phi_{2} \sin \phi_{2} \sin ^{\epsilon_{1}-1} \phi_{1} \cos \phi_{1} \\
0
\end{array}\right]=\left[x_{, 21}\right]} \\
& {\left[x_{, 22}\right]=\left[\begin{array}{c}
-\frac{1}{2} r_{1} \epsilon_{2} \cos ^{\epsilon_{2}-2} \phi_{2} \cos ^{\epsilon_{1}} \phi_{1}\left(2-\epsilon_{2}+\epsilon_{2} \cos 2 \phi_{2}\right) \\
-\frac{1}{2} r_{2} \epsilon_{2} \cos ^{\epsilon_{2}-2} \phi_{2} \sin ^{\epsilon_{1}} \phi_{1}\left(2-\epsilon_{2}+\epsilon_{2} \cos 2 \phi_{2}\right) \\
\frac{1}{2} r_{3} \epsilon_{2} \sin ^{\epsilon_{2}-2} \phi_{2}\left(-2+\epsilon_{2}+\epsilon_{2} \cos 2 \phi_{2}\right)
\end{array}\right]}
\end{aligned}
$$




\section{A.IV Algoritmo Levenberg-Marquardt}

O algoritmo de otimização de Levenberg-Marquardt (LM) utilizado na busca de contatos entre superelipsóides é mostrado nesta seção.

1. Definição dos ângulos iniciais $\zeta_{1}$ e $\zeta_{2}$ e coeficientes de $\operatorname{LM} \beta_{i=1}, a_{1}$ e $a_{2}$ (o índice $i$ representa a iteração atual). Os ângulos são iguais a zero se nenhum contato prévio existir entre as partículas, ou poderá ser o ângulo do contato no instante anterior, quando o contato já é existente.

2. Cálculo do gradiente da função $\nabla f\left(\zeta_{1}, \zeta_{2}\right)=\nabla f\left(\zeta_{i}\right)=\nabla f_{i}$, tal que $\zeta=\left(\zeta_{1}, \zeta_{2}\right)$.

3. Teste de optimalidade para o ponto $\zeta_{i}$. Se $\left\|\nabla f_{i}\right\| \leq \varepsilon$, então $\zeta_{i}$ é ótimo e o processo termina. Senão, vá para o passo 4.

4. Cálculo do novo vetor $\zeta_{i+1}=\zeta_{i}-\left[H_{i}+\beta_{i} I\right]^{-1} \nabla f_{i}$. Onde $H$ é a matriz hessiana da função $f$ e $I$ é a matriz identidade.

5. Comparar os valores de $f_{i+1}$ e $f_{i}$. Se $f_{i+1}<f_{i}$, então vá para o passo 6. Senão, vá para o passo 7 .

6. Definir $\beta_{i+1}=a \beta_{i}, i=i+1 \mathrm{e}$ ir para o passo 2 .

7. Definir $\beta=a_{2} \beta_{i}$ e ir para o passo 4 .

Em geral, a calibração dos parâmetros é feita para cada caso. Nas simulações apresentadas neste trabalho, utilizou-se como padrão $\beta_{1}=10^{4}, a_{1}=0,25$ e $a_{2}=2$. Alguns critérios de parada são adicionados ao algoritmo apresentado nesta seção, conforme mostrado em 3.1.1.

Uma das principais características do algoritmo de LM é que ele inicia a busca como sendo um método Steepest Descent e termina como um método de Newton. Note que a hessiana da função é penalizada por um valor alto, $\beta_{i}$, e a hessiana modificada $H_{i}^{*}=H_{i}+\beta_{i} I$ tende a uma matriz diagonal cuja inversa é muito próxima de $\frac{1}{\beta_{i}} I$, que é a característica principal do método Steepest Descent. O coeficiente $a_{1}$ reduz o valor de $\beta_{i} I$ à medida que o método converge $\mathrm{e}$ isto faz com que $H_{i}^{*} \sim H_{i}$, que é o método de Newton. Note que a inversa da matriz hessiana modificada (passo 4) pode ser substituída por sistema linear do tipo $H^{*} \Delta \zeta=-\nabla f$, onde $\Delta \zeta=\zeta_{i+1}-\zeta_{i}$ 


\section{A.V Pós processamento}

O pós-processamento das simulações é feito no Paraview. O Paraview é um software código aberto e multiplataforma desenvolvido para análise de dados e muito frequentemente usado como pós processador para análises da mecânica computacional com o MEF, CFD, partículas e meshless. O software permite entrada de dados em diversos formatos. Neste trabalho foi utilizado o formato aberto VTK, com o padrão vtkxml para processamentos em paralelo. Para utilizar superelipsóides no Paraview, foi necessário desenvolver um filtro de leitura em linguagem Python (programmble filter). Para usos futuros, o código do filtro é mostrado abaixo

\#

\#Desenvolvido por: Marco Antônio Brasiel Sampaio, 2016.

\#Versão: 1.0

\#Paraview Programmable Filter

\#Python 2.7

\#Paraview 5

\#Filtro para leitura de um conjunto de arquivos.vtu/.vtk (_01.vtu,_02.vtu,_03.vtu,...) utilizando um arquivo .pvd.

\#

\#Definições gerais:

\#No paraview os parâmetros Phi e Theta funcionam da seguinte forma:

\# - Phi: modifica a curvatura nos planos xy e yz

\# - Theta: modifica a curvatura no plano $x z$

\#Para gerar um superelipsóide alongado deve-se aumentar o valor do scaleY, sendo scaleY>(scaleX=scaleZ).

\#O parâmetro Theta regula a curvatura da seção transversal, e Phi regula a curvatura das seções longitudinais.

\#Compatibilização com o padrão da tese: Theta := Epsilon1; Phi:=Epsilon2

\#Configurar no Paraview:

\# - No campo programmable Filter: Output Data Set Type = vtkMultiBlockDataSet

import vtk

\#Recebe o input do pipeline. Este é o conjunto de vtk's.

pipeLinelnput $=$ inputs $[0]$

for $\mathrm{i}$ in range(0, pipeLinelnput.GetNumberOfPoints()):

partic $=$ vtk.vtkSuperquadricSource ()

partic.SetCenter $(0,0,0)$ \#Posiciona a partícula no ponto 0,0,0

partic.SetSize(1) \#Torna a partícula unitária

r1 = pipeLinelnput.GetPointData().GetArray('r1').GetValue(i) \#Leitura da variável Scales do arquivo vtk, que contém a dimensão da partícula no eixo 1. A variável Scales é uma matriz linha $1 \times 3$.

r2 = pipeLinelnput.GetPointData().GetArray('r2').GetValue(i) \#Leitura da variável Scales do arquivo vtk, que contém a dimensão da partícula no eixo 2.

r3 = pipeLinelnput.GetPointData().GetArray('r3').GetValue(i) \#Leitura da variável Scales do arquivo vtk, que contém a dimensão da partícula no eixo 3.

partic.SetScale(r1,r2,r3) \#Dimensionamento da partícula

partic.SetPhiRoundness(pipeLinelnput.GetPointData().GetArray('epsilon2').GetValue(i)) \#Leitura e configuração do parâmetro geométrico Phi.

partic.SetThetaRoundness(pipeLinelnput.GetPointData().GetArray('epsilon1').GetValue(i)) \#Leitura e configuração do parâmetro geométrico Theta.

partic.SetThetaResolution(60)

partic.SetPhiResolution(60) 
transform = vtk.vtkTransform() \#Criação de um objeto que contêm uma transformação.

transform.PostMultiply() \#Configuração que irá permitir que as transformações sejam aplicadas na configuração inicial.

rotationAngle1 = pipeLinelnput.GetPointData().GetArray('RotationAngle1').GetValue(i) \#Leitura do ângulo de rotação

rotationAngle2 = pipeLinelnput.GetPointData().GetArray('RotationAngle2').GetValue(i) \#Leitura do ângulo de rotação

transform.RotateX(90) \#Esta rotação faz com que o sistema de coordenadas do programa fique igual ao sistema do paraview.

transform.RotateZ(rotationAngle2) \#Esta rotação faz a "torção" da partícula em torno do eixo principal.

rotationAxis = pipeLineInput.GetPointData().GetArray('rotationAxis').GetTuple(i) \#Leitura do ângulo de rotação

transform.RotateWXYZ(rotationAngle1, rotationAxis) \#Configurar a rotação da partícula, tal que: RotateWXYZ(Ângulo, EixoDeRotação(e1,e2,e3))

transformFilter = vtk.vtkTransformPolyDataFilter() \#Criação de um objeto que aplica uma transformação em um vtk.

transformFilter.SetTransform(transform) \#Configuração do objeto que irá aplicar a transformação no vtk. transformFilter.SetInputConnection(partic.GetOutputPort()) \#Aplicação da rotação na partícula transformFilter.Update() \#Atualização

transform.Translate(pipeLinelnput.GetPoint(i)) \#Configuração da translação que irá levar do ponto 0,0,0 à posição da partícula

transformFilter.SetTransform(transform) \#Configuração do objeto que irá aplicar a transformação no vtk. transformFilter.SetInputConnection(partic.GetOutputPort()) \#Aplicação da rotação na partícula transformFilter.Update() \#Atualização

output.SetBlock(i, transformFilter.GetOutput()) \#Alimentação da saída do filtro 


\section{LISTA DE SÍMBOLOS, ABREVIAÇÕES E SIGLAS}

\begin{tabular}{|c|c|}
\hline MED & Método Dos Elementos Discretos \\
\hline MEF & Método dos Elementos Finitos \\
\hline MEC & Método dos Elementos de Contorno \\
\hline CFD & Computational fluid dynamics \\
\hline $\boldsymbol{e}$ & Eixo de rotação \\
\hline $\boldsymbol{e}_{i}$ & Base do sistema de coordenadas global \\
\hline$\hat{\boldsymbol{e}}_{i}$ & Base do sistema de coordenadas local (partícula) \\
\hline$\tilde{\boldsymbol{e}}_{i}$ & Base do sistema de coordenadas de contato \\
\hline$x$ & Posição do centro de uma partícula \\
\hline$\dot{x}$ & Velocidade linear do centro de uma partícula \\
\hline$\ddot{\boldsymbol{x}}$ & Aceleração linear do centro de uma partícula \\
\hline $\boldsymbol{\omega}$ & Velocidade angular de uma partícula \\
\hline$\dot{\boldsymbol{\omega}}$ & Aceleração angular de uma partícula \\
\hline $\boldsymbol{\mu}$ & Momento angular \\
\hline$\epsilon$ & Coeficiente de atrito de Coulomb \\
\hline$\mu_{i}$ & Componentes de $\boldsymbol{\mu}$ \\
\hline$\dot{\mu}$ & Torque (momento) \\
\hline $\boldsymbol{J}$ & Tensor de inércia \\
\hline$v$ & Idem $\dot{x}$ \\
\hline$f$ & Força total \\
\hline $\boldsymbol{f}^{n}$ & Força na direção normal \\
\hline$f^{s}$ & Força na direção tangente \\
\hline $\boldsymbol{f}_{\text {lim }}$ & Força limite de Coulomb \\
\hline$m$ & Massa \\
\hline$t$ & Instante de tempo \\
\hline$t$ & Vetor tangente \\
\hline$t_{1}$ & Componente do plano tangente \\
\hline$t_{2}$ & Componente do plano tangente \\
\hline$t_{i}$ & Componentes do vetor $\boldsymbol{t}$ \\
\hline$\dot{x}_{0}$ & Velocidade inicial \\
\hline
\end{tabular}




\begin{tabular}{|c|c|}
\hline$x_{0}$ & Posição inicial \\
\hline$k^{n}$ & Coeficiente de penalidade normal \\
\hline$k^{s}$ & Coeficiente de penalidade tangente \\
\hline $\boldsymbol{R}$ & Vetor rotação qualquer \\
\hline $\boldsymbol{A}$ & Tensor antissimétrico de Rodrigues \\
\hline$[A]$ & Representação matricial de $\boldsymbol{A}$ \\
\hline$[R]$ & Representação matricial de $\boldsymbol{R}$ \\
\hline$Q$ & Tensor rotação de Rodrigues \\
\hline$\alpha$ & Vetor rotação de Rodrigues \\
\hline$\theta$ & Ângulo de rotação \\
\hline $\boldsymbol{Q}_{\Delta}$ & Tensor rotação incremental de Rodrigues \\
\hline$\alpha_{\Delta}$ & Vetor rotação incremental de Rodrigues \\
\hline$F$ & Equação do superelipsóide \\
\hline$r^{i}$ & Raios de um superelipsóide \\
\hline$r$ & Raio de uma esfera \\
\hline $\boldsymbol{r}$ & Vetor raio (do centro da partícula até um ponto de contato) \\
\hline$r_{i}$ & Componentes de $\boldsymbol{r}$ \\
\hline$\rho$ & Densidade do material \\
\hline$\epsilon_{i}$ & Parâmetros de curvatura de um superelipsóide \\
\hline$\phi_{1}$ & Parâmetro de coordenadas curvilíneas \\
\hline$\phi_{2}$ & Parâmetro de coordenadas curvilíneas \\
\hline$\Gamma$ & Função gama \\
\hline $\boldsymbol{n}$ & Vetor normal \\
\hline $\boldsymbol{c}$ & Vetor mestre para algoritmo de otimização de contato \\
\hline$\zeta_{1}$ & Parâmetro de coordenadas esféricas \\
\hline$\zeta_{2}$ & Parâmetro de coordenadas esféricas \\
\hline $\boldsymbol{p}$ & Ponto na superfície da partícula \\
\hline$d$ & Vetor distância \\
\hline $\boldsymbol{\delta}$ & Vetor do deslocamento tangente \\
\hline$g$ & Vetor do deslocamento tangente relativo \\
\hline$(\cdot)^{r}$ & $\begin{array}{l}\text { Representa uma grandeza configuração de referência. }(\cdot) \text { pode } \\
\text { ser um vetor, um tensor ou qualquer outra grandeza. }\end{array}$ \\
\hline
\end{tabular}




\section{REFERÊNCIAS BIBLIOGRÁFICAS}

[1] MOHAMMADI, S. Discontinuum Mechanics - Using Finite and Discrete Elements. 2003. 163 p.

[2] CUNDALL, P. A. A computer model for simulating progressive large scale movements in blocky rock systems. Symposium on International Society of Rock Mechanics, 1971.

[3] CUNDALL, P. A.; STRACK, D. L. A discrete numerical model for granular assemblies. Geotechnique, v. 29, p. 47-65, 1979.

[4] HART, R.; CUNDALL, P. A.; LEMOS, J. Formulation of a three-dimensional distinct element model -Part I. A scheme to detect and represent contacts in a system composed of many polyhedral blocks. International Journal of Rock Mechanics and Mining Sciences \\& Geomechanics Abstracts, v. 25, p. 117-125, 1988.

[5] LUDING, S. About contact force-laws for cohesive frictional materials in 2D and 3D. 2006. Cap. 4, p. 137-147.

[6] BICANIC, N. Encyclopedia of Computational Mechanics. 2004.

[7] ARGYRIS, J. An excursion into large rotations. Computer Methods in Applied Mechanics and Engineering, v. 32, p. 85-155, 1982.

[8] CAMPELLO, E. M. B.; ZOHDI, T. I. A computational framework for simulation of the delivery of substances into cells. International Journal for Numerical Methods in Biomedical Engineering, 2014. 
[9] FLEISSNER, F.; GAUGELE, T.; EBERHARD, P. Applications of the discrete element method in mechanical engineering. Multibody System Dynamics, v. 18, p. 81-94, 2007.

[10] WELlMANN, C.; LILLIE, C.; WRIGGERS, P. A contact detection algorithm for superellipsoids based on the common-normal concept. Engineering Computations, v. 25, n. 5, p. 432-442, Jul 2008. ISSN: 0264-4401 DOI: 10.1108/02644400810881374.

[11] BOON, C. W.; HOULSBY, G. T.; UTILI, S. A new contact detection algorithm for three-dimensional non-spherical particles. Powder Technology, v. 248, p. 94-102, Nov 2013. ISSN: 0032-5910 DOI: 10.1016/j.powtec.2012.12.040.

[12] HAMILTON, W. R. ON QUATERNIONS, OR ON A NEW SYSTEM OF IMAGINARIES IN ALGEBRA. Philosophical Magazine, 1844-1850.

[13] ALtMAnN, S. L. Rotations, Quaternions, and Double groups. Oxford: Oxford University Press, 1986.

[14] KRUGGEL-EMDEN, H. et al. Selection of an appropriate time integration scheme for the discrete element method (DEM). Computers \& Chemical Engineering, v. 32, p. 2263-2279, out 2008. DOI: 10.1016/j.compchemeng.2007.11.002.

[15] FRAIGE, F. Y.; LANGSTON, P. A. Integration schemes and damping algorithms in distinct element models. Advanced Powder Technology, v. 15, n. 2, p. 227-245, mar 2004. DOI: $10.1163 / 156855204773644454$.

[16] BAUCHAU, O. A. Flexible Multibody Dynamics. v. 176, 2011.

[17] PIMENTA, P. M.; CAMPELlO, E. M. B.; WRIGGERS, P. An exact conserving algorithm for nonlinear dynamics with rotational DOFs and general hyperelasticity. Part 
1: Rods. Computational Mechanics, v. 42, p. 715-732, 2008.

[18] GAY NETO, A.; PIMENTA, P. M.; WRIGGERS, P. Contact between rolling beams and flat surfaces. International Journal for Numerical Methods in Engineering, v. 97, p. 683-706, 2014.

[19] DAI, J. S. An historical review of the theoretical development of rigid body displacements from Rodrigues parameters to the finite twist. Mechanism and Machine Theory, v. 41, p. 41-52, 2006.

[20] IBRAHIMBEGOVIC, A. On the choice of finite rotation parameters. Computer Methods in Applied Mechanics and Engineering, v. 149, p. 49-71, oct 1997.

[21] MALVERN, L. E. Introduction to the Mechanics of a Continuous Medium. 1977. ISBN: 0134876032.

[22] WITTENBURG, J. Dynamics of multibody systems. Second Edition. ed. 2008.

[23] CUNDALL, P. A. Numerical experiments on localization in frictional materials. Ingenieur-Archiv, v. 59, p. 148-159, 1989.

[24] CUNDALL, P. A. Computer Interactive Graphics and the Distinct Element Method. Rock Engineering for Foundations \& Slopes. 1977.

[25] CUNDALL, P. A. BALL - a program to model granular media using the distinct element method. Technical Report TN-LN-13, Dames and Moore, Advanced Technology Group, 1978.

[26] ZIENKIEWICZ, O. C.; TAYLOR, R. L. The Finite Element Method - The Basis. 6. ed. v. Volume 1, 2000. 
[27] BREBBIA, C. A.; DOMINGUEZ, J. Boundary Elements - An Introductory Course. 1998.

[28] HOGUE, C. Shape representation and contact detection for discrete element simulations of arbitrary eometries. Engineering Computations, v. 15, p. 374-390, 1998.

[29] SHABANA, A. A. Dynamics of multibody systems. Third Edition. ed. 2005.

[30] PIMENTA, P. M. Apostila - Mecânica dos sólidos e das estruturas. 2006.

[31] WRIGGERS, P. Computational Contact Mechanics. 2006.

[32] JOHNSON, K. L. Contact Mechanics. 1985.

[33] RENZO, A. D.; MAIO, F. P. D. Comparison of contact-force models for the simulation of collisions in DEM-based granular flow codes. Chemical Engineering Science, v. 59, p. 525-541, 2004.

[34] BARR, A. H. Superquadrics and angle-preserving transformations. IEEE Computer graphics and Applications, v. 1, n. 1, p. 11-23, 1981.

[35] PORTAL, R.; DIAS, J.; DE SOUSA, L. Contact detection between convex superquadric surfaces. Archive of Mechanical Engineering, v. 57, p. 165-186, 2010.

[36] LOPES, D. S. et al. A mathematical framework for rigid contact detection between quadric and superquadric surfaces. Multibody System Dynamics, v. 24, p. 255-280, October 2010.

[37] LU, G.; THIRD, J. R.; MÜLLER, C. R. Critical assessment of two approaches for 
evaluating contacts between super-quadric shaped particles in DEM simulations. Chemical engineering science, v. 78, p. 226-235, 2012.

[38] PODLOZHNYUK, A.; PIRKER, S.; KLOSS, C. Efficient implementation of superquadric particles in Discrete Element Method within an open-source framework. Computational Particle Mechanics, v. 4, p. 101-118, 2017.

[39] SYNGE, J. L.; SCHILD, A. Tensor calculus. v. 5, 1969.

[40] PIMENTA, P. M.; YOJO, T. Geometrically Exact Analysis of Spatial Frames. Appl. Mech. Rev., v. 46, p. S118, 1993. ISSN: 0003-6900. DOI: 10.1115/1.3122626.

[41] PIMENTA, P. M.; CAMPELLO, E. M. B. Geometrically nonlinear analysis of thinwalled space frames. European Conference on computationl Mechanics. 2001.

[42] PIMENTA, P. D. M.; CAMPELLO, E. D. M. B.; OTHERS. Shell curvature as an initial deformation: a geometrically exact finite element approach. International journal for numerical methods in engineering, v. 78, p. 1094, 2009.

[43] IVANNIKOV, V.; TIAGO, C.; PIMENTA, P. M. Generalization of the C1 TUBA plate finite elements to the geometrically exact Kirchhoff--Love shell model. Computer Methods in Applied Mechanics and Engineering, v. 294, p. 210-244, 2015.

[44] OTA, N. S. N. et al. Nonlinear dynamic analysis of creased shells. Finite Elements in Analysis and Design, v. 121, p. 64-74, 2016.

[45] WALIZER, L. E. A bounding box search algorithm for DEM simulation. Computer Physics Communications, v. 182, p. 281-288, 2011.

[46] LU, L. et al. An efficient algorithm for detecting particle contact in non-uniform size 
particulate system. Particuology, v. 8, p. 127-132, 2010.

[47] OGARKO, V.; LUDING, S. A fast multilevel algorithm for contact detection of arbitrarily polydisperse objects. Computer Physics Communications, v. 183, p. 931936, 2012.

[48] SWOPE, W. C. A computer simulation method for the calculation of equilibrium constants for the formation of physical clusters of molecules: Application to small water clusters. The Journal of Chemical Physics, v. 76, n. 1, p. 637, 1982. DOI: 10.1063/1.442716.

[49] FINCHAM, D. Leapfrog Rotational Algorithms. Molecular Simulation, v. 8, n. 3-5, p. 165-178, jan 1992. DOI: 10.1080/08927029208022474.

[50] FINCHAM, D. Leapfrog Rotational Algorithms for Linear Molecules. Molecular Simulation, v. 11, n. 1, p. 79-89, sep 1993. DOI: 10.1080/08927029308022178.

[51] MARIOTTI, C. A new Leapfrog scheme for rotational motion in 3D. International Journal for Numerical Methods in Engineering, v. 107, n. 4, p. 273-289, jan 2016. DOI: $10.1002 / n m e .5165$.

[52] GOVENDER, N.; WILKE, D. N.; KOK, S. Blaze-DEMGPU: modular high performance DEM framework for the GPU architecture. SoftwareX, v. 5, p. 62-66, 2016.

[53] QI, J. et al. GPU-accelerated DEM implementation with CUDA. International Journal of Computational Science and Engineering, v. 11, p. 330-337, 2015.

[54] SHIGETO, Y.; SAKAI, M. Parallel computing of discrete element method on multi-core processors. Particuology, v. 9, p. 398-405, 2011. 
[55] ADAMS, J. C. et al. The Fortran 2003 Handbook. 2009.

[56] METCALF, M.; REID, J.; COHEN, M. Modern Fortran Explained. 2011. ISBN: 9780-19-960141-7.

[57] BRAINERD, W. S. Guide to Fortran 2003 Programming. 2009. ISBN: 978-1-84882542-0.

[58] LAI, W. M. et al. Introduction to continuum mechanics. 2009.

[59] WELlMANN, C.; WRIGGERS, P.; LILliE, C. Comparison of the macroscopic behavior of granular materials modeled by different constitutive equations on the microscale. Finite Elements in Analysis and Design, v. 44, p. 259-271, 2008.

[60] VAN BEARS, S. Discrete element modelling of granular materials. Heron, v. Vol. 41 No. 2, p. 139-157., 1996.

[61] RODRÍGUEZ-VALVERDE， M. Á.; TIRADO-MIRANDA， M. Tensor-based derivation of standard vector identities. Grupo de Física de Fluidos y Biocoloides, Departamento de Física Aplicada, Facultad de Ciencias, Universidad de Granada. E18071 Granada. 2009. 